Florida International University FIU Digital Commons

FIU Electronic Theses and Dissertations

University Graduate School

10-30-2002

\title{
Teams leading teams: examining the role of leadership in multi-team systems
}

Leslie A. DeChurch

Florida International University

DOI: $10.25148 /$ etd.FI14062229

Follow this and additional works at: https://digitalcommons.fiu.edu/etd

Part of the Psychology Commons

\section{Recommended Citation}

DeChurch, Leslie A., "Teams leading teams: examining the role of leadership in multi-team systems" (2002). FIU Electronic Theses and Dissertations. 2759.

https://digitalcommons.fiu.edu/etd/2759

This work is brought to you for free and open access by the University Graduate School at FIU Digital Commons. It has been accepted for inclusion in FIU Electronic Theses and Dissertations by an authorized administrator of FIU Digital Commons. For more information, please contact dcc@fiu.edu. 
FLORIDA INTERNATIONAL UNIVERSITY

Miami, Florida

TEAMS LEADING TEAMS:

EXAMINING THE ROLE OF LEADERSHIP IN

MULTI-TEAM SYSTEMS

A dissertation submitted in partial fulfillment of the

requirements for the degree of

DOCTOR OF PHILOSOPHY

in

PSYCHOLOGY

by

Leslie A. DeChurch 
To: Dean Arthur W. Herriott

College of Arts and Sciences

This dissertation, written by Leslie A. DeChurch, and entitled Teams Leading Teams: Examining the Role of Leadership in Multi-Team Systems, having been approved in respect to style and intellectual content, is referred to you for judgment.

We have read this dissertation and recommend that it be approved.

Kimberly Taylor, Ph.D.

Leslie Frazier, Ph.D.

Michelle Marks. Co-Maior Professor

Chockalingam Viswesvaran, Co-Major Professor

Date of Defense: October 30, 2002

The dissertation of Leslie A. DeChurch is approved.

Dean Arthur W. Herriott College of Arts and Sciences

Dean Douglas Wartzok University Graduate School

Florida International University, 2002 
(C) Copyright 2002 by Leslie A. DeChurch

All rights reserved. 


\section{DEDICATION}

For my home team: Jeff, Cameron, Mom, \& Joe 


\section{ACKNOWLEDGMENTS}

I sincerely thank my committee members: Professors Chockalingam (Vish)

Viswesvaran, Leslie Frazier, and Kim Taylor for their guidance and support in seeing me through this process. I thank the graduate students (Alex Alonso, Dana Plummer, Fred Panzer, Julio Frenandez de Cueto, Rebecca Reichard, and Dana Sims) and undergraduate students (Jean Ali, Michelle Paduda, Eric Richardson, Dianne Young, and Rebecca Hoffman) whose efforts in running the experimental sessions and coding countless hours of videotapes greatly contributed to the backbone of this project. The following faculty members were instrumental in recruiting participants: Robert Benneckson, Bill Kurtines, Margaret Bull-Kovera, Kevin Brown, Ivette Riano, Armando Pina, and Karrie Lum Lock. I thank John Mathieu, Michelle Marks, and Steve Zaccaro for the opportunity to complete this project as a part of their funded research on Multi-Team Systems; and thank the Air Force Office of Sponsored Research (AFSOR) and the Florida International University Graduate Student Association (GSA) for their financial support of this project.

The three most significant contributions to this work were made by my mentor, Michelle Marks, my lab co-manager, Fred Panzer, and fellow graduate student, Alex Alonso. Michelle, you were a true inspiration in so many ways. Fred, thank you for making the methods section possible. Alex, thank you for being a phenomenal organizational citizen. Working with the three of you made the completion of this project, and graduate school, wonderful and rewarding experiences.

On a personal note, I thank my very large and wonderful family for all of their support during this long educational endeavor. I especially thank my mom for being such an amazing role model, and for instilling in me the value of higher education. I thank my 
husband Jeff for being so supportive and encouraging, and for keeping me in touch with the real world. I thank my son Cameron for making everything worthwhile. And lastly, I thank my informal mentor Maurice Schweitzer for his unwavering support and belief in me as an academic. 
ABSTRACT OF THE DISSERTATION

TEAMS LEADING TEAMS:

EXAMINING THE ROLE OF LEADERSHIP IN

MULTI-TEAM SYSTEMS

by

Leslie A. DeChurch

Florida International University, 2002

Miami, Florida

Professor Michelle A. Marks, Co-Major Professor

Professor Chockalingam Viswesvaran, Co-Major Professor

A major challenge of modern teams lies in the coordination of the efforts not just of individuals within a team, but also of teams whose efforts are ultimately entwined with those of other teams. Despite this fact, much of the research on work teams fails to consider the external dependencies that exist in organizational teams and instead focuses on internal or within team processes. Multi-Team Systems Theory is used as a theoretical framework for understanding teams-of-teams organizational forms (Multi-Team Systems; MTS's); and leadership teams are proposed as one remedy that enable MTS members to dedicate needed resources to intra-team activities while ensuring effective synchronization of between-team activities. Two functions of leader teams were identified: strategy development and coordination facilitation; and a model was developed delineating the effects of the two leader roles on multi-team cognitions, processes, and performance. 
Three hundred eighty four undergraduate psychology and business students participated in a laboratory simulation that modeled an MTS; each MTS was comprised of three, two-member teams each performing distinct but interdependent components of an F-22 battle simulation task. Two roles of leader teams supported in the literature were manipulated through training in a 2 (strategy training vs. control) $\times 2$ (coordination training vs. control) design. Multivariate analysis of variance (MANOVA) and mediated regression analysis were used to test the study's hypotheses.

Results indicate that both training manipulations produced differences in the effectiveness of the intended form of leader behavior. The enhanced leader strategy training resulted in more accurate (but not more similar) MTS mental models, better inter-team coordination, and higher levels of multi-team (but not component team) performance. Moreover, mental model accuracy fully mediated the relationship between leader strategy and inter-team coordination; and inter-team coordination fully mediated the effect of leader strategy on multi-team performance. Leader coordination training led to better inter-team coordination, but not to higher levels of either team or multi-team performance. Mediated Input-Process-Output (I-P-O) relationships were not supported with leader coordination; rather, leader coordination facilitation and inter-team coordination uniquely contributed to component team and multi-team level performance. The implications of these findings and future research directions are also discussed. 
I. INTRODUCTION

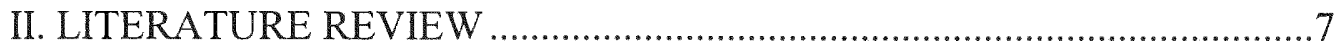

Multi-Team Systems Theory .................................................................

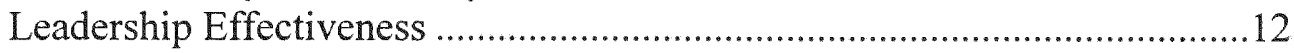

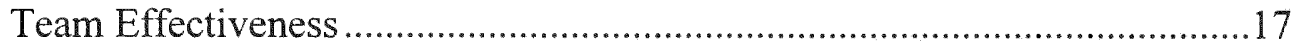

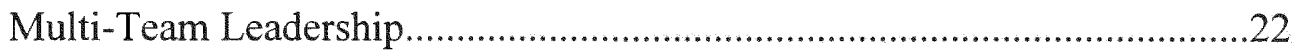

III. A MODEL OF MTS LEADER EFFECTIVENESS …................................33

Leader Team Strategy Development ..........................................................33

Leader Team Coordination Facilitation ……...........................................39

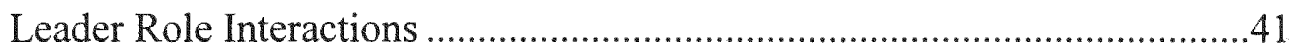

IV. METHOD …

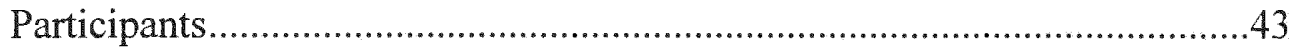

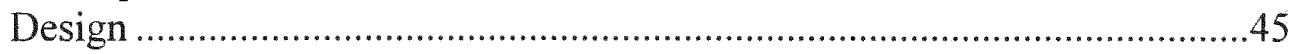

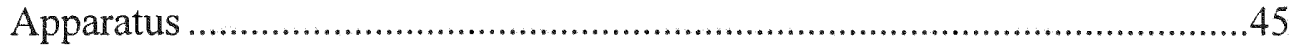

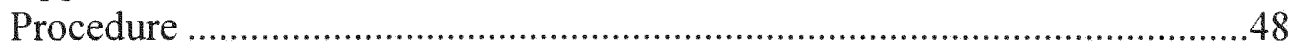

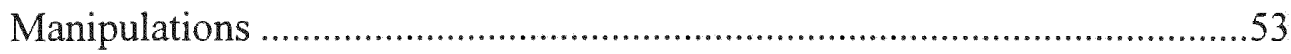

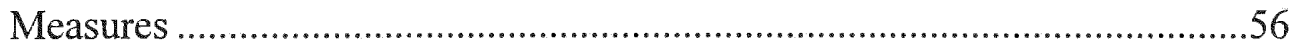

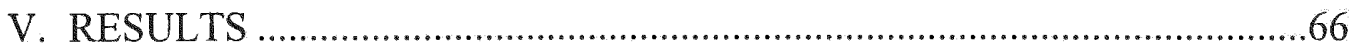

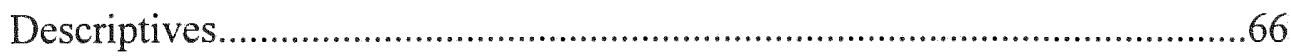

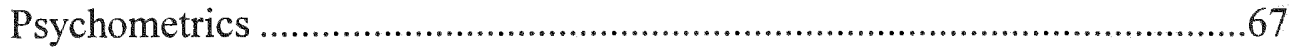

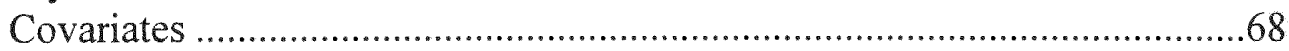

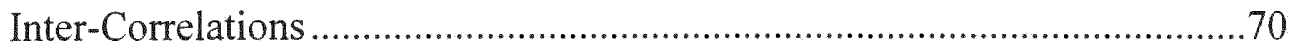

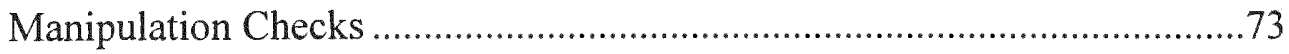

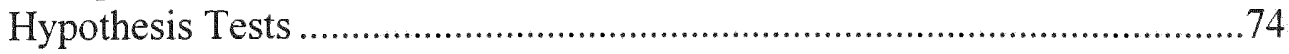

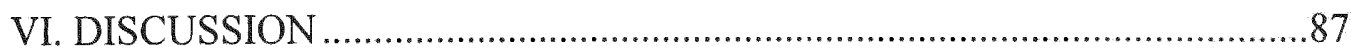

The Impact of Leader Strategy Development …….......................................8 88

Multi-Team Mental Models....................................................................90

The Impact of Leader Coordination Facilitation............................................93

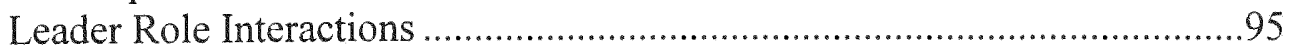

Limitations and Future Research Directions.............................................95

Practical Implications........................................................................100

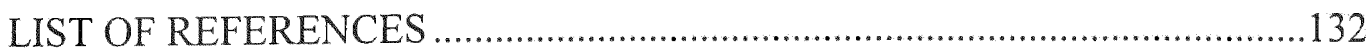

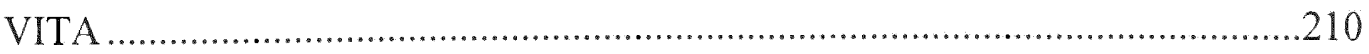




\section{LIST OF TABLES}

TABLE

1. Summary of Team Leader Behavioral Taxonomies ..........................................102

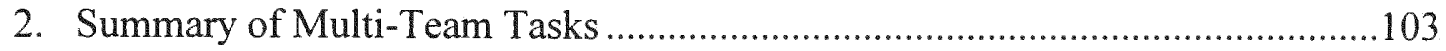

3. Descriptive Statistics for Key Study Variables .................................................104

4. Internal Consistency Reliabilities ( $\alpha$ ) and Median Within Group Agreement Coefficients $\left(\mathrm{r}_{\mathrm{wg}(\mathrm{j})}\right)$ for Leader Behavior Scales (Reported at the Individual

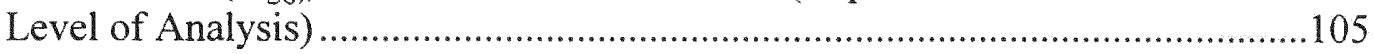

5. Correlations of Potential Covariates with Key Study Variables $(N=64)$...........106

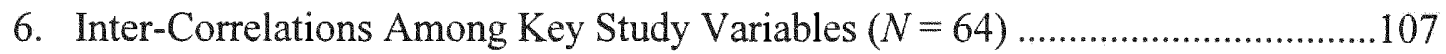

7. Analysis of Variance for Training Manipulation Checks ..................................108

8. Mean Manipulation Check Scores by Leader Training Condition ......................109

9. Analysis of Variance for Leader Strategy Behavior.............................................110

10. Mean Leader Strategy Ratings by Leader Training Condition..............................111

11. Analysis of Variance for Inter-Team Coordination ............................................112

12. Mean Inter-Team Coordination Ratings by Leader Training Condition..............113

13. Summary of Hierarchical Regression Analyses Examining Inter-Team Coordination as a Mediator in Predicting Multi-Team Performance ..................114

14. Analysis of Variance for Mental Model Similarity and Accuracy ......................115

15. Mean Mental Model Accuracy and Similarity Scores by Leader Training Condition

16. Summary of Hierarchical Regression Analyses Examining Mental Model Accuracy as a Mediator....

17. Summary of Hierarchical Regression Analyses Examining Mental Model Similarity as a Mediator....

18. Analysis of Variance for Leader Coordinating Behavior.....................................118

19. Mean Leader Coordinating Behavior Ratings by Leader Training Condition .....119 
20. Summary of Hierarchical Regression Analyses Examining

Inter-Team Coordination as a Mediator...

21. Analysis of Variance for Multi-Team Performance............................................121

22. Mean Multi-Team Performance by Leader Training Condition ..........................121

23. Summary of Results of Hypothesis Tests ........................................................122 


\section{LIST OF FIGURES}

FIGURE

1. Overview of Current Research Model.

2. Illustration of a Multi-Team System for Handling Severely Injured Accident Victims (Adapted from Mathieu, Marks, \& Zaccaro, 2001).

3. The Rhythm of Team Task Accomplishment (Adapted from Marks, Mathieu, \& Zaccaro, 2001)

4. Research Model and Hypotheses Describing the Impact of Leader Team Strategy Development on Multi-Team Effectiveness

5. Research Model and Hypotheses Describing the Impact of Leader Team Coordinating on Multi-Team Effectiveness

6. Graphical Representation of Anticipated Findings from Hypothesis 12

7. Graphical Representation of Anticipated Findings from Hypothesis 13

8. MTS Simulation: Team Structure

9. MTS Simulation: Apparatus. 
Synergy is defined by the American Heritage Dictionary as "the action of two or more substances, organs, or organisms to achieve an effect of which each is individually incapable (Boyer, Ellis, Harris, \& Soukhanov, 1983, p. 691)." The study of how teams produce synergistic process gains that surpass the sum of individual contributions has drawn significant attention from both academics and practitioners in the organizational sciences. Focusing on individual teams, however, limits our understanding of how teams operate as part of larger collectives to attain both proximal team goals, and more distal goals that are attained through the synchronization of multiple team efforts. Thus, not only do individuals within teams work together to attain team goals, but larger collectives of teams, or teams-of-teams, also must work together to attain larger system goals. Collectives comprised of multiple interdependent teams are vehicles for accomplishing goals too large to be undertaken by an individual team working alone and are present in a variety of settings including organizations, government, education, military, and athletics. As an illustration, the successful introduction of a new product requires coordination among a firm's product design, finance, and marketing divisions. The success of this three-team system depends on both effective synchronization of activities within each team and the effective synchronization of activities conducted by multiple teams. For example, within the marketing team, individuals responsible for designing promotional materials must coordinate with the researchers to ensure promotional materials are appropriate to the product's target market. In addition, the marketing team must work closely with the design team to be sure its promotional materials accurately represent the product's key features, and with the finance team to 
ensure the promotion plans are within the allocated budget. Success, then, depends not only on each component team working together to attain its proximal goal (e.g. designing promotional materials), but also on component teams working with one another towards the accomplishment of their more distal goals (e.g. the timely and effective introduction of the product to market).

How team members work together to effectively combine their efforts is not a new area of inquiry. In fact, a large body of research has accumulated that explores various aspects of team performance, and the topic has been the focus of a number of large reviews (Bettenhausen, 1991; Cohen \& Bailey, 1997; Kozlowski \& Bell, in press; Levine \& Moreland, 1990). What has not been explored is how multiple teams linked by common goals coordinate their efforts so that the entire system of teams is successful. While this level of inquiry is complex and not as neatly contained as examining single teams, it is a reality in many team settings. Although the literature often views team success as an ultimate criteria, in organizations, individual team successes are actually building blocks for system effectiveness. Goals such as organizational performance in business settings, mission accomplishment in military settings, and winning games in athletic settings are ultimately the result of the effectiveness of the teams of teams that work towards those aims.

Further, without the synchronization of the array of teams that contribute to the larger goal, component teams can be highly effective and yet fail as a system. Unfortunately, in many instances where there are multiple interconnected teams, there are large failures to coordinate across team boundaries. This is evident in many government settings where multiple agencies all working towards the same goal work in relative 
isolation and fail to benefit from the work of other teams in the system. An example of the magnitude of potential consequences from inter-team coordination failure surfaced in the weeks following the September eleventh terrorist tragedy. President George W. Bush created a leadership role for homeland defense responsible for coordinating the activities of the hundreds of agencies responsible for activities that contribute to domestic safety. This action was taken in direct response to observed failures in inter-agency coordination. In an $\mathrm{ABC}$ interview, Senator Richard Shelby (personal communication, October 7, 2001) stated, "there's not enough coordination between the FBI and CIA." This underscores the need for research that explains how leaders, like Tom Ridge, facilitate coordination among multiple teams working towards the same distal goals.

This failure to coordinate across team boundaries may be attributable to the complexity and ensuing cognitive demands of working in this type of system. Cognitive psychologists have repeatedly demonstrated that individuals like to simplify their environments and, in doing so, develop simple rules for filtering information. One filter employed in group settings is the perception of a group boundary. Two results of classifying individuals as either insiders or outsiders are the "we versus them" mentality (Sheriff, 1966) and the negative external stereotyping that arises from high internal cohesiveness (Janis, 1991). Evidence suggests this internal focus may be functional to group maintenance. Ancona (1990) found groups with high levels of external interaction suffered from low cohesiveness and member satisfaction while groups that insulated themselves from their environments exhibited strong cohesion and satisfaction. While functional for group maintenance, Ancona (1990) found internal focus to be dysfunctional to task performance. In fact, in groups with external dependence, external 
activities like communication with constituents were found to be more important to team performance than were internal activities like decision making.

How then, do multiple interconnected teams work together effectively? While the role of coordination with other teams can originate within the team, it is likely to be more effective when it originates from external leadership. This is because team members are already engaged in taskwork and teamwork, and dedicating resources to intra-team coordination necessarily detracts from resources allocated to inter-team coordination which lays a critical foundation for multi-team performance (Kanfer, Ackerman, Murtha, \& Dugdale, 1994). Though Ancona (1990) found directive internal leadership provided these resources in decision making teams, in teams where each team member is actively engaged in specific role requirements, a formal and external leadership position is needed to provide these resources.

The role of leadership in guiding individual efforts has been well explored (Yukl \& Van Fleet, 1991). The role of leadership in guiding team efforts has received some attention (Kozlowski et al., 1996). However, the role of leadership in integrating a system of interconnected teams has not been explored. Since organizations are not only increasing their reliance on teams, but also on management teams (Rawlings, 2000), investigations such as this that examine the boundary activities of teams are increasingly critical to our understanding of organizational performance.

Towards this aim, Mathieu, Marks, and Zaccaro (2001) recently introduced MultiTeam Systems Theory (MTST) to describe the central features of how Multi-Team Systems (MTS's) operate. Formally, MTS's are defined as "two or more teams that interface directly and interdependently in response to environmental contingencies 
toward the accomplishment of collective goals (Mathieu et al., p. 290)." The increased structural complexity of MTS's as compared with single teams requires effective process both within component teams and between teams. Research has long recognized the critical function of leadership in uniting individuals within teams (Hackman, 1987; Hackman \& Walton, 1986). In multi-team systems, the necessity for and impact of leadership is even more critical to effectiveness. Further, just as teams form to synergistically combine the inputs of individuals, leadership of larger collectives, such as multi-teams, will often be conducted not by one individual but by a team of leaders. This research explores the role of leadership teams in integrating multiple interdependent teams.

The current research extends the leadership and teams literatures by examining how leadership teams direct inter-team process. Kozlowski and Bell (in press) underscore a deficiency in the team and leadership literatures to examine "what leaders should actually be doing to enhance team effectiveness (p. 31)." Work that examines the effectiveness of single teams is extensive (see Kozlowski \& Bell, in press, for a review). This stream of research has consistently shown interaction processes (see Marks et al., 2001, for a review), leadership (Komaki et al., 1989; Kozlowski et al., 1996; Marks et al., 2000), and more recently, shared cognitions (Mathieu et al., 2000; Stout et al., 2001) impact team functioning. Other research has demonstrated that external activities of team members are also important to team effectiveness. Ancona and colleagues examined the impact of different team strategies toward interacting with their environments on effectiveness (Ancona \& Caldwell, 1992; Ancona, 1990). However, research has not yet 
examined how a leadership team improves team and multi-team performance by shaping and facilitating the process between teams.

This dissertation takes an important first step towards this aim. In the following chapter a model outlining key components of team leadership and multi-team effectiveness is introduced in the context of the extant literature on teams, leadership, and shared cognition (Chapter 2). Figure 1 (on page 123) presents an overview of the current research framework. Next a set of hypotheses designed to test the model links is presented (Chapter 3). Chapter 4 outlines the experimental methodology of the current study. Results and findings are presented in Chapter 5. Finally, Chapter 6 discusses the important findings and conclusions of this work, discusses important limitations and next steps for research on multi-team systems and team leadership, and concludes with an elaboration of the practical implications of this work to organizational managers and team members. 
This review is organized into four main sections. First, an overview of the main theoretical points related to the entities currently under investigation is provided. Since this research focuses on collectives that are comprised of multiple interdependent teams, this will include a delineation of the core aspects of Multi-Team Systems Theory (Mathieu et al., 2000). Second, since this research examines the impact of leadership teams on multi-team effectiveness, conceptions of leadership will be reviewed toward the development of a framework for understanding the roles of leadership in multi-team systems. Next, McGrath's (1984) input-process-output model and Marks, Mathieu, and Zaccaro's (2001) recurring phase model of team effectiveness will be described as both are central to the development of a model of leader effectiveness in multi-team systems. Finally, the specific mechanisms through which leadership impacts multi-team functioning will be reviewed. This will include a discussion of research on team cognition, team planning, and team coordination.

\section{Multi-Team Systems Theory}

Gist, Locke, and Taylor (1987) ended their review of the field of organizational behavior stating, "the dearth of literature on intergroup relations of any type is of concern (p. 252)," and encouraging future research to, "extend beyond the study of groups in isolation to the study of groups as part of a system of organizational activity (p. 253)." The recent introduction of Multi-Team Systems Theory (MTST) represents a sizable advancement in our conceptualization of teams. There are substantial bodies of research targeted at both the team and organizational levels. Team level research recognizes that teams interact with their environments, and organization level research recognizes that 
organizations are composed of individuals and teams, however, there is a substantial disconnect between these two bodies of literature. MTST bridges this gap by providing a conceptual framework for understanding how collectives that are comprised of multiple teams operate. In doing so it aids in our understanding of both the subsystems that comprise organizations, and also of interconnected subsystems from multiple organizations.

The key unit of analysis in MTST is the Multi Team System (MTS). MTST identifies five defining characteristics of MTS's. First, MTS's are composed of two or more component teams. Component teams are traditional teams and can be defined as, "any distinguishable set of two or more people who interact, dynamically, interdependently, and adaptively toward a common and valued goal/objective/mission, who have each been assigned specific roles or functions to perform, and who have a limited life-span of membership (Salas, Dickinson, Converse, \& Tannenbaum, 1992, p. 4)." While MTS's are comprised of teams, a second distinction is that they are themselves unique entities. Thirdly, component teams within the MTS exhibit input, process, and outcome interdependence with at least one other team in the MTS. Fourth, MTS's are open systems. And fifth, while each team within an MTS has its own proximal goal, proximal goals are ultimately linked towards the attainment of at least one shared distal goal of the MTS.

Each of these defining characteristics can be better understood by considering a specific MTS. Figure 2 (on page 124) presents an example of an MTS whose ultimate goal is to save victims' lives. This MTS is comprised of four teams; fire fighters and emergency medical technicians represent two teams from the county government, an 
emergency room surgery team and a recovery team represent two teams from a local hospital. These teams are themselves part of a larger system whose ultimate goal is to save lives. In the event of an accident, the attainment of the MTS goal will require the synchronized efforts of all four teams. First, the firefighters and EMT's must simultaneously report to the scene of the accident and work together closely to extract victims from the vehicles and stabilize them. Next, the EMT's need to transport the victims to a hospital where they can receive care by an emergency room surgical team if their injuries are severe. Following surgery, patients would likely be admitted to an intensive care unit and attended to by a recovery team of doctors and nurses. While this is a simplified example, it captures the complex network of teams involved in attaining the same ultimate goal.

A defining characteristic of an MTS is that component teams exhibit some degree of interdependence. Essentially, interdependence among component teams both describes the nature of inter-team relationships and determines the required types of interactions within the MTS. At the team level, this idea was supported by Lord and Rowzee (1979) who examined the relationship between leader functional behavior and performance on both low and high interdependence tasks. Most notable was the finding that coordinating behavior was significantly positively related to performance on highly interdependent tasks, and significantly negatively related to performance on non interdependent tasks. In MTS's, the nature of the interdependence among teams can stem from three sources. Component teams may have to share resources; this is termed input interdependence. Using the example above, if the fire fighters and EMT's use common tools at the accident site, they can be said to exhibit input interdependence. Component 
teams could also be linked operationally such that they must interact in order to attain proximal team goals. This is analogous to task interdependence in teams but is termed process interdependence in MTS's. In our MTS example, the fire fighters and EMT's exhibit process interdependence since they must work together closely in order to do their respective tasks. The work of the firefighters (e.g., extracting victims) and EMT's (e.g., stabilizing victims) must be carefully sequenced. Finally, interdependence can result less directly through the ultimate requirement of another team in order to attain a distal shared goal, termed outcome interdependence. In our example, saving lives is a goal shared by all four of the teams. Without the efforts of any one of the teams, this goal cannot be realized.

Because the performance of MTS's depends on both the successful performance of component teams and, depending on the combination and degree of interdependence, the successful coordination of efforts among teams, the performance setting of an MTS is far more complicated than that of a single team. This phenomenon has been recognized by researchers such as Tjosvold (1984) who found that groups focusing on their own goal related efforts find it difficult to coordinate with others, even when their goals are related. The increased demands on teams operating within an MTS underscore the need for interventions that compensate for these demands and improve the likelihood that the MTS will be successful. Mathieu et al. (2001) discuss several interventions including shared cognitions, leadership, technology, and reward systems that are central to MTS functioning. Of these, leadership is especially relevant as it not only directly impacts MTS functioning, but also indirectly impacts MTS functioning as leaders shape cognitions, facilitate the use of technology, and implement effective reward systems. Of 
the levers identified by Mathieu et al. (2001), leadership is the most critical and most influential.

The inherent complexity of a system of teams working interdependently not only introduces the need for leadership, but of a team of leaders. This is often the case in organizations where top management teams are comprised of experts from key functional or geographical areas. The team structure affords individuals both the compilation of their resources as well as synergistic process gains realized from working together. MTS leadership is charged with integrating the activities of multiple teams working simultaneously on multiple subgoals and so more realistically, team leadership is required. How leadership teams successfully integrate component teams is a pressing issue in today's team based organizations and has not been investigated.

Scholars have long recognized the necessity for leadership in organizations, small groups, political establishments, and basically any setting where multiple individual, group, team, organization, or nation's efforts are to be seamlessly combined. Hackman (1987) in describing the role of leadership in small groups stated:

"It often does make sense to have such a role, especially when substantial coordination among members is required, when there is lots of information to be processed, or when it is advisable to have one person be the liaison with other groups or with higher management (p. 338)."

Each of these circumstances is present in multi-team systems. Substantial coordination is required not only among team members, but between members of interdependent teams. The nature of the system inherently demands significant information processing and by 
definition requires horizontal coordination with other component teams. Thus, in multiteam settings, the value of leadership is even more pronounced than in single teams.

In the organizational sciences, leadership is studied by examining how leader behaviors influence followers and more rarely, teams. However, how leader behavior impacts teams functioning as part of a larger system (i.e., an MTS) has not yet been empirically explored. The importance of this issue to today's organizations is captured in the following excerpt from a popular consulting magazine,

"As businesses have grown more complex, cross-functional collaboration at leadership and organizational levels has become central to driving results.

Working collaboratively across functions is a complex leadership team issue (Rawlings, 2000, p. 37, emphasis added)."

In order to advance and test a model explicating the role of leadership within a multiteam system, the literature on leadership in general and specifically on team leadership are first reviewed and then considered in conjunction with our current understanding of team effectiveness.

\section{Leadership Effectiveness}

Though research on leadership is extensive, research that examines leadership within team contexts is less abundant. While organizational researchers generally recognize the value of using teams as a basic unit of work accomplishment, and of leadership in improving employee performance and satisfaction, our understanding of how leadership aids in the success of teams represents a substantial gap in the organizational literature (Kozlowski \& Bell, in press). That is, our understanding of how 
leaders ought to behave to best facilitate not only individual, but also team outcomes is limited.

This section will first provide a brief overview of the major approaches to studying leadership. A discussion of the team leadership approaches will follow. Finally, this section will conclude with an attempt to integrate these approaches towards the development of a framework for understanding the role of leadership in multi-team systems.

Leadership approaches. In the broad leadership literature, there are a multitude of approaches each of which defines and explores leadership from a unique perspective. Leadership researchers have explored leadership as arising from a quality or set of qualities of an individual. For example, individuals with high energy levels, tolerance for stress, and self-confidence have been linked to managerial effectiveness (see Bass, 1990 for a review). Others have focused more on the actual behaviors of leaders, such as initiating structure and consideration (Fleishman, 1953). This is termed the functional leadership approach. Still others view leadership as arising from one's power over followers (French \& Raven, 1959); or reciprocal influence, as is typified in the leadermember exchange paradigm (see Schriesheim, Castro, \& Cogliser, 1999, for a review). While these approaches focus primarily on the direct effects of leadership, other approaches such as Fiedler's (1967) contingency theory and House's (1971) path-goal theory focus on how leaders need to tailor their behaviors or styles to the specific context within which they operate. And more recently, significant attention has been directed toward charismatic (House, 1977; Conger \& Kanungo, 1987) and transformational (Burns, 1978; Bass, 1985) approaches to leadership. 
Of these general leadership approaches, functional leadership theory is particularly useful in understanding team leadership since it specifies the leader's job as, "to do, or get done, whatever is not being adequately handled for group needs (McGrath, 1962, p.5)." Existing taxonomies of functional leadership behaviors were synthesized by Fleishman et al. (1991), leading to the development of an integrating taxonomy with four superordinate leadership activities: information search, problem solving, management of people, and management of materials. In the next section, the state of research on leadership in teams will be reviewed. Most of the research investigating team leadership focuses on skills of leaders and behaviors used by leaders to facilitate team effectiveness.

Team-based leadership approaches. As interest in utilizing team-based forms has grown, so has the concern with leadership's role within collectives such as teams. In the following section, research to explicitly examine leadership within teams is reviewed.

Paralleling ideas from the more general functional theory of leadership, Hackman and Walton (1986) described a functional theory of leadership in task-performing groups. Five primary leader functions were identified: setting directions, designing the group, tuning the context, coaching and assisting, and providing resources. While these dimensions provide descriptive utility, their effectiveness in teams has yet to be empirically validated.

Komaki and colleagues advanced an operant approach to leader effectiveness in teams. Central to the operant approach is the prescription that team leaders provide monitors and consequences. Monitors include supervisory behaviors aimed at "collecting performance information" and consequences are behaviors that "indicate knowledge of performance" (Komaki et al., 1989, p. 523). Support for this approach was provided in a 
field study of sailing teams. Significant correlations were observed between leader monitors and consequences and team standings indicating that successful team leaders were observed to provide these two behaviors more than those of unsuccessful teams.

Kozlowski and colleagues (1996) provide a conceptual framework that describes team leadership as centered around a developmental and a task-contingent role. Their approach states that once a team progresses through the basic developmental stages including role development and individual task competence, the primary leader function occurs within the team's task cycle. Kozlowski et al. (1996) argue that it is the leader's job "to facilitate the development of coherence on role expectations and goal-strategy linkages that encompass the entire team (p. 24)." In other words, team leadership needs to make the connection between team goals and how teams will attain those goals.

According to Kozlowski et al.'s (1996) model, leaders serve two task contingent functions that are critical to team performance: instruction and intervention. Leader instruction includes goal setting, monitoring, diagnosis, and feedback. Leader intervention is leader behavior that initially frames the situation for team members and then assesses the situation and redefines team members' understanding of the task and team when necessary. Situation framing is done primarily in low intensity task situations, while situation assessment and task/team redefinition occur during high intensity task engagement.

Bachiochi et al. (1999) conducted a series of focus groups that examined the qualities necessary for effective team leaders. Six categories of behaviors were identified. Two deal with individual characteristics (background/expertise and personal characteristics) and the other four specify leader skills consistent with those identified by 
Fleishman et al.'s (1991) taxonomy. Task oriented skills include planning, organizing, problem solving, and facilitating the process. Interpersonal skills include coaching and supporting. Communication skills include communicating information and providing feedback. Finally, liaison skills include boundary-spanning activities.

A final theory of team leadership was proposed by Morgeson (1996) who advanced a conception of team leadership that defines the leaders task as managing "the variety of events that impact team functioning (page 29)." Specifically, Morgeson argues leaders must engage in three primary activities: monitoring, diagnosis, and intervention. Leaders must monitor activities both internally and externally, diagnose or interpret this information, and intervene as appropriate. Intervention can include team establishment, development, motivation, and boundary management activities.

The work on team leadership, and Fleishman's taxonomic work on functional leadership, exhibit substantial overlap in their delineations of critical leader behaviors. Taken together, these works seem to suggest two primary avenues by which leadership impacts teams. The first is by establishing mechanisms for making effective team interactions routine, and the second is by directly regulating team interactions. A summary of the leader behaviors included by each approach is presented in Table 1 (on page 102).

First, leaders influence teams by establishing conditions that foster effective team interactions. These activities have been represented in the literature as goal setting and situational framing (Kozlowski et al., 1996), setting directions (Hackman \& Walton, 1986), communicating information (Bachiochi, 1999; Fleishman, 1991), planning (Bachiochi, 1999), and diagnosis (Morgeson, 1996). 
Next, leaders influence teams more directly by regulating their interactions. This element of team leadership has been captured in the monitoring performance and providing feedback (Komaki et al, 1989; Kozlowski et al., 1996), coaching and assisting (Hackman \& Walton, 1986), problem solving (Fleishman, 1991), assessing the situation, redefining the task and team (Kozlowski et al., 1996), and intervention (Morgeson, 1996) activities described in previous research.

Having developed a preliminary framework for viewing multi-team leadership, the following section will examine the specific ways in which leaders can improve team functioning. This will be achieved by first examining two important models of team effectiveness, and then by incorporating these two categories of leader behavior within them to construct a more complete model explicating the role of leadership in multi-team systems.

Team Effectiveness

Input-process-output model. Since multi-team systems are teams themselves comprised not of individuals, but of teams of individuals, understanding single team effectiveness is a necessary starting point. The dominant paradigm in small group and team research is the input-process-output model introduced by McGrath (1984). According to the model, inputs such as organizational context, group design, and leadership (Gist et al., 1987) impact the effectiveness of a group or team by altering the interaction patterns among members. These interaction patterns are termed processes.

Recurring phase model. Marks et al. (2001) extended our understanding of team performance episodes with their introduction of the recurring phase model of team processes. Rather than viewing team performance as static, as in the case of traditional I- 
P-O models, or as occurring over a team's entire lifecycle, as group development models have done (e.g. Tuckman, Gersick), the recurring phase model suggests that team performance is best viewed as a series of interrelated episodes. Each episode contains IP-O linkages and most notably, outcomes of prior episodes then become inputs for future episodes. Figure 3 (on page 125) presents a graphical illustration the Marks et al. model.

Marks et al. (2001) also suggest that team performance episodes consist of two phases. Action phases "are periods of time when teams are engaged in acts that contribute directly to goal accomplishment (Marks et al., 2001, p. 360)." Transition phases "are periods of time when teams focus primarily on evaluation and/or planning activities to guide their accomplishment of a team goal or objective (Marks et al., 2001, p. 360)." This is an important distinction because the nature of taskwork, or team process, is thought to be different during each of these phases.

During transition and action phases, just as teams need to engage in different types of process behaviors to be effective, leaders need to exhibit different functional behaviors to be effective. Initial support for this idea was found by Komaki et al. (1989) who observed that leader behaviors differed across preparation and race phases in sailing teams. Monitoring behavior occurred with the same frequency during the preparation and action phases, though providing feedback, instruction, and information about performance expectations occurred more often during the actual race. While their work did not examine differences in leader effectiveness based on the pattern of these behaviors, it did provide some indication that leaders recognize the need for different behaviors during different team phases. Along the same lines, Kozlowski et al. (1996) posited that team leader instruction and situation framing take place during periods of 
low intensity task engagement, analogous to transition phases; while behaviors such as situation assessment and task/team redefinition take place primarily during periods of high intensity task engagement, analogous to action phases.

Team coordination. Though the specific behaviors included under the term process has varied extensively from study to study, processes such as cooperation and coordination have consistently been shown to mediate input-output relationships.

Definitions of coordination are abundant in the organizational literature. Some are concrete such as Guastello and Guastello's (1998) statement that coordination "occurs when two or more people do the same or complementary tasks at the same time (p. 423)." Other definitions are much more abstract; for example Thompson (1967) described coordination as "a means by which organizations can pursue difficult and complex goals and manage uncertainty (page 16)." Most definitions of coordination capture the elements of interdependent tasks being performed with synchronicity (Zalesny, Salas, \& Prince, 1995). That is, with respect to appropriate timing. Marks et al. (2001) capture these two critical elements in their definition of coordination: "the process of orchestrating the timing and sequence of interdependent actions (pp. 367-368)."

Marks et al.'s (2001) definition is especially useful since its target is not specific to a unit of analysis and rather can be applied broadly. Actions can be performed by an individual, hence hand-eye coordination involves the timing of actions performed by one's hand and eyes. In teams, coordination occurs when members appropriately time their actions. For instance when a quarterback throws the ball so that it lands in the hands of the wide receiver as he is running towards the end zone, the team is exhibiting good coordination. At the multi-team level, coordination is effective when the activities of 
component teams are effectively synchronized. Using the earlier example of the system of teams responsible for introducing a new product to market, coordination occurs when the marketing team has its promotion plans in place during or immediately before the period when the development team has shipped the product to retailers. Thus, coordination is a process that can occur in many types of systems and at many levels of analysis. When the actions of subunits must be combined, such as in teams and multiteams, coordination is the heart of effective process.

A closely related process described in the literature is cooperation. Cooperation is defined as "the willful contribution of personal efforts to the completion of interdependent jobs (Wagner, 1995, p. 152)," and is a more general construct than coordination. Further, while coordination clearly refers to the temporal sequencing of interdependent actions, cooperation only specifies that actions work towards the same aim.

Both coordination and cooperation have been shown to improve team performance in laboratory teams. Jehn and Shah (1997) found cooperation, defined as, "behavior which aids the performance of another group member or contributes to the ease with which group members coordinate their efforts (Weldon \& Weingart, 1988, p.22)," improved the performance of three member teams. Significant positive relationships were observed between coordination and performance for teams working on both a problem solving and a model building task. Stout, Salas, and Carson (1995) found observer ratings of overall team coordination were significantly related to the task performance of two member teams performing a flight simulation. The same effect was observed by Harris and Barnes-Farrell (1997) in three person decision making teams. Observer ratings of 
coordination were significantly related to both overall team performance on the task and rated team productivity.

Research on inter-team coordination is less abundant and primarily theoretical in nature. Ancona and colleages (Ancona, 1990; Ancona \& Caldwell, 1988; Ancona \& Caldwell, 1992) made significant advances in our knowledge of the types and differential effectiveness of group external activities. Group leaders were found to exhibit one of three external strategies of increasing effectiveness: informing, parading, and probing. Informing, the most isolationist strategy, is characterized by a focus on internal process. External activity is limited to informing external stakeholders of what the team has decided. Parading also focuses on internal group process, but at the same time maintains visibility with external constituents. Finally, probing involves intensive interaction with the group's environment and was found to characterize the most effective groups when external dependence existed.

While this typology describes very broad and general external strategies, Ancona and Caldwell (1992) also provide a more detailed description of external activities that include vertical and horizontal communication and feedback solicitation. Vertical communication, also termed task-coordinator activity, is aimed at coordinating work. In a field study of new product development teams, Ancona and Caldwell (1992) found taskcoordinator activities were positively related to four external measures of group performance. Similarly, Denison, Hart, and Kahn (1996) supported a model of crossfunctional team effectiveness where coordination with other teams was included as a contextual factor impacting the team's process. 
While this line of research underscores the importance of inter-unit coordination to the performance of individual teams, it still fails to address the importance of inter-unit coordination on overall system performance. The organizational theory literature provides some evidence linking inter-team coordination to organizational performance. Specifically, cooperation across functions has been examined as a predictor of organizational effectiveness. Pinto, Pinto, and Prescott (1993) found perceived cooperation among health care functional units related positively to perceptions of task performance and psychosocial outcomes of unit membership.

Both team and organizationally based research have identified coordination among interrelated units as a critical process. These findings suggest the process of coordination is doubly important in multi-team settings. First, intrateam coordination is critical to each component team's performance. In addition, coordination among related teams is also essential. As was noted earlier, when teams are interdependent such that the goals of multiple teams all contribute to a larger system goal, and/or one team's goal accomplishment is prerequisite to another team's performance, inter-team coordination is critical. Otherwise, it is conceivable for component teams to be individually successful and yet the system to fail. Therefore, the critical function of leadership in multi-team systems is to engage in behaviors that lead to effective inter-team coordination.

\section{Multi-Team Leadership}

As was reviewed earlier, the literature on team leadership suggests leaders impact teams in two ways. First by routinizing functional behavior patterns through transition phase activities such as goal setting and planning and second by directly facilitating functional behavior patterns during action phases by engaging in activities such as 
monitoring and intervening. Research based on McGrath's (1984) I-P-O model that explores the impact of process on performance suggests teams need to coordinate effectively. Thus, leadership will be effective to the extent that it (1) sets the stage for successful coordination and (2) facilitates successful coordination. Leaders set the stage for coordination by developing shared understandings of requisite interactions with the system. The following section will elaborate the role of leadership in team transition phases by describing the importance of shared cognitions within teams, the ability of leadership to shape those cognitions, and the instrumentality of leader planning activities in shaping team member cognitions.

Team mental models. The concepts of shared mental models, teamwork schema, transactional memory and other group-level cognition have recently become the focus of significant research attention (Klimoski \& Mohammed, 1994; Kozlowski et al., 2000). While there remains some debate on the exact nature of these team level cognitive constructs, recent conceptual work has refined important definitional issues and empirical studies utilizing the construct further add to its predictive utility. Based on the construct elucidation of Klimoski and Mohammed (1994), the current research utilizes the team mental model construct.

What exactly is a team mental model? Broadly applied, "mental models are the mechanisms whereby humans are able to generate descriptions of system purpose and form, explanations of system functioning and observed system states, and predictions of futures system states (Rouse \& Morris, 1986, p. 351)." In the team context, CannonBowers, Salas and Converse (1993) defined team mental models as "knowledge 
structures held by team members that enable the formation of accurate expectations of the task and team (p.26)."

Rouse and Morris (1986) emphasize that while mental models contain knowledge, they represent a distinct construct that describes how knowledge is arranged or organized. In a two member flight team whose task is to avoid enemy fire, relevant knowledge might include flying at an altitude of 15,000 feet, firing chaffs and flares, and decreasing the radar range. This knowledge, however, does not in itself constitute a team mental model. The team level construct arises when this knowledge is arranged in a certain way; for instance first the radar range is decreased, then the altitude is maintained, and if an enemy missile approaches, chaffs and flares are released. Here it is the sequencing or organization of the knowledge that is of interest. To the extent that the sequence is functional to the team, this would be an accurate mental model; to the extent that team members agree on or share a similar understanding of this sequence, this would be a shared mental model.

As both general and team-specific definitions agree that mental models represent organized knowledge, understanding them requires one to specify both the knowledge domain and how it is organized (Klimoski \& Mohammed, 1994; Mohammed, Klimoski, $\&$ Rentch, 2000; Rouse \& Morris, 1986). In the above example, the content is task related, and it is organized into an ordering or sequence of relevant task actions. An area of continuing debate is the nature of the group level construct. That is, how do individual cognitions combine to comprise the team mental model. Klimoski and Mohammed (1996) describe three types of sharedness. Shared models could mean identical, requiring team members to have the exact same knowledge structures. Shared models could also be 
distributed, requiring only compatible knowledge structures. Finally, an open issue in this area is whether sharedness is in fact the most relevant aspect of mental models. In fact it may be accuracy or some combination of similarity and accuracy that best predicts teamwork (Mathieu et al., 2000).

Cannon-Bowers et al. (1993) shed some light on what is contained in team mental models by offering four types of mental models. First, team task models contain knowledge related to the completion of the team's task. (insert example) Team models contain knowledge of the team member's task relevant knowledge, skills, abilities, attitudes, preferences, and tendencies. This model is similar to the construct of transactional memory. Team interaction models contain information about how team members must interact to perform effectively. Finally, equipment models contain knowledge of team technology, equipment, and operating procedures used in performing the team's task. Other researchers have introduced additional content types. For instance, Converse and Kahler (1992) distinguish a strategic model that includes information about plans for specific goals and situations.

As was noted earlier, an area of continued uncertainty with respect to team mental models is how information contained in the model should be examined. Most importantly, is it sufficient for team members to contain similar knowledge structures or do those knowledge structures need to be functional or contain some degree of accuracy. This point was made succinctly by Matheiu, Heffner, Goodwin, Salas, and CannonBowers (2000) who stated, "convergence does not equal quality-and teammates may share a common vision of their situation yet be wrong about the circumstances that they are confronting (p. 281)." 
Research on team mental models has examined both the sharedness and accuracy of mental models, yet findings have not been consistent. Marks et al. (2000) examined the impact of both sharedness and accuracy and found strong relationships of both with communication and performance. In their study it is also notable that similarity and accuracy were significantly correlated. Mathieu et al. (2000) examined only convergence, or sharedness, and found it related significantly to both team process and performance. Finally, Webber, Chen, Payne, Marsh, and Zaccaro (2000) examined both similarity and accuracy, and found similarity was most predictive of team performance. Contrary to the findings of Marks et al. (2000), Webber et al. (2000) did not find a significant relationship between similarity (measured with an index of within group agreement) and accuracy.

Given these findings, it seems the best approach is for future research on the team mental model construct to measure and report results for both types of indices. This will provide an accumulation of findings that in their aggregate may further elucidate the unique role of each index or possibly even an optimal combination of the two. A final note on the topic is echoed from Matheiu et al. (2000) who point out that additional work examining ways to operationalize the accuracy of mental models is needed. Past studies have used comparisons to experts; however, especially in teamwork settings, it seems highly plausible that multiple accurate models may exist (Matheiu et al., 2000).

Theoretically it is argued that mental models serve an important function in teams. Cannon-Bowers et al. (1993) submit that shared mental models improve coordinated team performance by allowing team members to anticipate the actions of their teammates. Marks et al. (2000) furthered this logic stating that mental model 
sharedness will be increasingly critical to team performance when team members are faced with changing situations. By allowing members to rely on their common understandings, team mental models will enable teams to adapt their behavior to the changing task conditions. Further, Stout, Cannon-Bowers, and Salas (1996) found mental model sharedness improved performance in teams when substitute mechanisms, such as explicit communication, were not feasible.

Both lab and field evidence has linked mental models with team performance. Webber et al. (2000) found team member agreement on strategic mental models was associated with improved performance in a field setting examining community basketball teams. In a laboratory study, Stout, Cannon-Bowers, Salas, and Milanovich (1999) supported a link between shared models of team member informational requirements and team performance on a helicopter battle simulation.

Additional laboratory work has linked mental models to both team process and team performance. Mathieu et al. (2000) found the convergence of both team and task mental models led to improved team process and performance in two person teams performing a flight simulation task. Marks, Matheiu, and Zaccaro (2000) found shared team mental models facilitated team communication and performance in three member teams performing a tank battle simulation.

Both direct and indirect evidence supports a relationship between leadership and team mental model development. While mental models were not explicitly investigated, several studies support the basic idea that leader behavior influences the cognitive structures of subordinates and thereby improves performance. Lord (1976) found leader behaviors that defined a problem were associated with improved performance. Similarly, 
Lord and Rowzee (1979) observed a positive but nonsignificant relation between leader behavior that develops an orientation toward the problem (i.e. shared understanding) and team performance on a laboratory task.

Marks et al. (2000) provide direct evidence that team leadership impacts the development of shared models. In a laboratory experiment using three member tank teams, a leader's communication of information about the team's task environment led to more shared and accurate team mental models, better intra team communication, and ultimately, better team performance. This study, in particular, demonstrates the valuable role leaders play in forming team member cognitive structures in advance of task engagement. This is in line with the first function of team leadership identified in the current investigation: establishing mechanisms to routinize coordination. During transition phases, leaders communicated information to followers that facilitated better process in their action phase.

In sum, the recent teams literature supports a central role of shared knowledge structures in facilitating team process and performance, and of leadership in facilitating mental model development. The current research will examine these relationships at the multi-team level of analysis by examining how leadership teams influence multi-team process and performance. More specifically, it is argued that in a multi-team setting the most important knowledge to be shared is how teams are to work together effectively and so a multi-team interaction model will be the focus of this study. One primary way leader teams impact mental model development is by conveying plans and strategy information to team members during transition phases. 
Team planning. When multiple individual or team efforts must be combined toward the attainment of a common goal, planning is a critical route that enables members to anticipate one another's actions and therefore coordinate efficiently and effectively. Further, planning is one way leader teams can set up conditions for effective team process. By communicating effective plans to team members, leader teams foster a shared understanding of how the teams should work together and increase the likelihood that teams will work together effectively during periods of task engagement.

According to Locke, Durham, Poon, and Weldon (1997) a plan or task strategy is "a procedure or means for attaining a goal (p. 239)." Group plans can be classified according to their target level (individual or group) and type (deliberate, contingency, or reactive). Individual plans specify procedures for performing individual tasks assigned to specific group members while group plans specify procedures to coordinate the actions of members (Locke et al., 1997). In addition, group plans can be classified according to Marks et al.'s (2001) three subdimensions. Deliberate planning results in a primary course of action. Contingency planning utilizes if/then logic to decide up front on how different situations will be handled by the team. Finally, reactive planning is done in response to changing conditions or inadequate deliberate plans.

Extending these descriptions to the multi-team context, plans can specify what individual teams should do and how teams should coordinate interdependent actions (analogous to individual and group plans). Plans can also specify a primary course of action for teams and the overall system, how teams should respond to unexpected events (specified a priori), and how teams will react to an ineffective deliberate or contingency plan (developed in process). 
A number of studies have established links between team planning and team performance. In an experiment manipulating the amount of planning used, Hackman et al. (1976) found that encouraging the discussion of performance strategies led to improved performance in highly interdependent teams. Thus when team member roles are intertwined, planning enabled smooth coordination. Similar results were obtained in other experimental investigations. Weingart (1992) found individual planning and the quality of planning jointly improved the performance of four person laboratory teams on a tinker toy construction task.

While Weingart (1992) did not find group planning for coordination to improve performance, it was suggested that the free communication and observation of team members allowed by this type of task might not have required up front planning about coordination since members could easily synchronize efforts during task accomplishment. However, on highly resource intensive tasks, or in complex task environments, it is likely to be critical for team members to have coordination plans in advance of task engagement.

While mental models were beyond the scope of these investigations, they demonstrate a general connection between strategizing and team performance. Stout et al. (1999) extended our understanding of how planning leads to improved team performance by establishing a link between planning and the development of shared team mental models. Thus, planning activities, whether conducted by members of the team or by a leadership team, once communicated to team members are likely to lead to a shared understanding of how team task accomplishment should proceed. In a related area of inquiry, Pinkley and Northcraft (1992) found support for this logic. In dyadic 
negotiations, the manner in which partners framed their conflict converged throughout the course of the open discussion of the issues. This illustrates how discussion provides a medium for enhancing similar cognitions in a dyadic setting. The same effect is likely when a leadership team communicates with team members during transition periods.

Coordination facilitation. In addition to communicating effective plans that improve coordination by developing shared team mental models, leadership teams can also directly facilitate coordination during action phases. The literature has discussed a number of behaviors team leaders engage in, and there is substantial overlap in the behaviors discussed by various works.

The first leadership behavior is information gathering. The team approaches all mention some type of leader monitoring behavior. Komaki (1989) highlights the importance of leader monitoring of performance and Kozlowski et al. (1996) describe leader situation assessment as a crucial leader behavior during periods of intense task engagement. Thus within MTS's, one essential leadership behavior is to monitor information that is relevant to the teams. As MTS leadership needs to facilitate coordination, monitoring information such as the status and progress of each team's interdependent activities will not only be relevant but critical to the coordination of activities conducted by multiple component teams.

In addition to staying aware of information, leader teams also need to communicate information to their teams when necessary. This highlights two aspects of MTS leadership. The first is the problem solving function described by functional leadership theory (Fleishman et al., 1991) and diagnosis activity described by existing team leadership approaches (Kozlowski et al., 1996; Morgeson, 1996). Thus, leader 
teams need to know when information is important to a component team's inter-team interactions and when it is not. Secondly, this highlights the importance of leader communication of information. Communicating information was found by Marks et al. (2000) to predict effective team process and performance. In MTS's leader team communication of information should have a similar effect.

In sum, teams leading teams need to both establish conditions necessary for effective coordination during transition phases and work to improve coordination during action phases. During transition phases, the communication of plans and the ensuing development of shared mental models are posited to improve coordination. During action phases, leader coordinating behaviors that include monitoring and communicating information, are proposed to improve coordination. Since coordination has been shown to have a significant impact on individual team functioning, it should likewise prove critical in the effective operations of a multi-team system. In the next chapter, a research model will be presented that investigates these two roles of leadership teams in facilitating interteam coordination and multi-team effectiveness. 
Figure 1 (on page 123) presents the overall model under investigation. While the previous chapter reviewed the bulk of literature bearing on these relationships, this chapter will highlight key findings that support the relationships being tested. First, the role of leader team strategy development will be examined. Figure 4 (on page 126) presents a summary of hypotheses related to the impact of leader team strategy development on multi-team effectiveness. Next, the role of leader team coordinating will be discussed. Figure 5 (on page 127) summarizes the hypotheses related to leader team coordinating and multi-team effectiveness. Finally, the two leader team roles will be considered together.

\section{Leader Team Strategy Development}

As was discussed in the literature review, planning is an important team process that occurs during transition phases (Marks et al., 2001). Planning involves the "development of alternative courses of action for mission accomplishment (Marks et al., 2001, p. 365)." At the team level, good strategies contain information about "member roles and responsibilities, the order and timing of actions, and how task-related activities should be executed (Marks et al., 2001, p. 365)." Teams are comprised of individuals, and so team strategies specify what individual team members should be doing during task accomplishment. MTS's, on the other hand, are comprised of teams, and so effective MTS strategies need to specify the order and timing of team actions and how each team's task-related activities should be executed.

Leader teams play an important part in strategy development. It is often the responsibility of leadership to develop plans. In fact, functional leadership theory 
identifies planning as one of four functions of leadership (Fleishman et al., 1991). In team contexts, leader planning is likely to be especially critical since teams usually do not plan on their own (Hackman et al., 1976).

Leader strategizing was defined earlier as communicating effective plans to team members. Training leader teams to develop and communicate a strategy that contains the two critical elements of a multi-team strategy should lead to more effective leader strategy communication.

Hypothesis 1: Leader teams trained in strategy development will more effectively communicate plans that specify the order and timing of component team actions and how component team actions are to be executed.

Leader team strategy development and multi-team effectiveness. Several studies have investigated the impact of planning on performance at the group level of analysis and have found effective planning relates positively to measures of group productivity (Hackman et al., 1976; Weingart, 1992). It is expected that effective planning by MTS leader teams will similarly lead to effective MTS performance.

Understanding how leader team planning activities come to impact multi-team outcomes is an important issue. According to the recurring phase model of team task accomplishment, planning activities generally occur during transition periods. Transition periods are succeeded by action phases where team members are directly engaged with their task. Finally, performance assessments can be made at the conclusion of action phases. In order to impact multi-team functioning, leader team strategizing that occurs during transition periods must make a difference in the action phase processes of the system. 
Team level research identifies two likely mechanisms through which transition activities lead to effective performance. Multi-team systems are themselves teams, and so it is expected that similar mechanisms operate at both the team and multi-team levels of analysis. First, action processes like coordination provide a behavioral mechanism that lead to improved performance. By specifying more efficient ways to perform work during action periods, leader teams can be expected to improve effectiveness. In addition, shared mental models allow transition activities to impact work patterns by providing team members with a common understanding of the relevant interaction patterns they will use during action periods. The current investigation will test a model of multi-team leadership that considers both shared mental models and coordination as mediators of the effects of leadership on performance outcomes.

\section{Leader team strategy development and inter-team coordination. By} communicating effective strategies to team members, leader teams are describing how teams ought to work together during action periods. Since research generally shows that teams do not naturally work together across team boundaries, leader team communication of a strategy that specifies productive inter-team interactions should result in effective inter-team coordination during action phases.

Hypothesis 2: Multi-team systems will exhibit better coordination when led by leader teams trained in strategy development than when led by leader teams not trained in strategy development.

Inter-team coordination as a mediator. This improvement in inter-team coordination that results from leader team strategizing is one way leader teams can improve the functioning of both component teams and the overall MTS. Component 
teams of a multi-team system are by definition highly interdependent with one another. Hence, often one team's output serves as another's input. It is expected then that component teams who effectively synchronize their actions will perform better than those who do not. Effective leader teams communicate strategies that specify how team efforts should be combined, and so effective leader team strategizing can be expected to improve team performance by efficiently coordinating inter-team actions.

Hypothesis 3: Inter-team coordination will mediate the positive effects of leader team strategy communication on team performance.

Multi-team performance is not only a function of the performance of component teams, but also depends upon team efforts being combined effectively towards the attainment of the larger MTS goal. Thus, effective leader team strategizing that communicates specific plans for inter-team interaction should improve MTS performance by facilitating better inter-team coordination process.

Hypothesis 4: Inter-team coordination will mediate the positive effects of leader team strategy communication on multi-team performance.

Leader team strategy development and mental models. A strategy outlines how a goal will be attained (Locke et al., 1997). In an MTS, a strategy will specify how the members of each team will operate in order to attain both proximal team goals and distal MTS goals. Information contained in the strategy will include what each team should be doing during action phases. According to Cannon-Bowers et al. (1993) the team interaction model includes information about role interdependencies and interaction patterns. At the MTS level, the team interaction model would then specify how component teams are interdependent and the interaction patterns that should be used. 
Stout et al. (1999) found teams that planned better exhibited more closely shared team mental models. This suggests planning behaviors provide information to team members that serves as a common basis for knowledge organization. Whether arising from team member activities or from leader teams, the presentation of similar information should have the same effect on knowledge structures. Therefore, in their communication of a strategy to MTS component teams, leader teams are influencing the formation of team interaction models in their constituencies. To the extent that the leader strategy (i.e. quality of the plan) is functional to performance, we would expect the mental models fostered to be accurate.

Hypothesis 5a: Multi-team systems will exhibit more accurate mental models when led by leader teams trained in strategy development than when led by leader teams not trained in strategy development.

In addition to conveying their expert understanding of how component teams can best work together, the act of communicating specific information about inter-team activities to component team members will foster an understanding of team interactions that is likely to be more similar across members. Specifically, by clearly communicating a strategy to MTS members, regardless of the accuracy of the strategy, leader teams are conveying information to component team members about how they should interact with other component teams that serves as the basis for a shared knowledge structure. As members are hearing this same set of information about MTS interactions, they are likely to emerge from the transition phase with more closely aligned perceptions of how they ought to interact. Marks et al. (2000) found initial support for this idea as leader 
communication of enhanced information led to not only more accurate but also more closely shared mental models.

Hypothesis 5b: Multi-team systems will exhibit more similar mental models when led by leader teams trained in strategy development than when led by leader teams not trained in strategy development.

Mental models as mediators. Leader teams usually communicate strategies to team members during periods of low intensity task engagement (Kozlowski et al., 1996) also called transition phases (Marks et al., 2001). However, the actual coordination among teams occurs during active task engagement or action phases. This suggests a cognitive mechanism through which the communication of information about the task (i.e. strategy) will lead to improved coordination between teams. Team mental models (TMM's) are likely to transmit this effect. By allowing members to anticipate the actions of other members, TMM's are said to directly improve team coordination (CannonBowers et al., 1993). Generalized to the MTS level, by allowing teams to anticipate the actions of other teams, TMM's should improve the coordination between component teams.

Hypothesis 6: The accuracy (H6a) and similarity (H6b) of MTS mental models will relate positively to inter-team coordination.

While strategies that specify inter-team interactions are likely to improve coordination directly, their impact is also likely to be transmitted through the development of shared mental models. Each action period can be expected to include some combination of predictable and unpredictable events. The content of the strategy conveyed by leader teams will foster effective coordination to the extent that action phase 
events are predictable. However, leader team strategizing can further improve coordination by fostering shared knowledge structures that MTS members can rely upon when events are beyond what has been explicitly planned for during transition periods. Support for this line of thinking was provided by Marks et al. (2000) who found shared mental models were more predictive of team performance in novel as opposed to routine environments.

Hypothesis 7a: The accuracy of MTS interaction models will partially mediate the relationship between leader team strategy communication and inter-team coordination.

Hypothesis $7 b$ : The similarity of MTS interaction models will partially mediate the relationship between leader team strategy communication and inter-team coordination.

\section{Leader Team Coordinating}

The second leader role, facilitating coordination, is needed during action phases. During action phases, leader teams need to engage in behaviors that will enable the smooth synchronization of interdependent actions among teams. These behaviors are somewhat specific to the task environment, but at general level will encompass activities that allow component teams to maintain awareness of the activities of interdependent teams. Training leader teams to coordinate multi-team tasks during action phases should result in higher quality coordinating behavior.

Hypothesis 8: Leader teams trained in coordination will exhibit higher quality coordinating behavior during action phases. 
can be broadly described as any activities that enable subunits to effectively time and sequence interdependent actions. Using the earlier example of an emergency response MTS, in order for the surgical team to effectively care for accident victims it will be necessary for them to be aware of the status of the EMT's activities. Specifically, they will need to know the number of patients, their status, and the estimated time of arrival. As was argued earlier, while these coordinating activities can be initiated from within the teams, the high demands already placed on the teams makes a leader team especially useful in fulfilling this function. To the extent that leader teams can effectively engage in coordinating activities, we would expect that inter-team coordination would be more effective.

Hypothesis 9: Multi-team systems will exhibit better coordination when led by leader teams trained in coordinating behavior than when led by leader teams not trained in coordinating behavior.

Leader team coordinating and performance. Team level research has shown processes like coordination are essential when members are interdependent (Jehn \& Shah, 1997; Stout et al., 1995; Weldon \& Weingart, 1988). Lord and Rowzee (1979) found leader coordinating behavior improved team performance when team members were interdependent. Likewise, in MTS's whose component teams are highly interdependent, smooth synchronization of team actions should enhance both the performance of component teams and the performance of the overall MTS. As with leader team strategy behaviors, the impact of leader team coordinating on performance outcomes should arise from improved inter-team coordination. 
Hypothesis 10: The quality of inter-team coordination will mediate the relationship between leader team coordinating and team performance. Hypothesis 11: The quality of inter-team coordination will mediate the relationship between leader team coordinating and multi-team performance.

\section{Leader Role Interactions}

Until now, leader strategy development and coordinating activities have been considered independently. It is argued that each is important to MTS functioning. In fact, in many settings leader teams may be limited by geographical, time, or other constraints in the way in which they are able to influence component team members. By examining the unique contribution of each to MTS performance, recommendations can be made as to the effectiveness of each type of leader team activity.

On the other hand, in situations where both types of leader team activities are possible it seems likely that MTS effectiveness can be optimized. Strategy development provides members with similar knowledge structures that enable them to more easily adapt to situations and perform effectively in them. Coordinating provides additional resources during action phases and allows teams to seamlessly coordinate interdependent actions. In MTS's whose leader teams are able to first set the stage for effective coordination during transition phases, during action phases, leader coordinating activities are likely to be even more effective than when exhibited in the absence of strategy development. Similarly, strategy development is likely to have an even greater impact on the behavioral functioning of the MTS when leader teams can provide support for coordination during action phases. Thus, it is proposed that the combination of strategy 
development and coordinating activities will lead to a nonlinear increase in MTS process and overall MTS performance.

Hypothesis 12: Leader team strategy and coordination training will multiplicatively predict inter-team coordination such that the effects of the quality of each type of leadership on inter-team coordination will be stronger as the quality of the other type of leadership increases.

Hypothesis 13: Leader team strategy and coordination training will interactively predict multi-team performance such that the effects of the quality of each type of leadership on multi-team performance will be stronger as the quality of the other type of leadership increases.

Figures 6 and 7 (on pages 128 and 129, respectively) present the anticipated pattern of findings from Hypotheses 12 and 13. 


\section{Chapter 4: Method}

\section{Participants}

Three hundred eighty four undergraduate psychology and business students from a large southeastern university were recruited to participate in the study in exchange for research participation or extra credit. A multi-team system task was simulated using a personal computer based F-22 flight simulation. Each MTS was comprised of six participants arranged into three two-person teams. Figure 8 (on page 130) depicts the MTS created for the current study. Two two-member teams flew F-22's while the third two-member team functioned as the leader team.

Sample demographics are reported for the leader and flight teams individually. The overall sample was predominantly female. Leader teams were $31 \%$ male and $69 \%$ female. Flight teams were $28 \%$ male and $72 \%$ female. The sample was also predominantly Hispanic. Leader team members were $62 \%$ Hispanic, $17 \%$ Caucasian, $13 \%$ African American, and 8\% "other" national origin. Flight team members were $70 \%$ Hispanic, 15\% Caucasian, 10\% African American, and 5\% "other" national origin. The average age of leader team and flight team members was 22 and 21 respectively. The prior knowledge of team members was also assessed and $92 \%$ of leader team members indicated that they had either "never met" their partners or knew their partners "hardly at all." For flight team members, $85 \%$ indicated that they had either "never met" any other flight team member or indicated that they knew the other members "hardly at all." Thus the sample was largely comprised of members with no prior information about their teammates. 
Participants were assigned to teams so that (1) leader intelligence scores were the same or higher than flight team members, and (2) flight team member demographic composition was stratified across levels of the independent variables. All potential participants were given the Wonderlic Personnel Test (Wonderlic Inc., 2000), a measure of general intelligence $(\mathrm{g})$, during their participating psychology or business course. Demographic data was also collected during this class session, and the session concluded by allowing participants to sign up for specific experimental sessions.

Participants were assigned to roles within teams at the start of each experimental session. First, the two participants with the highest intelligence test scores were assigned to the leader team; roles within the leader team (i.e. air team leader, ground team leader) were randomly assigned. Next a subset of four flight team members was selected from the remaining pool of participants so that the heterogeneity of gender and ethnic composition were evenly distributed across experimental conditions. Due to the already challenging demands of collecting a sample requiring six participants for each observation, this effort was made to equalize any potential effects of compositional variables without the need for later statistical control.

Gender and ethnicity were selected as the compositional variables to control as these are generally the most visible differences and are likely to be the most formative of member interaction patterns in short term team tasks. With regard to gender, teams were comprised so that each flight team was either mixed gender (i.e. half male, half female) or all members were the same gender (i.e. all female, all male). With regard to ethnicity, flight teams were comprised so that members were either the same (e.g., all Hispanic) or different in ethnic background (e.g., half Hispanic, half Caucasian). Crossing these two 
compositional variables results in four possible gender-ethnicity combinations. An equal number of teams of each composition were assigned to each leader team treatment condition. Logistically, the compositional balance of flight team members was achieved by having a greater number of participants arrive at each session than were actually needed.

Design

A 2 (leader team strategy training vs. control) $\times 2$ (leader team coordination training vs. control) between subjects design was used. Leader strategy behavior, leader coordinating behavior, multi-team interaction models, inter-team coordination, team performance, and multi-team performance were all measured variables.

The sample size of 64 was selected based on an a priori power analysis where the effect size and error variance estimates were obtained from a similar study (Marks et al., $2001)$ and desired power was set at .80. These estimates showed a sample size of 64 (16 per treatment cell) would result in an $82 \%$ chance of detecting effects of the same magnitude at an alpha level of .05 .

\section{Apparatus}

A laboratory simulation was used to model a multi-team system comprised of three interdependent teams. Figure 9 (on page 131) presents a visual depiction of the apparatus used by the study's MTS. Each of the three teams was comprised of two members. Two of the teams flew an F-22 simulation while the third team was a landbased leader team with access to the pilot screens of both F-22's. One of the F-22's was designated as an air team and is responsible for destroying air targets (e.g., enemy planes); the other team was designated as a ground team and was responsible for 
destroying ground targets (e.g., enemy tanks). Within each of the F-22 teams, one member served as the pilot and the other as the weapons specialist. The following sections describe the equipment used to simulate the MTS environment as well as the methods used to record data generated during the simulation.

Audio communication. All six MTS members were linked via microphoneequipped headsets and could speak freely to one another and can hear all communications among team members. Combat sounds, audio prompts, and status reports generated by the simulation program were also heard through the headsets. This also ensured all communications can be recorded for later analyses.

Equipment. The flight simulation was run using a 100 Base TX, TCI/P local area network (LAN) comprised of two Pentium II 300 PCs. The video signal from each PC was then spit to three monitors so that within each flight team the pilot and weapons specialist both had visual access to the simulation, and the leader team also had visual access to the same information. Each flight team member viewed a screen from the cockpit of their respective aircraft, and could not view cockpit information about the other flight team. The leader team was situated in front of two monitors, one with the cockpit screen from each of the two flight teams.

Each of the two flight team pilots flew their respective F-22's using a joystick and throttle. Using the joystick and throttle, the pilots were able to maneuver their aircraft, simulate 360-degree head movement around their aircraft, fire weapons, and activate an airbrake. Each of the two weapons specialists used a standard PS2 keyboard to select weapons, add targets to weapon shoot lists, cycle through weapons, and release chaff and 
flares (defensive "missile decoys"). The keys needed and their functions were labeled using colored tabs.

The audio communications from all six MTS team members, the simulation sounds, and the visual cockpit screen were routed to two VCR's (one for each team). This allowed recording of communications and simulation information for later analyses. In addition, two files from the simulation's Air Combat Maneuvers Instrumentation (ACMI) program were recorded for each MTS (one file for each team). These files provided digital encoding of flight information that could be viewed after participants completed the mission.

Task simulation. The battle task assigned to the MTS was constructed using a low fidelity PC based flight simulator called F22 Total Air War (Digital Image Design Limited, 1998). Four parallel battle mission tasks were constructed for the MTS's to perform; three practice missions and a fourth experimental mission after which performance was assessed. Each mission was constructed to exhibit similar complexity by placing the exact same number, type, and presentation of targets (see Table 2 on page 103) in each mission. In addition, MTS members had the same resources (i.e. time and weapons) to complete the missions. The only difference in the four missions was the order in which target installments were encountered by the flight teams. Pilot testing was used to further ensure the parallel nature of the missions. Fifteen MTS's comprised the pilot sample and provided feedback useful in further editing the missions to ensure they were of similar difficulty level, and also to ensure they were appropriately difficult to the sample participants. 
For each mission task, MTS's were instructed to eliminate enemy occupation of a battlefield. This required the destruction of three planes (SU-27's), four helicopters (M124's), three missile launchers (SAM's), and six tanks (T-120's). The air team was equipped with six long-range missiles (AIM 120C's), six close range missiles (AIM $9 \mathrm{x}$ 's), and 1,760 rounds of a cannon. The ground team was equipped with six radar guided HARM missiles (AGM 88's), six MAVERICK missiles (AGM 65's), and 1760 rounds of cannon.

Though the two flight teams had the same number of weapons, the ground team had a greater number of targets to destroy. Since ground team targets are not mobile and therefore cannot evade attack, this was done to produce tasks of comparable difficulty across the two flight teams. Essentially, if the ground team fires the weapon appropriately, the target will be destroyed with near $100 \%$ accuracy. The air team is destroying enemy air targets that are mobile and therefore can evade attack by moving away from incoming missiles and using defensive devices (i.e. chaff and flares). This will necessitate a larger ratio of weapons to targets for the air team to make their task of similar difficulty to the ground team.

In addition to enemies, flight teams also encountered neutral aircraft and ground units in each of the four missions. This ensured the popular gaming strategy of "shooting at everything" would not lead to improved performance. Instead, the task environment required MTS members to distinguish enemy and neutral units and destroy their designated targets only. Destruction of neutral forces resulted in a reduction in the performance score for that team, and made MTS goals more difficult to obtain by decreasing the resources (i.e. weapons) available for destroying enemy targets. 
Prior to their arrival at an experimental session, participants completed a background measure and an intelligence test during class. Participants then signed up for experimental sessions in groups of ten. Each experimental session lasted approximately five hours and commenced in three general phases: introduction, training, and task engagement. The introduction phase lasted approximately forty-five minutes while the training and task engagement phases each lasted approximately two hours. Appendix A (on page 142) contains the experimental procedure outline that was followed during each session.

Phase 1: Introduction. Upon arriving for the session, participants were read a brief introduction to the study and completed an informed consent form. Next a series of background measures were collected. Team assignments were made by first selecting the two members with the highest intelligence test scores for the leader team, and then the two members with the highest psychomotor ability scores to the pilot roles. Other team members were selected from the pool of participants so that the gender and ethnic composition of the teams would be evenly stratified within treatment conditions. Once all participants were assigned to their component teams, participants were seated in chairs labeled with their position assignments and were given a general introduction to the study and the simulation.

Phase 2: Flight team training. The four flight team members received task training on the simulation and then flew two training missions. During the training missions the leader team was receiving training on their roles and were not be present in the simulation room. 
Flight team training began by instructing each member of his/her duties in operating the simulation. This training was based on a task analysis and was designed to teach the task competencies relevant to each position; this training lasted approximately thirty minutes. During this training each two member flight team member was seated at his/her station on the simulation and was guided through a series of three modules by an experimenter. The training modules were titled: basic maneuvering, navigating a flight route, and basic air-to-air/ground. At the conclusion of each module the experimenter conducted a competency check by asking participants to perform the duties taught in the training. For example, after participants were taught how to maneuver the aircraft and what to do when the plane is stalling, the experimenter drove the plane into a stall and handed the joystick to the pilot with the instruction to recover the plane to its normal operation. The training scripts and task competency checks for the air team are presented in Appendix B on page 148; the training scripts and task competency checks for the ground team are presented in Appendix C, on page 153.

Once participants were trained on the basic duties of their task, they flew two practice missions. In the first mission they were actively coached by experimenters on task training points. In the second mission they were not coached, but were given a chance to practice their duties without the added complexity of the leader team.

In accordance with the Marks et al. (2001) recurring phase model, team tasks were structured so that they emulate the naturally occurring transition and action phases present in actual team settings. Before each mission participants were given time to review information and plan for their mission; this served as a transition period. The 
mission flight represented the MTS action period. Measures were taken immediately following each phase of the team task.

The order of events was as follows. After task training, members were given materials about the first practice mission and time to discuss them. At the start of each transition period, members (or the leader team when present) were given a mission briefing and a map of the mission location for each team. Appendices D through $G$, on pages 158 to 167 , contain the briefings for each of the four missions. Appendices $\mathrm{H}$ through $\mathrm{K}$, on pages 170 to 173 , contain the maps for each of the missions.

Once participants had received these materials, the discussion took place while all team members were seated around a round table. Discussions were video recorded for later coding and analyses. Once participants finished discussing the mission, they filled out measures and then proceeded to the simulation room to perform the mission task. Upon expiration of the twenty minutes allotted to each mission, participants then filled out additional measures before planning for the next practice mission. The procedures for the second practice mission were the same as in the first one. During the first practice mission the experimenter who trained the team provided hands on coaching. The second practice mission provided participants an opportunity to practice performing their duties without experimenter task coaching or leader team intervention.

Phase 2: Leader team training. As the flight teams were being task trained and were flying their two practice missions, the two member leader team received their training. Appendix L on page 174 presents an outline of the leader team training procedures. First, the leader team went through the task training of the ground team (basic maneuvering, navigating a flight route, and basic air-to-ground). In addition, they 
completed the basic air-to-air module from the air team's training so that they would have received the same training as their team members.

At this point the leader training manipulations were introduced. Each leader team received a combination of leadership training depending on the treatment condition. The content of this training will be outlined in the descriptions of the manipulations that follow. First, leader teams received either the experimental or control version of the strategy training. The strategy training manipulation check was completed next. Leader teams then received either the experimental or control version of the coordination training, which was followed by the completion of the coordination manipulation check. After completing this training, the leader team was given a short break while the flight teams were finishing their training missions. Once the flight teams finished their training segment, the task engagement phase began.

Phase 3: Task engagement. In this phase the actual performance episodes commenced involving all three teams performing two mission tasks. First, leader teams were given ten minutes to plan for the mission while the flight teams were on a break. Next the leader team had ten minutes to meet with the flight teams before the mission to discuss how the mission would proceed. Both the leader and full MTS planning sessions were video recorded for later analysis. This latter planning period represented the MTS transition phase. Following the two planning periods, all members filled out a series of measures and then proceeded to the simulation room to complete the mission. After the twenty minutes allotted for the mission had elapsed, MTS members filled out additional measures. 
The second mission proceeded in the same manner. First the leader team had ten minutes to plan alone, and then were joined by the flight teams to continue planning. Measures were collected at the conclusion of this planning period. Finally, all three teams flew the fourth and final mission task, filled out measures, and were debriefed.

\section{Manipulations}

Leader team strategy training. Based on Marks et al.'s (2001) team process taxonomy, effective leader team strategizing includes the effective communication of a plan that specifies a) the order and timing of team actions and b) how teams should execute their actions. The manipulation training was developed to teach leader teams to develop and communicate a strategy that includes these two core elements.

The strategy training consisted of a PowerPoint presentation, videotaped MTS planning session, and a practice planning session. To maximize transfer, this training and the practice session that was included in it, occurred in the strategy room utilized during the experimental performance mission. An outline of the training for the experimental group is presented in Appendix M on page 175, and for the control group in Appendix N on page 176. The training of the experimental teams will be described and then differences in the control training will be presented.

Experimental teams were first told they would receive training on how to plan for a mission. An experimenter then talked through a PowerPoint presentation (see Appendix O on page 177) that first introduced the elements of an effective strategy, and next instructed leader teams as to how it should be developed. This was accomplished by informing leader teams of four basic situations they could anticipate in the coming missions. For each situation, the leader team was taught the appropriate order and timing 
of team actions and how each team should execute those actions. For example, one of the situations involved an enemy SU-27 located near enemy tanks. In this situation the air team would need to destroy the enemy SU-27 before the ground team even approached the tanks. The ground team would then need to slow down and lower their altitude as they waited for the air team to destroy the enemy plane. Here the situation required the efforts of both teams, and orchestrating the appropriate timing of each team's actions was critical to the MTS's success.

Finally, leader teams were given the materials for the second practice mission completed by their flight teams (see Appendices E \& I, on pages 161 and 171 respectively). They were given ten minutes to develop a plan for this mission and then will report their plan to the experimenter as though he/she were a flight team member. The experimenter then compared the strategy presented by the leader team to an expert strategy (Appendix P on page 179) and provided feedback to the leader team on the effectiveness of the plan using the key presented in Appendix Q (on page 180).

Just as in the experimental teams, in control teams an experimenter began by telling teams they would receive training on how to plan for a mission. Control teams were taught generally that they need to develop a strategy for the missions, and were introduced to the types of information available for planning (e.g., mission briefing), but were not taught specifically how to plan for multi-team interaction (e.g. correct sequence of team actions). The control teams were also given time to practice planning and report back to the experimenter, however the experimenter did not provide feedback on the content of the plan. 
Leader team coordination facilitation training. The coordination training was designed to teach leader teams to directly facilitate coordination during multi-team action phases. Leader teams were taught to monitor and communicate information about interteam activities.

This training consisted of an explanation of a pre-recorded video of an MTS flying a mission and coaching during the practice mission. An outline of the training for the experimental group is presented in Appendix R on page 181. The training outline for the control group is presented in Appendix S on page 184. The training of the experimental teams will be described first, and then differences in the control training will be discussed.

Experimental teams were told the next training would be designed to teach them how and when to assist teams in working together during the mission. In order to effectively coordinate teams must be aware of the activities of the other team and so leader teams were trained to monitor and communicate information that facilitates coordination of interdependent actions. After this short general introduction, an experimenter turned on two videotapes that played on two televisions located side by side. These monitors were labeled with the team names, and looked identical to the leader team stations in the simulation room. The videos were of an MTS (eagle and wolf team) flying a mission. During the video there were instances where the leader team (on the video) was effectively coordinating the two teams, and the experimenter followed a script that outlined each of those instances to the trainees. For example, when air and ground team targets are located together, the leader team was taught to inform each team of the other team's progress. During the final sequence on the tapes, the experimenter asked the 
trainees what information needed to be communicated and were provided feedback on their coaching. The feedback instructions to the experimenter are presented in Appendix T on page 187. The final component of this training was administered during the third [practice] mission, and consisted of an experimenter reminding the leader trainees of the content of the prior training and coaching them on these behaviors.

Control teams were given the same training introduction, and were also shown a video of a pre-recorded MTS mission flight. This video differed only in that the leader team did not communicate coordination information. The task related coaching of the leaders was identical. The experimenter also pointed out task relevant content in the mission, but did not reference the leader's coordination facilitation role. Trainees were also asked what information to communicate at the end of the sequence and were given feedback on the task relevant accuracy of their coaching. During the third mission, they were provided with instruction and feedback on task related leadership actions.

\section{Measures}

Covariates. There are a number of variables that could have impacted performance in the current environment that were not directly under investigation. A few of the most probable variables were measured and correlations with key study variables were examined prior to proceeding with the main analyses.

Psychomotor ability reflects an individual's hand-eye coordination. Since the current task involves monitoring information on a simulation screen and reacting with hand movements either using a joystick or keyboard, individual differences in psychomotor ability may impact performance indicators. During the first phase of the experiment participants took a psychomotor test designed to assess their capability to 
track objects in a visual field while manipulating electronic controls (i.e., joystick and throttle). The test is called, "Pop the Balloons." It was developed by USAF researchers at Brooks Laboratory, San Antonio TX, and validated in a similar laboratory setting by Cobb (2000). The test requires participants to watch a set of red balloons floating on the screen. One at a time, each balloon turns red for a few seconds and participants must line up a cursor with the balloon and press the joystick trigger. The test requires the same hand eye coordination skills as the simulation task.

Spatial ability describes individual differences in accurately perceiving information in three-dimensional space based on two-dimensional representations. The current simulation presented information about flight activity on a computer monitor in two dimensional space, the successful execution of tasks such as reading the radar and maneuvering the plane were in part determined by participant spatial ability levels. An eight item measure was administered during the first phase of the experiment that required participants to determine the three dimensional representation of plane based on a two dimensional picture (see Appendix $U$ on page 188).

With regard to the leaders, the individual difference most likely to impact leader effectiveness was intelligence. This variable was somewhat controlled by design (assignment to leader role so that intelligence was maximized) but nonetheless, variability between teams was still present and so leader intelligence scores were also examined as a potential covariate. The Wonderlic Personnel Test (WPT; Wonderlic Inc., 2000) was used for this purpose.

Manipulation checks. The effectiveness of the leader team training manipulations were assessed by determining the accuracy of leader team task, strategy, and coordination 
facilitation knowledge. Short questionnaires were developed for these purposes and will be described below.

First a leader task knowledge measure was administered that consisted of ten questions that asked the responder to look at diagrams of a screen capture picture and describe task relevant aspects of the diagrams (see Appendix V on page 191). For example, questions ask the current speed, altitude, and target selection. The goal of this measure was to ensure that all teams obtained the same level of task related simulation knowledge, regardless of experimental condition. This questionnaire was administered immediately following the conclusion of all training segments. Next leader team members completed measures of the strategy and coordination manipulation checks.

The leader team strategy manipulation was designed to train the leader team to communicate an effective mission strategy based on the information provided before the mission. The final part of the strategy training provided leader teams with the planning materials for the Botswana Battle. Once the leader team had finished their practice planning session, a four-item questionnaire (see Appendix W on page 193) was administered to assess the accuracy of the plan developed.

The leader team coordination facilitation manipulation was designed to train the leader team on two skills critical to helping the teams coordinate during the mission: monitoring and communicating information about interdependent actions. Leader teams who received this training should know not only how to monitor and communicate information, but also when to engage in these behaviors to assist the flight teams. All teams (control and experimental) should be knowledgeable about how to monitor flight team information. Thus an eight-item measure of coordination facilitation knowledge 
(see Appendix X on page 195) was developed that assessed the leader team's knowledge of both how to monitor information and when to monitor information (four items each). Means on the monitoring scale were not expected to differ across groups since the manipulation was not designed to represent a difference in skill in the leader team. Rather, the training manipulation was designed to produce differences in the leader team's knowledge of when to effectively facilitate coordination among the flight teams, and so the means of experimental and control leader teams should differ significantly on the coordination component of the measure.

Leader team strategy communication. Leader strategy communication was assessed using both a seven-item subordinate report measure (see Appendix Y on page 197) and SME ratings of actual leader team behavior. The subordinate report measure was designed to assess the degree to which leader teams communicated a clear understanding of the mission strategy to team members. Specifically, the team members should understand how to work with the other team during the mission. A sample item is, "The leader team clearly informed us of our mission strategy." Response anchors range from 1 (strongly disagree) to 5 (strongly agree). In addition, the leader team's communication of their plans to MTS team members were videotaped and coded by SME's using BARS scales (see Appendix Z on page 198).

Leader team coordinating behavior. Leader team coordinating behavior was also assessed using two measures. First, a six-item subordinate report scale was used that assessed the quality of leader team coordinating activities (see Appendix AA on page 199). Leader team coordinating behavior includes the monitoring and communication of information to teams that relates to interdependent actions. Specifically, effective leader 
team coordinating behavior occurs when leader teams communicate target location and status information to team members throughout the mission. A sample item from the scale is, "The leader team frequently informed us of the other team's location." Response anchors range from 1 (strongly disagree) to 5 (strongly agree.) In addition, leader team communication during the mission task was evaluated by SME's. BARS ratings (see Appendix BB on page 200) were used to quantify the quality of the leader team coordinating behaviors.

Multi-team interaction models. At a general level, mental models represent organized knowledge. Research using the mental models construct must first determine the knowledge content, and then formulate ideas about meaningful structuring of that knowledge (Klimoski \& Mohammed, 1994). Once the domain of cognitions is identified, measurement should then be aimed to capture not only the content, but also the structure that is to be uncovered.

According to Cannon-Bowers et al.'s (1993) taxonomy of mental models, team interaction models include information about interaction patterns that should be used among team members. Extended to the MTS level of analysis, MTS interaction models include information about how teams should interact. The current investigation invokes the mental model construct to explain one mechanism through which leader behavior impacts MTS process (i.e. inter-team coordination). It was proposed earlier that leader teams impact MTS interaction models, and in doing so, improve inter-team coordination. Conceptually then, the relevant content of MTS mental models is that which describes how teams should interact with each other. The experimental tasks were designed so that certain sequences of team actions would be maximally effective. Thus, with regard to 
structure or knowledge organization, it is important to capture how members arrange the ordering of team actions in interdependent contexts.

Cooke, Salas, Cannon-Bowers, and Stout (2000) identified three important features of mental model measurement: knowledge elicitation method, team metric, and aggregation method. The current measurement technique will be discussed in relation to these three qualities.

The goal of the current measurement is to uncover how MTS members view the appropriate interaction between teams. A measure was developed that asks participants to consider the interaction that would commence between the two teams during an interdependent situation (see Appendix CC on page 201). Participants first read the situation, then read a list of possible team actions, and finally participants rank ordered the team actions as they should be done. In this manner, the individual's beliefs about inter-team interactions were captured in their rankings.

The situation used in the measure was chosen by identifying situations that would be encountered during the multi-team tasks that would require the teams to work together in different ways, and then choosing one that would require sequenced interaction. The set of actions to be ranked was determined by asking three subject matter experts to describe their understanding of how the two teams should interact in each of these situations. Their responses were then used to generate a list of mutually exclusive and exhaustive actions that could be used by the teams in handling the situation.

Two team metrics were used to quantify the information yielded by the mental model measure. First, a similarity index was computed using the spearman rank order correlation. All six participants' rankings of each of the nine actions were correlated and 
the resulting correlation was used as the similarity index. Individual observations were excluded if more than one action was left blank, or if more than one tie occurred. MTS observations were not calculated unless at least 5 of the 6 members provided complete data.

Next an accuracy metric was computed for each individual participant using a specialized scoring system. The same SME's that developed the actions were used to develop the scoring system. Each SME independently ranked the actions and then their models were compared. There were several commonalities and also notable differences in expert models. Where there were commonalities, decision rules were constructed. For example, all experts ranked item 9 (eagle targets \& destroys the SU-27) lower than item 7 (work targets \& destroys the first tank). This pattern indicates that all experts agreed that the air combat team had to destroy the plane before the ground combat team should destroy the tank, though the absolute ranking given to the actions was not agreed upon. Therefore, one criteria was whether or not item 9 received a lower score than item 7 . In all, four contingencies, or accurate sequences, were developed based on expert models. Experts then developed a set of decision rules to classify mental model accuracy on a scale of 0 (completely inaccurate) to 4 (completely accurate). The detailed scoring system is presented in Appendix DD (on page 202). One SME then coded all 384 measures. MTS mental model accuracy was computed by averaging the six MTS members' scores.

Inter-team coordination. Coordination was assessed using two methods. First, BARS ratings were made by SME's. Second, an event-based measure was used. BARS ratings have been used to measure coordination within teams in a number of similar 
studies (e.g., Marks et al., 2000; Mathieu et al., 2000). The BARS for this study were developed by compiling expert depictions of the range of possible coordination behavior that could be exhibited between flight teams. During each of the missions two SME's observed the actions of and listened to the communications that took place between the two flight teams and compared them to the BARS scales. SME's then rate the MTS on how effectively they coordinated during the mission by choosing the anchor that best described the behavior that was exhibited during the mission. The BARS anchors are presented in Appendix EE (on page 203). The scale ranged from 1 (hardly any skill) to 5 (complete skill.) The consistency of the ratings made by the two SME's we assessed and the ratings were averaged to form a composite rating of inter-team coordination. This composite was then used in subsequent analyses.

One limitation of BARS ratings is that they are only able to capture overt or explicit coordination that is directly observable by an SME through communication. The literature on coordination has identified two types of coordination: explicit and implicit (Van de Ven, Delbecq, \& Koenig, 1976). It is unlikely that implicit coordination would be captured by these ratings. Entin and Serfaty (1999) found teams with more closely shared mental models relied more on implicit than explicit coordination strategies, and so the omission of these behaviors would represent a significant threat to the validity of the current study. To supplement the BARS ratings, a second measure of coordination, designed to capture implicit coordination, was also used.

The second measurement method involved identifying acts that require inter-team coordination and assessing the quality of coordination that was used during the completion of these acts. The current simulation tasks required the flight teams to time 
and sequence their actions in a certain way in order to destroy all enemy targets at a given base without being destroyed. Therefore, one way to capture the coordination that commences (either explicitly or implicitly), is to record and evaluate the sequencing of actions in interdependent settings. Each mission task was designed so that teams would be interdependent as they approach each waypoint. Based on the arrangement of targets at the waypoint, there was a best way to coordinate the actions of the two teams with regard to which team approached first and which targets were fired at first. Thus, how flight teams actually timed their arrival and ordered the destruction of targets is an indicator of how smoothly they coordinated interdependent actions. During the experimental sessions, one of two SME's completed an event based coordination measure by watching the actions of each team at the waypoints. Appendix FF (on page 204) presents the key for this measure. Resulting Inter-Team Coordination scores ranged from zero to sixteen.

Performance. During each mission's transition phase, the MTS was provided with two objectives. These were to: (1) ensure the survival of the F-22 strike team and (2) destroy enemy targets near four bases of operation. Accordingly, team performance for each component team was operationalized as the extent to which they achieved the parts of these objective assigned to their team. The performance of the air team consisted of the points earned for staying alive and the points earned for destroying air targets. Similarly, the ground team performance score was comprised of the points allotted for surviving and for destroying ground targets.

In addition to working towards the component team objectives, the air and ground team were ultimately charged with destroying four bases of enemy operation. This 
required the teams to work together so that all targets were destroyed and both F-22's remained undamaged. Therefore, MTS performance was operationalized as the number of bases destroyed and ranged from 0 (no bases destroyed) to 4 (all four bases destroyed). This measure of MTS performance was chosen because it captures the goal attainment of the MTS, as opposed to just summing the component teams' performance scores. The interdependence among component teams is a defining aspect of a Multi-Team System, and so MTS level performance measures need to identify the collective goal and quantify the degree of goal attainment. The current study's MTS were given the ultimate goal of disabling four enemy bases on a battlefield, and so while this requires the actions of all three component teams, the measure is conceptually tied to the collective goal as opposed to component team goals.

This MTS indicator is analogous to measuring the number of lives saved by the emergency response MTS described earlier. While each component team (e.g., fire fighters) has its objectives and could be evaluated based on the effectiveness of their duties (e.g., length of time to extinguish fire), the teams are ultimately linked by their MTS goal of saving lives and so MTS performance assessment should include this information. 
Findings from the current investigation of leader team roles in multi-team systems will be presented in four parts. First, general observations regarding the key variables will be discussed. Next, psychometric properties of the measures and multi-trait multi-method correlations will be discussed. Tests of the manipulation checks will be discussed third, and the chapter will conclude with the presentation of results of the thirteen hypothesis tests.

Descriptives

Table 3 (on page 104) presents descriptive statistics for all key study variables. Examining the ranges for the leader behavior measures shows the subordinate report scales generally produced higher ratings ( $x=4.55$ versus 2.89 for leader strategy; $\mathrm{x}=$ 3.78 versus 3.14 for leader coordinating) with less overall variability ( $s d=.33$ versus 1.21 for leader strategy; $s d=.60$ versus 1.17 for leader coordinating) than was observed for the expert ratings. This pattern is to be expected since subordinates are more novice to the task and to the leader roles than were the SME's, and so their ratings can be viewed as being more lenient than were the SMEs'. The variability pattern is also consistent with what would be expected. Subordinates only viewed their leader team and did not have access to other leader team efforts as a frame of reference. SME's, on the other hand, viewed an extensive number of leader team efforts and were thus better able to distinguish low and high performing leader teams.

With regard to mental model accuracy ratings, as would be expected leader teams scored higher and exhibited less variability than component teams across training conditions. Mental model similarity scores showed a somewhat different pattern. The 
range for leader team similarity (-.30 to 1.00$)$ was larger than for component team similarity $(-.03$ to .80$)$, though the mean level of mental model similarity was also higher for leader teams (.60) than for component teams (.44). Both measures of inter-team coordination exhibited scale means near the center anchor and reasonable scale variability. Finally, mean levels of team performance were generally above the scale midpoint (means $=109.77$ and 105.31 out of 150 possible points) while multi-team performance levels were generally below the scale midpoint (mean $=1.84$ out of five possible points).

Psychometrics

Internal consistency reliabilities and within group agreement coefficients for the two leader behavior scales are reported in Table 4 (on page 105). For both the leader strategy and leader coordinating behavior scales the coefficient alphas were above .70 and so individual responses to each item were averaged per individual. While both of the leader team behavior measures were collected using individual team members' responses, the target construct resides at the multi-team level of analysis. For conceptual consistency, all items were worded with the leader and multi-team system as referents. For example, a sample item from the leader coordinating scale was, "The leader team did a good job of helping us work with the other team."

Empirical justification for aggregating individual scores to the group level was obtained by computing an index of within group agreement using James, Demaree, and Wolf's (1984) $r_{\mathrm{wg}(\mathrm{j})}$. This method of estimating agreement essentially compares average observed variances within-groups on each item to that which would be expected based on a uniform distribution. The resulting coefficients range from 0 to 1 , with higher values 
indicating greater agreement among group members on the target construct. The median $r_{\mathrm{wg}(\mathrm{j})}$ 's for leader strategy behavior and coordinating behavior scales were .98 and .97 respectively. As these values indicate substantial within group agreement, individual scores were averaged for each team and the resulting group level composite was used in all analyses.

Both leader behavior and coordination process were assessed using behaviorally anchored rating scales (BARS). Two raters from a pool of ten subject matter experts (SME's) assessed each multi-team system. For each of the variables, one rater assessed all MTS's and the second rater was randomly selected from the remaining nine SME's to make the second rating. The two ratings were correlated for each variable to provide an index of rater reliability. Inter-rater correlations for leader strategy behavior, leader coordinating behavior, and inter-team coordination were $.78, .77$, and .69 respectively. Ratings were then averaged per MTS's and the resulting composite variables were used in the main analyses.

\section{Covariates}

As elaborated on in Chapter 4, several team member and leader knowledge, skill, and abilities are likely to impact the process and performance levels of the multi-team systems under investigation. In the current study, the average team member spatial ability level and psychomotor ability level and average leader intelligence were examined as potential covariates. While these are individual difference variables, aggregation to the unit of the MTS was first necessary to examine relationships with key study variables that reside at the MTS level. The aggregation was conducted to produce a set of variables 
that would most conceptually match the specific aspect of the individual difference that would be expected to relate to MTS processes and performance.

For spatial ability, each of the six members were required to synchronize their actions based on information viewed on a computer monitor, and so an average was computed using all six team members' spatial ability scores. For psychomotor ability, it is only the pilots and weapons specialists that must execute effective hand and eye coordination, and so only their four scores were used in the composite. With regard to intelligence, it was proposed that these were important qualities of leaders that would be relevant to team processes and performance, and so only the two leader scores were used in forming these composite variables. Table 5 (on page 106) presents correlations of each of these composite variables with the fifteen key study variables.

Overall, none of the composites evidenced statistically significant correlations with either team or multi-team level performance. As would be expected, neither of the individual differences in abilities (psychomotor or spatial) were significantly correlated with any of the leadership variables. Somewhat contrary to expectation, leader team intelligence was also unrelated to the leadership variables. Only one correlation was observed with the mental model variables. The composite of flight team member psychomotor ability was significantly positively correlated with leader team mental model accuracy. The only other significant correlation was observed between psychomotor ability and coordination (expert rating only).

The current design randomly assigned of multi-team systems to treatment conditions, and so variability due to each of these potential covariates should be evenly distributed across the four treatment combinations. Nonetheless, $2 \times 2$ ANOVAs were 
calculated using each of the potential covariates as a dependent variable (three separate factorial ANOVAs were run) to verify that differences based on these variables were not present across treatment conditions. For psychomotor ability and leader team intelligence as dependent variables, there were no significant main or interaction effects based on the manipulation conditions, and so differences were evenly distributed across conditions of the study. For spatial ability, there were no main effects but a significant interaction effect was observed where there were higher mean spatial ability levels in both the control-control and experimental-experimental conditions than were observed in either of the mixed treatment combinations. However, the spatial ability composite did not evidence any significant correlations with any of the fifteen key study variables (see Table 5), and so in order to maximize power, analyses were run without including the spatial ability composite as a covariate. Appendix GG (on pages 208-209) presents analysis of variance and means by conditions for each potential covariate.

\section{Inter-Correlations}

Table 6 (on page 107) presents inter-correlations among all key study variables. As the study employed multiple measures of several of the key study variables, multi-trait multi-method correlations are examined first. Leader strategy behavior and leader coordinating behavior were each assessed using both expert ratings and subordinate report scales. The two measures of leader strategy behavior correlated .28 with each other, and .56 and .45 with different traits measured using the same method. The two measures of leader coordinating behavior correlated .50 with each. Leader strategy measures exhibit substantial method variance, as the monotrait-heteromethod correlation 
is lower than the heterotrait-monomethod correlations. For leader coordinating behavior, the correlations by trait and method are similar.

Inter-team coordination was assessed using a BARS rating and an event based rating. The correlation between the two measures of coordination was .60 while the correlations of the coordination BARS rating with leader BARS ratings (monomethodheterotrait correlations) were .35 (leader strategy behavior) and .70 (leader coordinating behavior). This pattern of relationships supports discrimination between leader strategy and coordination as measured via BARS ratings, but does not support discriminability among the BARS ratings of leader coordinating behavior and inter-team coordination. However, it is also important to recognize the close conceptual proximity of these two constructs. Leader coordinating behavior occurs when leaders actively coach teams to coordinate their actions. Coordination occurs when the teams correctly sequence their actions, an anticipated consequence of leader coordinating behavior.

It is also interesting to note that different measures of the same construct sometimes resulted in different patterns of relations with other key variables. For example, mental model accuracy and leader coordinating behavior are not related when subordinate report measures of leader behavior are used, but are significantly positively related when BARS ratings of leader behavior are used. Interestingly, the same type of finding was evidenced with coordination using the two measures. Both measures of leader strategy exhibit significant positive correlations with BARS ratings of coordination, yet only the subordinate report rating of leader strategy significantly correlates with the event based coordination rating. In sum, there is certainly evidence for method variance in leader behavior and coordination ratings. The inclusion of multiple 
measures somewhat reduces this concern since relationships will be examined using difference assessments of the constructs under investigation.

Mental model and performance variables were not assessed using multiple measures and so these correlations will be discussed in terms of their relations to other key variables. First, it is notable that mental model accuracy and similarity were not correlated for flight teams $(r=.19, \mathrm{~ns})$ but were positively correlated $(r=.34, p \leq .01)$ for leader teams. Thus, flight teams exhibited all possible combinations of similarity and accuracy (e.g., similar inaccurate, dissimilar accurate), while leader teams were more likely to evidence either similar and accurate or dissimilar and inaccurate mental models. These differences are likely due to the manipulation of strategy training. Leader teams who received the training were likely to have shared and accurate models, while those who did not were likely to evolve the other three similarity - accuracy combinations. Despite this limitation, interesting patterns with regard to leader mental models were observed. Examining correlations of leader mental models and coordination shows that while accuracy related positively to both the BARS and event-based ratings of coordination, only similarity related positively to the event-based rating.

Examining correlations among performance variables showed no relationship between the component team (air and ground combat team) performance levels $(r=-.01$, ns), yet both air and ground combat team performance were significantly related to multiteam performance. Significant correlations were also observed between multi-team performance and both leader behavior and inter-team coordination. 
The current design employed two manipulations of leader training: strategy training and coordination training. Immediately following the instruction on the simulation (task training) and the administration of both training combinations, four manipulation check measures were administered. The first two measures assessed task competence. One measure assessed the competence of leaders in monitoring leader information, and the other assessed the competence in monitoring information relevant to the flight teams. It is important that the leader training manipulations only alter the knowledge about leader roles, and not impact the overall task competence. Thus these manipulation checks were included to examine the hypothesis that neither training manipulation impacted task competence. The third measure was a check on the strategy manipulation. Leaders were presented a description of a battle situation and asked to answer four multiple-choice questions that targeted the accuracy of the strategy selected. The fourth measure assessed the coordination facilitation manipulation by asking questions about when it is appropriate to engage in activities to facilitate coordination.

Each manipulation check was examined using a 2 (strategy training) $\mathrm{x} 2$ (coordination training) factorial ANOVA where the average leader team score on the manipulation check scales were used as the dependent variables. In all, four ANOVA's were run. ANOVA results for all manipulation checks are presented in Table 7 (on page 108), and means by training condition for each of the manipulation checks are presented in Table 8 (on page 109).

For the flight team task manipulation check, neither training manipulation produced mean differences in the task competency of the leaders. The same was found 
for the leader task manipulation check. Mean scores were not significantly different based on the training combination. For the strategy manipulation check only the strategy training led to mean differences in strategy knowledge. Examining the means in Table 8, shows the leader teams who received the enhanced strategy training scored more than one point (on a 5 point scale) above the leader teams that received only the control version of the strategy training. For the coordination manipulation check, the opposite was found. Only the coordination training produced mean differences in coordination knowledge, and examining the means in Table 8 reveals leader teams trained in coordination facilitation scored higher than leader teams receiving only the control version of the coordination training.

In sum, the manipulation check results indicate that the training conditions did not result in improved knowledge of the task. Rather, they impacted only the intended type of leader competency. Only the strategy training, and not the coordination training, impacted scores on strategy knowledge. Conversely, only the coordination training and not the strategy training impacted mean scores on the coordination knowledge measure. Thus, each manipulation cleanly impacted its target leadership construct and contamination of the manipulations was not evidenced. Hypothesis Tests

The proposed model involves the impact of two leader training manipulations and the resulting leadership behaviors on a set of multi-team processes and outcomes. Broadly, the hypothesis testing strategy will examine two types of relationships. The first type are direct relationships between leadership and multi-team process and performance. These relationships will be examined using an experimental framework using 2 (strategy 
training) $\times 2$ (coordination training) factorial analysis of variance (ANOVA) and where appropriate, multivariate analysis of variance (MANOVA). Consistent with the dominant paradigm in team research, the input-process-output model, mediated relationships will also be tested that examine process mediators of input - output relationships. These relationships will be tested using a regression approach where leader behaviors, and not the experimental manipulations, will serve as the predictors. This is done based on theoretical grounds that the focal construct of interest in testing mediated relationships is the ability of leader behaviors to impact teamwork and not of the type of training received.

Leader strategy behavior. Hypotheses 1 proposed leader teams trained in strategy development would engage in better strategy behavior during the transition, or planning period, than those not trained in strategy behavior. Since strategy behavior was assessed using two related measures, this hypothesis was tested using a 2 (strategy training) $\times 2$ (coordination training) MANOVA where the dependent variables were the two assessments of leader strategy behavior (expert rating, subordinate report). According to the hypothesis, differences in strategy behavior should result from the strategy condition. Results are presented in Table 9 (on page 110).

Hypothesis 1 was supported. Examining Wilks's lambda supports a main effect for leader strategy training, $\wedge=.59, p \leq .001$. Overall leader strategy behavior was better when leader teams were trained in strategy development. Follow up ANOVA's were used to examine the strategy behavior dependent variables individually and showed the strategy manipulation only produced mean differences in expert-rated strategy behavior, $F(3,60)=42.01, p \leq .001$, and not in subordinate-rated strategy behavior, $F(3,60)=$ 
$2.00, n s$. Means by condition are presented in Table 10 (on page 111). For the subordinate report strategy measure, there is very little overall variability in the means, and the means are all generally high. This is likely an artifact of the leniency of novice ratings that was highlighted earlier in the discussion of the descriptives. Expert ratings of leader strategy showed a clear difference in the mean ratings based on the strategy training condition.

While not predicted, the coordination training condition also resulted in an overall effect on leader strategy behavior, $\wedge=.89, p \leq .05$. Examining each leader strategy measure individually using ANOVA's showed the coordination manipulation resulted in mean differences in subordinate-rated strategy behavior, $F(3,60)=6.89, p<.05$, but not in expert-rated strategy behavior, $F(3,60)=.02, n s$. This is opposite the pattern that was seen with the strategy training manipulation. Though the overall amount of variability in subordinate ratings was low, it is possible that what little variability was present was influence more heavily by differences in observed leader behavior during the practice mission than by leader strategy behavior during the experimental mission. In the practice mission, team members may have formed overall impressions of leader competency that were more influenced by their effective coordinating behaviors resulting from the coordination (and not the strategy) training, and then these impressions could have been more salient when evaluating leader strategy behavior during the experimental mission.

Leader strategy and coordination. Hypothesis 2 went on to predict differences in the actual coordination among component teams during the task engagement, or action phase based on the strategy training. Coordination was assessed using both a BARS rating and an event-based rating of inter-team coordination. Though the target construct 
is the same, the two measurement methods were designed to capture both the coordination evidenced in team member communications and that that is evidenced by the correct sequencing of interdependent actions. A 2 × 2 MANOVA was used to test this hypothesis where the dependent variables were the BARS and event based ratings of coordination. Results of this hypothesis test are presented in Tables 11 on page 112, and the mean coordination scores by condition are plotted in Table 12 on page 113.

Hypothesis 2 was also supported. As predicted, there was a significant main effect for the strategy training condition, $\wedge=.80, p \leq .01$. Overall, the strategy training produced higher expert and event-based ratings of coordination for MTS's whose leader teams were trained in strategy development as compared with MTS's whose leaders were not trained in strategy development. Univariate analyses were conducted next to examine each measure of coordination individually. The strategy training produced significant mean differences in expert BARS ratings of coordination, $F(3,60)=14.77, p \leq .001$; but only marginally significant differences based on the event based rating, $F(3,60)=3.49$, $p=.07$. This may be explained by the fact that BARS ratings were based more on verbal discussion of strategy whereas the event-based rating was based solely on overt behavioral coordination. Hence, leader strategy may have resulted in more verbalization of plans but as would be expected, other factors came into play when predicting the actual behavioral coordination that commenced between the teams.

Leader strategy, coordination, and component team performance. Hypothesis 3 predicted a mediated relationship between leader strategy behavior and performance whereby coordination would transmit the effect of leader strategy behavior on component team performance. This hypothesis was examined using the regression procedure for 
testing mediation set forth by Baron and Kenny (1986). The predictor was leader strategy behavior, as measured by both subordinate reports and expert ratings. Bivariate correlations between predictor and criteria were examined in Table 6, and since neither measure of the predictor exhibited significant correlations with either of the component team's performance (the criteria), the first condition for mediation was not met and further tests were not conducted. Thus Hypothesis 3 was not supported.

Leader strategy, coordination, and multi-team performance. Hypothesis 4 proposed coordination as a mediator of the relationship between leader strategy behavior and multi-team performance. Baron and Kenny's (1996) hierarchical regression procedure was used to test this relationship. The predictor and mediator variables were assessed using two measures each, and so a total of four possible hierarchical regressions could be used to test this effect. First, correlations between leader strategy variables and multi-team performance were examined and only the subordinate reported measure of leader strategy exhibited a significant correlation with multi-team performance (as seen in Table 6 on page 107), and so two hierarchical regressions were conducted to examine both coordination measures (BARS and event based ratings) as mediators of the relationship between leader strategy (subordinate report) and multi-team performance. Results are presented in Table 13 (on page 114).

Mediation is supported when significant relationships are observed between predictor and mediator, between predictor and criteria, but not between predictor and criteria when controlling for the mediator variable. Having found support for the first two conditions based on bivariate correlations, the third condition was examined by entering the predictor in at step one of a hierarchical regression followed by the mediator at step 
two. Examining the coefficients showed a significant relationship between leader strategy (subordinate reported) and performance in step one, $b=.25, p \leq .05$. In step two, coordination (expert rated) significantly predicted performance, $b=.41, p \leq .01$, and the beta weight for leader strategy became non-significant. This finding was replicated in a separate hierarchical regression analysis using event-based coordination as the mediator. Thus both forms of coordination fully mediated the relationship between leader strategy behavior (as rated by subordinates) and multi-team performance. Hypothesis 4 was supported using the subordinate report measure of leader strategy behavior, but not using the expert rating of leader strategy behavior.

Leader strategy and mental models. Hypothesis 5 proposed differences in mean mental model accuracy (H5a) and similarity (H5b) levels based on the leader team strategy training. A $2 \times 2$ factorial ANOVA was used to test this hypothesis. A significant main effect for the strategy condition was predicted. Results are presented in Table 14 (on page 115).

Hypothesis 5a was supported. A significant main effect for strategy training was observed, $F(3,60)=17.96, p \leq .001$. Examining the cell means (see Table 15 on page 115) showed the main effect was in the predicted direction. The mental models of MTS's whose leaders were trained in strategy development were significantly more accurate than those whose leaders were not trained in strategy development.

Hypothesis $5 \mathrm{~b}$ was not supported. Rather than a main effect for strategy training, an interaction between training conditions was observed in predicting mental model similarity. Examining the cell means shows a pattern contrary to the logic of Hypothesis 5b. The most similar mental models were observed in MTS's whose leaders were either 
trained in both strategy and coordination or neither strategy nor coordination. When leader teams received one type of training, their MTS's had more dissimilar mental models. It may be that without any training models were more similar as all participants held a novice view of the task, whereas in the mixed training conditions members held somewhat more accurate but less similar models. The mixed training may have been just enough to cause cognitive structures of some members to progress beyond their novice forms, but not enough to produce consistently accurate and similar models among all team members.

Mental models and coordination. Hypothesis 6 proposed positive relationships between mental model accuracy (6a) and similarity $(6 b)$ and inter-team coordination. These hypotheses were tested by examining bivariate correlations among the two measures of coordination and mental model similarity and accuracy (see Table 6 on page 107). Hypothesis 6 a received partial support, while Hypothesis $6 \mathrm{~b}$ was not supported. With regard to mental model accuracy, a significant positive relationship was observed with SME rated coordination but not with the event-based rating. Neither measure of coordination correlated significantly with mental model similarity.

Leader strategy, mental models, and coordination. Hypothesis 7 proposed the relationship between leader strategy and coordination would be partially mediated by mental model accuracy (7a) and similarity (7b). Baron and Kenny's (1986) hierarchical regression procedure was used to test Hypothesis 7a by first regressing coordination on leader strategy behavior in step one, and next on mental model accuracy in step two. Two separate hierarchical regressions were conducted to examine these relationships using each form of coordination as a dependent variable. The two ratings of leader strategy 
behavior were entered simultaneously in step one of the hierarchical regressions. While these two measures were intended to capture the same construct, the relatively low intercorrelation $(r=.28)$ seems to support their capture of different aspects of leader strategy. Since the larger construct is of interest, the two measures were included as a set in testing Hypothesis 7a and 7b. Regression results for this hypothesis are presented in Table 16 (on page 116).

Regression results support mental model accuracy of mediator of the relationship between leader strategy behavior and expert-rated coordination. In step one, both forms of leader strategy behavior significantly predicted coordination, $b_{\text {subordinate }}=.27, p \leq .05$; $b_{\text {expert }}=.28, p \leq .05$. After entering mental model accuracy in step two, only mental model accuracy significantly predicted coordination, $b=.33, p \leq .01$. The betas for both forms of strategy behavior became non-significant. The analysis was repeated using the event-based coordination measure and failed to support Hypothesis 7a. In step one only subordinate-rated leader strategy behavior significantly predicted coordination, and the beta remained significant when mental model accuracy was entered. In fact, mental model accuracy did not relate significantly to coordination. Thus Hypothesis 7 a received partial support.

A similar procedure was used to test Hypothesis $7 \mathrm{~b}$. The set of leader strategy measures were entered in step one of a hierarchical regression. In step two, mental model similarity was entered. As with the test for Hypothesis 7a, two hierarchical regressions were run using the two measures of coordination as the dependent variables. Results are presented in Table 17 (on page 117). As mental model similarity failed to correlate 
significantly with either the independent or dependent variables, Hypothesis $7 \mathrm{~b}$ was not supported.

Leader coordinating behavior. Hypothesis 8 predicted leader teams trained in coordination facilitation would exhibit higher quality coordinating behaviors during the task engagement phase. A $2 \times 2$ MANOVA was used to examine this hypothesis where the two measures of leader coordinating behavior served as the set of dependent variables. Hypothesis 8 predicted a main effect for the coordination manipulation. Results are presented in Table 18 (on page 118), and means are presented in Table 19 (on page 119). Hypothesis 8 was supported. Wilks's lambda for the coordination training manipulation was significant, $\wedge=.75, p \leq .01$. Individual one-way ANOVAs revealed the coordination manipulation produced significant mean differences in both measures of leader coordinating behavior. In sum, leader teams trained in coordination facilitation exhibited significantly better coordinating behavior as rated by both experts and subordinates.

While not predicted by Hypothesis 8, the strategy training also had a significant main effect on coordinating behavior, $\wedge=.84, p \leq .01$. Follow up ANOVAs on each of the coordinating behavior measures shows the strategy manipulation only produced significant mean differences in the expert-rated form of leader coordinating behavior. Hence leader teams trained in strategy development were viewed by SME's but not by subordinates as exhibiting better coordination facilitation. This may be due to the priming that occurred in SME's as a result of also being trained to rate the strategy dimension. As results with the strategy ratings suggested earlier, subordinate ratings may have been more influenced by behavioral coordination during task engagement and thus their 
ratings of coordination behavior were based solely on coordination behavior (as is desirable).

Leader coordinating behavior and inter-team coordination. Hypothesis 9 predicted multi-team systems whose leader teams were trained in coordination facilitation would coordinate better than multi-team systems whose leader teams were not trained in coordination facilitation. Results from the same $2 \times 2$ MANOVA used to test Hypothesis 2 (presented in Tables 11-12 on pages 112 and 113 respectively) were again used to test Hypothesis 9, where the two coordination indicators were used as the dependent variables. Though Wilks's lambda for the coordination manipulation was not significant, examining the measures of coordination individually showed MTS's whose leader teams were trained in coordination facilitation exhibited better inter-team coordination (event based) than did MTS's whose leader teams were not trained in coordination facilitation. However, this finding did not hold for the expert rating of inter-team coordination. In all, Hypothesis 9 received only partial support.

Leader coordinating, inter-team coordination, and component team performance. Hypothesis 10 predicted the relationship between leader team coordinating behavior and team level (i.e. component team) performance would be mediated by interteam coordination. Baron and Kenny's (1986) hierarchical regression procedure was used to test for this mediated relationship. In a two step hierarchical regression, coordination was regressed on leader coordinating behavior in step one. In step two, coordination was regressed on both leader coordinating behavior and inter-team coordination. As with leader strategy development, leader coordinating behavior was assessed using both a subordinate report measure and an expert rating. The two measures correlated .50 , and 
were thus used as a set in representing leader coordinating behavior. Inter-team coordination was also measured using two instruments. The two instruments correlated .60 and so they too were entered as a set. Regression results are presented in Table 20 (on page 120).

The dependent variable, team performance, can be represented by both the air and ground combat team performance levels, and so two separate hierarchical regressions could have been used to examine this relationship. However, the first condition required for mediation is a significant relationship between the independent and dependent variables. Examining the correlations between leader coordinating behavior and air and ground combat team performance indicated that only the air teams' performance level was related to leader coordinating behavior. Thus one hierarchical regression was run. In step one, the subordinate report measure of leader coordinating behavior significantly predicted air combat team performance, $b=.39, p \leq .01$; the expert rating of leader coordinating behavior did not, $b=.03$, ns. In step two when coordination was entered, leader coordinating behavior (subordinate report) remained significant, $b=.39, p \leq .01$. The event based coordination measure, $b=.47, p \leq .01$, but not the expert rated coordination measure, $b=-.13$, ns, also significantly predicted air combat team performance. In sum, Hypothesis 10 was not supported. Interestingly, both leader coordinating behavior and coordination uniquely contributed to air combat team performance, while neither contributed to ground combat team performance. Leader coordinating, inter-team coordination, and multi-team performance. Following up on the same logic of Hypothesis 10, Hypothesis 11 predicted inter-team coordination would mediate the effect of leader coordinating behavior on multi-team 
level performance. The same procedure as was used to examine Hypothesis 10 was repeated where leader coordinating behavior was represented by two measures and interteam coordination was also represented by two measures. Results are also presented in Table 20 (on page 120). In step one, only the subordinate report measure of leader coordinating behavior significantly predicted multi-team level performance, $b=.45, p \leq$ .01 . In step two, leader coordinating behavior remained significant, $b=.42, p \leq .01$, and the event based coordination measure also significantly predicted multi-team performance, $b=.58, p \leq .01$. This pattern is similar to that which was found at the component team level, and does not support Hypothesis 11.

Leader strategy-leader coordinating interactions. Hypotheses 12 and 13 predicted the two leader training manipulations would multiplicatively impact both inter-team coordination (H12) and multi-team performance (H13). Hypothesis 12 was examined using the $2 \times 2$ MANOVA used to test Hypotheses 2 and 9 presented in Tables 11 and 12 where the two measures of inter-team coordination were the dependent variables. Hypothesis 12 was not supported. As was reported earlier with regard to hypotheses 2 and 9 , both the coordination and strategy manipulations evidenced main effects on interteam coordination, but an interaction effect was not found. Hypothesis 13 was examined in the same manner using a $2 \times 2$ ANOVA with multi-team performance as the dependent variable. Results and means are presented in Tables 21 and 22 (on page 121). The interaction was not significant and so Hypothesis 13 was not supported.

A summary of findings from the hypothesis tests is presented in Table 23 (on page 123). In terms of the overall model presented in Figure 1 (on page 123), the leader strategy training manipulation resulted in more effective leader strategy development 
during the transition phase, more accurate mental models at the conclusion of the transition phase, better quality inter-team coordination during the action phase, and higher levels of multi-team performance. Moreover, mental model accuracy fully mediated the relationship between leader strategy development and inter-team coordination, and inter-team coordination fully mediated the effect of leader strategy development on multi-team performance.

In examining leader coordinating or action-phase coaching behavior, findings indicate the leader coordination training manipulation resulted in more effective leader coordinating behavior during the task engagement or action phase, and there was some evidence that it resulted in more effective inter-team coordination. With regard to the mediated relationships, coordination did not mediate the relationship between leader coordination facilitation and performance, but rather contributed uniquely to it. The following chapter will elaborate on these findings and integrate them with the extant literature on team effectiveness, leadership, and multi-team systems theory. 
While the past decades of research on organizational team and leader effectiveness have greatly increased our knowledge of the specific behaviors requisite to leader effectiveness, and the inputs and processes necessary for effective team performance, a pressing problem in modern organizations remains elusive. The problem is twofold. First, how do teams effectively work together both within and between teams as part of larger systems? Second, what roles do leaders serve in synchronizing the efforts of interconnected teams, beyond those of synchronizing interconnected individuals?

The past decade of research on teams has acknowledged the limitations of foundational work in the discipline that viewed teams as closed systems and focused solely on internal dynamics (Ancona, 1990). Ancona and colleagues (Ancona, 1990; Ancona \& Caldwell, 1992) made significant theoretical contributions to the teams literature through their study of external processes. More recently, Mathieu et al. (2001) further advanced theory in this area by introducing multi-team systems theory (MTST) which extends our conceptualization of this issue beyond the external context of single teams and towards the view of MTS's as the focal unit of analysis. The primary contributions of these works, however, have been theoretical. The current study was undertaken to empirically examine I-P-O relationships in multi-team systems. Specifically, leader behavior was manipulated and the resulting MTS mental models, coordination processes and performance levels were examined.

After reviewing the extant literature bearing on these relationships, a model of multi-team effectiveness was developed to explore two mechanisms whereby leader teams improve the process and performance of multi-team systems. The strategy 
development role is enacted during team transition periods, and was proposed to lead to more accurate and closely shared mental models that would serve as the basis for improved between team coordination and subsequent performance. A second leader role, coordination facilitation, is enacted during team action phases and involves hands on coaching during real time performance episodes.

The current investigation modeled a multi-team system comprised of three interdependent teams and experimentally manipulated the two leadership roles: strategy development and coordination facilitation, through training. The impact of leader team training on leader behaviors, team cognitions, team process, and performance outcomes were assessed. Results indicate a number of important findings with regard to the differential effects of the two leader roles in guiding multi-team performance.

\section{The Impact of Leader Strategy Development}

Training in strategy development resulted in leader teams who more effectively developed and communicated plans to component team members (as rated by both team members and SME's). MTS's led by leader teams trained in strategy development evidenced superior inter-team coordination process to those whose leader teams were not trained in strategy development. Further, coordination process was found to mediate the relationship between leader strategy behavior (team member reported) and multi-team system performance.

Prior work has investigated the impact of planning at the team level and found both the amount (Hackman et al., 1976) and quality (Weingart, 1992) of planning impact team effectiveness. Weingart (1992) did not find coordination plans to impact performance, and suggested this was likely due to the ease with which her teams could 
rely on ad hoc planning during the action phase. The current study employed a substantially more complex task than was employed by Weingart (1992); consequently coordination (by the leaders) did improve overall performance, and the effect was mediated by coordination process. Thus the complexity of the task and resources demanded of team members to execute the task appear to be critical determinants of the importance of coordination planning.

Two unexpected results were also observed with regard to leader strategy development. First, in testing Hypothesis 1 (leader strategy training leads to improved leader strategy behavior), a main effect was observed for both the strategy and coordination training conditions. Due to the lack of contamination evidenced by the manipulation check analyses, it was surprising to see differences in mean levels of subordinate reported strategy behavior based on the coordination training condition. Simply stated, teams rated their leaders as better at strategizing if the leaders were trained in either coordination or strategy. Teams worked together during a practice mission before completing the experimental mission where these ratings were taken. Thus it is possible that leader behavior during the practice mission, in the form of more effective coordinating behavior, impacted subordinate ratings of strategy behavior in the following (experimental) mission.

A second unexpected finding was the lack of support for Hypothesis 3. It was proposed that leader strategy development would improve team level performance, and that inter-team coordination would mediate this relationship. Since MTS component teams interact dynamic and interchangeably towards goal attainment (Matheiu et al., 2001), component team outcomes serve as inputs to other component teams. Thus, by 
improving inter-team coordination, leader teams were expected to improve team, in addition to multi-team performance. This was not the case. Leader strategy was positively related to inter-team coordination, and inter-team coordination was positively related to team level performance; however, leader strategy was not significantly related to team level performance.

A probable explanation of this pattern is the difference in the determinants of performance at the team versus multi-team levels. Leader planning was targeted at the multi-team level; specifically leader teams were trained to develop plans for between rather than within team coordination. This is supported by the positive relationship between leader planning and inter-team coordination. It is also understandable that interteam coordination improved team performance by allowing interdependent team actions to complement one another. However, leader strategy behavior is a multi-team level variable while team performance resides at the lower, component team level. Thus many more factors necessarily come into play in determining component team performance. While a mediated relationship was not supported, it seems leader team strategy behaviors do impact component team performance levels - thought they do so indirectly by improving inter-team coordination.

\section{Multi-Team Mental Models}

Team effectiveness research has found planning activities result in more shared team member mental models (Stout et al., 1999); and that the similarity of team member mental models predict communication (Marks et al., 2000), process (Mathieu et al., 2000) and performance (Marks et al., 2000; Mathieu et al., 2000; Webber et al., 2000). The current study extends this work by considering the mental model construct in an even 
more complex and macroscopic organizational unit, and by considering the impact of leader behavior on team member mental models.

With regard to leadership, the current study proposed leader planning activities that take place during transition periods would be formative of both accurate and similar cognitive structures of multi-team interaction patterns. The strategy training manipulation did produce significant differences in mental model accuracy but not in similarity. Leader teams trained in effective strategy behavior led their teams to possess more accurate models of effective inter-team interaction. With regard to similarity, an unanticipated interaction effect was found such that teams where leaders had received either the control-control or experimental-experimental training combinations possessed the most similar models, while teams in the two mixed training cells held the most dissimilar mental models.

A potential explanation for this findings is that without any enhanced training, leaders and team members share similar novice perceptions of how to interact and with fully enhanced training, leaders and team members share similar expert perceptions of how to interact; yet when either the knowledge of strategy or of coordination facilitation is present in isolation, new but not consistent ideas on viable interaction patterns are generated in team member minds so that they are more accurate (in some ways) but are also less similar to one another.

Prior work supports mental models as precursors to effective team coordination. The current study examined mental model similarity and accuracy as predictors of effective multi-team coordination. Results were mixed and not as clear at the MTS level as they have been at the team level. Mental model accuracy was significantly related to 
BARS ratings of inter-team coordination, while mental model similarity was not related to either index of coordination. At the team level, mental model similarity is considered critical to effective coordination since it enables team member to anticipate the actions of their teammates even in the presence of changing environments by relying on their shared understanding of effective interaction patterns (Marks et al., 2000). The current results run counter to this logic and to the findings of earlier work on mental models (Marks et al., 2000; Matheiu et al., 2000; Webber et al., 2000) as it was accuracy and not similarity that related significantly to coordination process in the current study.

Post hoc analyses were used to examine the nature of the mental model similarity - coordination relationship at different conceptual levels of analysis. The lack of findings with mental model similarity raise the issue: Who needs to share information within a multi-team system in order to effectively coordinate? Three alternatives seem plausible. First, it may be that only leaders need to posses similar knowledge structures to be able to effectively guide component team actions during task engagement. Second, perhaps only component team members need to share information to complete interdependent tasks consistently during action phases. And third, as was originally proposed in Chapter 3, perhaps all MTS members must have similar knowledge structures to ensure consistent interaction patterns across situations encountered during action phases. Table 6 (on page 107) reports correlations between mental model similarity at all three levels: leader team, component team, and multi-team system and other key study variables (e.g., coordination, performance).

The original hypothesis (H6b) was targeted at the MTS level but exploring the pattern of correlations shows only leader team mental model similarity was significantly 
related to inter-team coordination. Thus, team members within the MTS did not all need similar knowledge structures to effectively coordinate. Rather, combining the results of this analysis with those testing Hypothesis $6 \mathrm{a}$, leaders need to have similar knowledge structures and team members need to have accurate knowledge structures in order to coordinate effectively. Perhaps effective leader team planning activities result in team members evolving interpretations of how leader plans will be carried out that are role specific and therefore functionally dissimilar.

To further complicate matters, the results differed for each type of coordination for each level of analysis. Event based coordination was predicted by leader team accuracy and leader team similarity, but was not predicted by either component team mental model accuracy or component team mental model similarity. A different pattern was observed for the BARS coordination index. Here flight team mental model accuracy evidenced the strongest relationship with coordination, followed by leader team mental model accuracy; neither component team nor leader team mental model similarity was significantly related to the BARS coordination measure. In sum, the strongest predictor of the more verbally based BARS rating of coordination was flight team member mental model accuracy and the strongest predictor of the more behaviorally based event measure was leader team mental model similarity. The relationship between mental models and coordination is clearly very complex in both the level of analysis that drives the effect, and also the impact of content accuracy versus member similarity.

\section{Leader Coordination Facilitation}

The second role of leader teams in multi-team systems is the direct facilitation of inter-team coordination that occurs during task engagement. Prior conceptual and 
empirical work on team leadership has identified action phase behaviors like monitoring performance and providing feedback (Komaki, 1989; Kozlowski et al., 1996; Morgeson, 1996) as critical to team performance. The current study identified comparable behaviors important in multi-team systems such as monitoring team progress and reporting component team progress to other component teams, that provide another means for leaders to improve the coordination and subsequent performance of multi-team systems. While leader coordination training did improve the leaders' knowledge about how to facilitate coordination (manipulation check) and also resulted in higher quality coordinating behaviors as rated by both SME's and team members (Hypothesis 8), only partial evidence was found linking leader coordination training to inter-team coordination (Hypothesis 9). Further, though leader coordinating behavior was expected to impact performance outcomes through improved inter-team coordination (hypotheses $10 \& 11$ ), results instead indicate that leader behavior and inter-team coordination contributed uniquely to the prediction of performance. Taken together, these findings seem to suggest that leader coordinating behavior enacted during task engagement is distinct from actual coordination and improves performance directly, rather than by improving coordination.

Another unexpected finding was observed with leader coordinating behavior. Both the strategy and coordination training manipulations resulted in higher SME ratings of leader coordinating behavior. Coordination training was designed to impact coordinating behavior, yet the strategy training did not teach and was not expected to improve leader coordinating behavior. In fact, manipulation check results show leader teams who received the strategy training but not the coordination training knew less about how to effectively facilitate inter-team coordination. Further, this pattern only held 
for SME ratings. Subordinate report ratings were only impacted by the coordination training, as was predicted.

Two explanations seem possible. First, if differences in subordinate and SME ratings are due to their differential capture of true score variance in the leader coordinating behavior construct, then this result suggests the differences in leader strategy knowledge created by the leader strategy training manipulation had the side effect of also producing competence in leader coordinating behavior. On the other hand, it is also plausible that rating differences are due to differential capture of error variance. Specifically, since the same SME's who made the coordinating behavior ratings were also trained to make the strategy development ratings, their ratings may have been contaminated by this knowledge. As was discussed in Chapter 5 with regard to psychometrics, it is apparent from the pattern of correlations in Table 6 (on page 107) that substantial source variance was present in both the subordinate and SME ratings.

\section{Leader Role Interactions}

With regard to hypotheses 12 and 13 , it was originally believed that the two types of leadership would multiplicatively improve coordination and performance, yet support was not found for either effect. Instead, with regard to both coordination and performance, it appears strategy development and coordination facilitation have additive effects and operate through distinct mechanisms.

When findings with regard to each of the leader roles are considered jointly the distinction between the two leader roles seems even greater. Results suggest both types of leader behaviors are means for leader teams to facilitate the performance of complex multi-team systems, however, each operates even more differently than was proposed in 
Figure 1 (on page 123). Leader strategy improves mental model accuracy and inter-team coordination, which in turn improves performance. Leader coordinating behavior does not impact team process, but rather directly improves overall system performance.

These findings support the application of Kozlowski et al.'s (1996) conceptual model of team leadership to the MTS level. Kozlowski and colleagues proposed team leaders have two task functions critical to performance: instruction and intervention. The current study found these two functions were important and distinct determinants of the effectiveness of multi-team systems.

\section{Limitations and Future Research Directions}

While the current study makes a substantial contribution to the organizational literature through its explication and test of a preliminary model of multi-team leader effectiveness, results of this study also suggest a number of important limitations and future research directions. Possibly the largest limitation of the current study is the use of short-term teams performing a laboratory simulation task to model a complex multi-team system. While the lab and experimental elements of the study afforded strict control over extraneous variables, it is likely that contextual factors present only in field settings employing ongoing teams set important boundary conditions on the relationships examined in this study. Nonetheless, research on multi-team systems and on mental models is in its infancy, and so research that maximizes internal validity is critical at this stage of the research cycle. Future works of both the laboratory and field variety are needed. Laboratory investigations are needed to elucidate the functional forms of key relationships, and follow up work is needed that examines the nature of relationships in applied business settings. 
A second limitation of the current study was the sample size. Though three hundred sixty four individuals participated in the experiment, the sample size for testing model relationships was only sixty-four. This precluded the use of structural modeling to examine the overall model fit, and to test alternative conceptualizations of relationships. Future work is needed that examines either larger samples of multi-team systems or fewer relationships per study so that more detailed analyses may be done.

The current analysis strategy employed a combination of experimentally driven ANOVAs and observationally based regressions. In choosing the analyses that would be used, there was a tradeoff to be made between using the manipulations solely as the predictors of model relationships versus using the leader behaviors that were largely impacted by but also exhibited MTS level individual differences from the leader manipulations. Though the strong effects of the manipulations on leadership behaviors results in similar findings, the combination of approaches was used to be consistent with the goals and implications of each hypothesis. In general, direct relationships were examined using the manipulations and mediated relationships were examined using the leader behaviors as predictors.

The goal of the study was to explore relationships between leader behavior and team process and performance variables, not to explore the impact of training on process and performance. Training was utilized in this study as a tool to produce variability in leader behavior that could, in turn, be modeled against process and performance. However, it is acknowledged that a strength of the study was the experimental manipulation of leadership, and so to rely solely on correlational results undermines this strength. Thus, the experimental component was retained to examine differences in key 
variables as arising from leader training differences; yet when the aim was to model a mediated relationship, a regression approach was used where the behaviors themselves (and not the manipulations) were used as predictors. This approach was preferred because these measured behaviors are believed to capture additional variability in leader behavior beyond that which is produced by the manipulations; further it is proposed that this additional variance is due to the leadership constructs and is therefore meaningful.

The current study employed a new measure of mental models designed to more effectively capture the underlying structure of sequential inter-team actions than was afforded by prior concept mapping and proximity matrix methodologies. However, due to the already complex nature of the study, the measurement of mental models by multiple methods was not feasible. Future work is needed that examines the use of this type of measure in other types of teams, and that explores the convergence of this type of measure with other measures.

The current measure of mental models operationalized model accuracy and similarity differently than has been done in prior work. The current method of capturing mental model accuracy was designed to improve upon the existing method of comparing ratings to those of experts. The criterion-related validity of this measure of accuracy is supported by positive relationships with both coordination and performance. As for similarity, correlations among team members were used as opposed to agreement (Webber et al., 2000) or proximity indexes (Marks et al., 2000; Mathieu et al., 2000), yet the criterion validity evidence here is less convincing. In fact, overall MTS model similarity only related significantly to mental model accuracy. Leader team similarity was positively correlated with MTS coordination. As was discussed earlier, the levels issue of 
mental model similarity is a critical one for future research on macro organizational forms. In sum, data that affords comparisons of multiple conceptualizations of accuracy and sharedness obtained using multiple methodologies are needed if knowledge of team mental models is to advance.

Several of the current study's findings with regard to mental models are in contrast to those found in prior research, and suggest fruitful avenues for future research. First, the level of analysis in this study was more complex. Prior work has focused on single teams ranging from 2 to 4 members while the current study examined multi-team systems comprised of three 2 member teams. Second, the current study examined team interaction models while prior work has focused on team (Marks et al., 2000; Mathieu et al., 2000; Webber et al., 2000), task (Mathieu et al., 2000), and technology (Stout et al., 1999) models. Future research should explore how different mental model content domains impact team outcomes. Prior work has found the similarity of member models of the team, task and technology (Marks et al., 2000; Mathieu et al., 2000; Stout et al., 1999; Webber et al., 2000) predict success, while the current study found the accuracy of team interaction models predicted process and performance. In addition, future research needs to explore the congruence of mental model-process-outcome relationships at multiple levels. Results of this study suggest they may not be isomorphic. Team level work has generally found mental model similarity as critical to teamwork; though this study found it was component team accuracy and leader team similarity that ultimately mattered.

As was pointed out by Ancona (1996), Mathieu et al. (2001) and others, while we know a great deal about the effective interactions within teams, we know very little about the external dependencies of teams. Though multi-team systems are abundant in 
organizations, and despite the fact that it is the system performance that is the ultimate criteria of teams, relatively little is known about how large systems of teams interact effectively. The current study provides a first look at how leadership, mental models, and coordination process impact performance, but future work is needed that explores these relationships in different types of tasks and in more applied field settings.

\section{Implications and Conclusions}

A primary motivation for this research was to inform a pressing issue in today's team based organizations: What predicts effectiveness in multi-team systems? Several important implications have been supported. First, as the context of an MTS is significantly more complex and demanding of member resources than is working in a single team, these results suggest leader teams can greatly improve the functioning of the system by developing coordination plans during transition phases and by working to facilitate coordination during action phases. While the current sample of leaders was selected so that leaders were at least as intelligent as component team members, they were not necessarily more expert at the task at hand. In fact, the training they received on the simulation task was less extensive than that which component team members received. Despite this fact, leaders were able to effectively improve the performance of their systems by engaging in planning and coordination facilitation behaviors.

Prior research has demonstrated that significant biases tend to develop as a result of team cohesiveness that prevent effective inter-team interaction (Janis, 1991; Sheriff, 1966). However, consistent with prior work on the importance of inter-team processes (Ancona, 1990; 1988; Ancona \& Caldwell, 1992; Denison et al., 1996), the current study found inter-team coordination significantly predicted component team and multi-team 
performance. In the absence of leadership, team members must balance teamwork efforts between maximizing intra- and inter-team processes.

In sum, just as constantly changing environmental contingencies such as markets and competitors require businesses to move past maximizing individual performance and look towards the optimization of larger systems of interconnected teams like multi-team systems, organizational research must move beyond the exploration of isolated within team processes and develop theory and empirical work that guides this transition. Multiteam systems provide a new unit of analysis where similarities and discontinuities between relationships previously examined at the component team level have yet to be explored. The current work developed and tested a preliminary research framework for extending team level leadership, mental model, and process relationships to multi-team systems. Initial evidence suggests highly complex relationships exist and future research is greatly needed that explores these relationships in additional types of teams (e.g., parallel teams), and that explores different precursors (e.g., feedback) to multi-team effectiveness. 
Table 1

Summary of Team Leader Behavioral Taxonomies

Fit with Current

Framework

\begin{tabular}{llcc} 
Source & Team Leader Behaviors & $\begin{array}{c}\text { Foster } \\
\text { Teamwork }\end{array}$ & $\begin{array}{c}\text { Regulate } \\
\text { Teamwork }\end{array}$ \\
\hline $\begin{array}{llc}\text { Bachiochi } \\
\text { (1999) }\end{array}$ & Task Skills (e.g., planning) & $\mathrm{X}$ & \\
& $\begin{array}{l}\text { Interpersonal Skills (e.g., coaching) } \\
\text { Communication Skills (e.g., } \\
\text { communicating information) }\end{array}$ & $\mathrm{X}$ \\
& Liaison Skills (e.g., boundary spanning) & $\mathrm{X}$ & \\
& Setting Direction & $\mathrm{X}$ & \\
Hackman \& & Designing the Group & $\mathrm{X}$ & \\
& Tuning the Context & $\mathrm{X}$ & \\
& Coaching \& Assisting & & $\mathrm{X}$ \\
& Providing Resources & & $\mathrm{X}$ \\
\hline Komaki et al. & Monitors & & $\mathrm{X}$
\end{tabular}
(1989)

Consequences $\quad X$

Kozlowski et Goal setting

al. (1996)

\begin{tabular}{lll} 
& Monitoring & $\mathrm{X}$ \\
& Diagnosis & $\mathrm{X}$ \\
& Feedback & $\mathrm{X}$ \\
& Situation Framing & \\
& Situation Assessment & $\mathrm{X}$ \\
& Task/Team Redefinition & $\mathrm{X}$ \\
\hline Morgeson & Monitoring & $\mathrm{X}$ \\
$(1996)$ & & \\
& Diagnosis & $\mathrm{X}$ \\
& Intervention & $\mathrm{X}$ \\
\hline
\end{tabular}




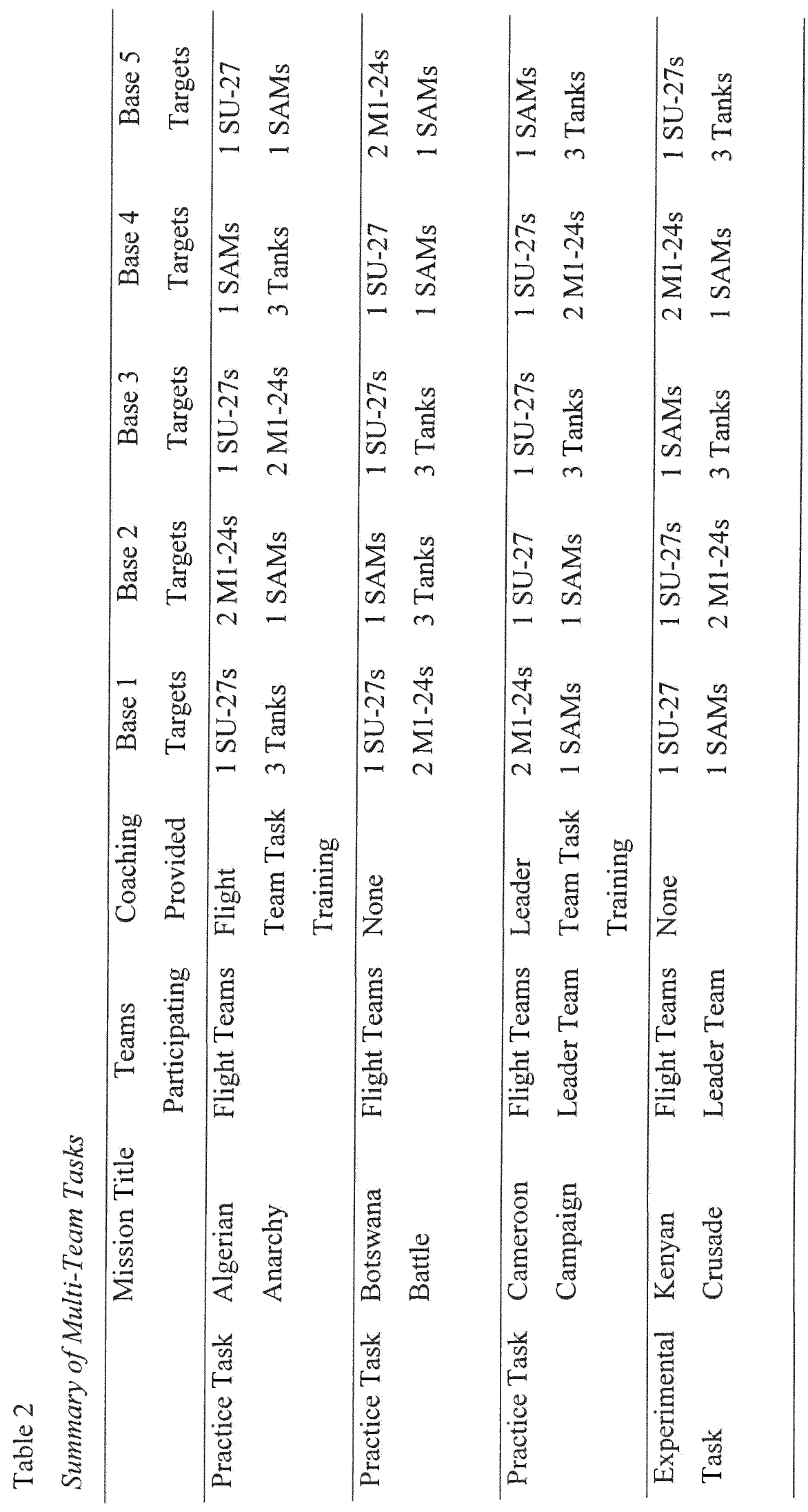




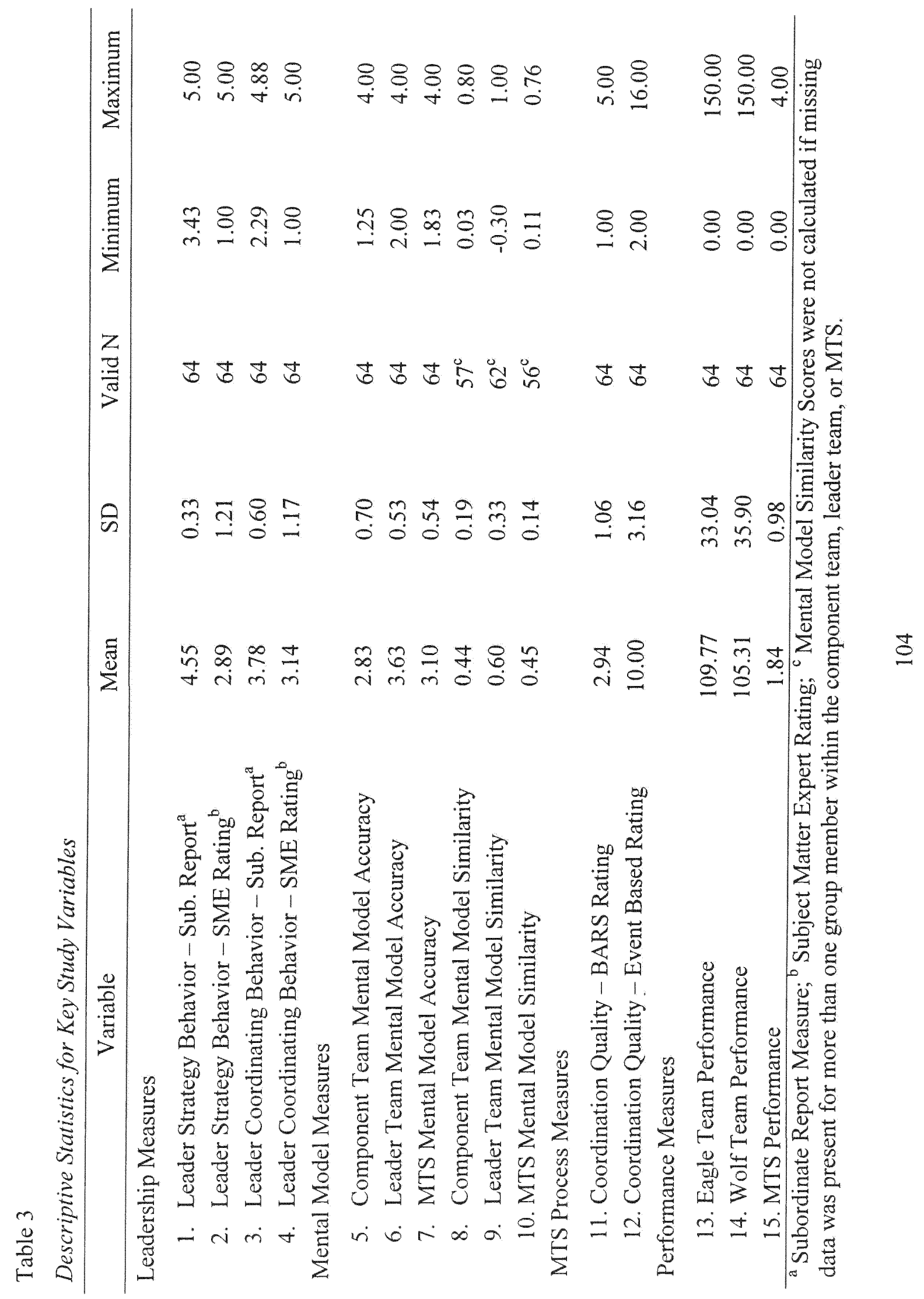


Table 4

Internal Consistency Reliabilities ( $\alpha$ ) and Median Within Group Agreement Coefficients (rwg(j)) for Leader Behavior Scales (Reported at the Individual Level of Analysis)

\begin{tabular}{|c|c|c|c|c|c|c|}
\hline & \multirow[b]{2}{*}{ Variable } & \multirow[b]{2}{*}{$\mathrm{n}$} & \multicolumn{2}{|c|}{$\begin{array}{c}\text { Scale } \\
\text { Reliability }\end{array}$} & \multicolumn{2}{|c|}{$\begin{array}{l}\text { Within Team } \\
\text { Agreement }\end{array}$} \\
\hline & & & $\mathrm{j}^{\mathrm{a}}$ & $\alpha$ & $\mathrm{k}^{\mathrm{b}}$ & $\operatorname{rwg}(j)$ \\
\hline 1. & $\begin{array}{l}\text { Leader strategy behavior (subordinate- } \\
\text { report) }\end{array}$ & 255 & 7 & .80 & 4 & .98 \\
\hline & $\begin{array}{l}\text { Leader coordinating behavior } \\
\text { (subordinate-report) }\end{array}$ & 254 & 6 & .82 & 4 & .97 \\
\hline
\end{tabular}

${ }^{\mathrm{a}} \mathrm{j}=$ number of items; ${ }^{\mathrm{b}} \mathrm{k}=$ number of team members 


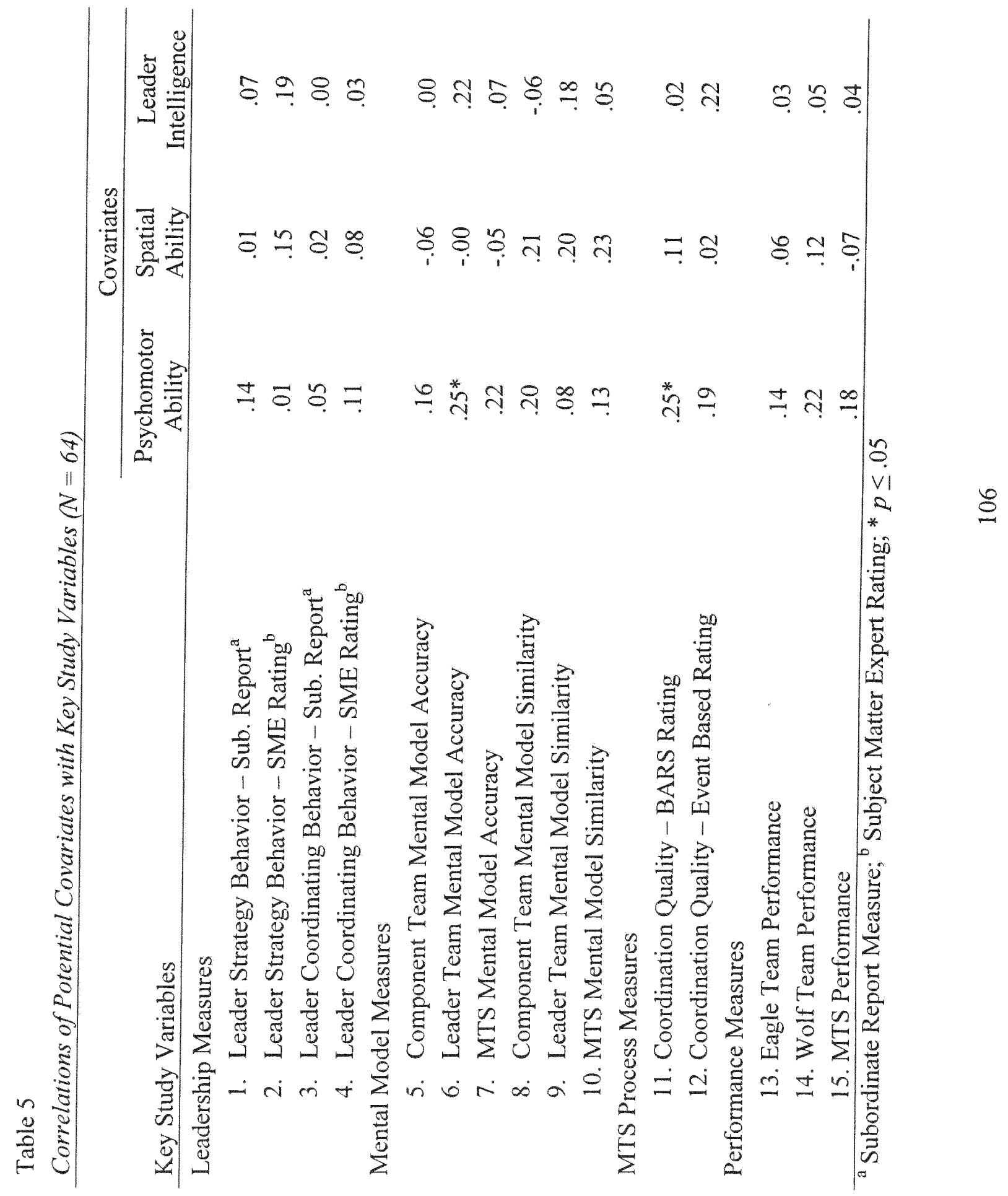




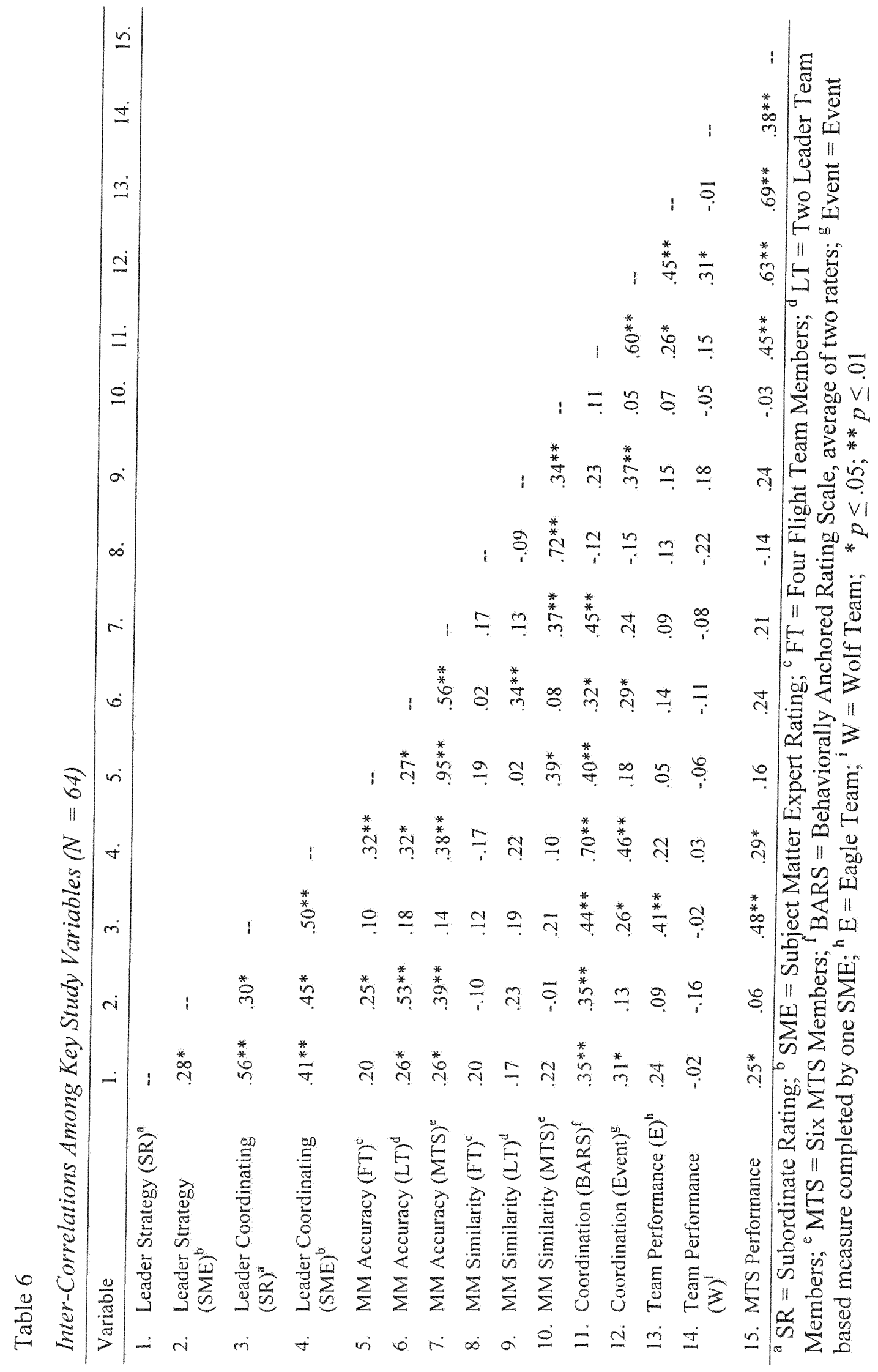


Table 7

Analysis of Variance for Training Manipulation Checks

DV $=$ Task Training Manipulation Check (Leader Knowledge)

\begin{tabular}{lll}
\hline Source & df & F-value \\
Strategy Manipulation (SM) & 1 & 1.67 \\
Coordination Manipulation (CM) & 1 & 0.12 \\
$\mathrm{SM}^{*} \mathrm{CM}$ Interaction & 1 & 0.01 \\
Total & 63 & -- \\
\hline
\end{tabular}

DV $=$ Task Training Manipulation Check (Flight Team Knowledge)

\begin{tabular}{lll}
\hline Source & df & F-value \\
Strategy Manipulation (SM) & 1 & 1.17 \\
Coordination Manipulation (CM) & 1 & 0.34 \\
SM ${ }^{*}$ CM Interaction & 1 & 0.17 \\
Total & 63 & -- \\
\hline DV = Strategy Training Manipulation Check & & \\
\hline Source & df & F-value \\
Strategy Manipulation (SM) & 1 & $83.00^{* *}$ \\
Coordination Manipulation (CM) & 1 & 0.16 \\
SM * CM Interaction & 1 & 0.00 \\
Total & 63 & -- \\
\hline DV = Coordination Training Manipulation Check & & \\
\hline Source & df & F-value \\
Strategy Manipulation (SM) & 1 & 0.70 \\
Coordination Manipulation (CM) & 1 & $8.49^{* *}$ \\
SM * CM Interaction & 1 & 0.34 \\
Total & 63 & -- \\
\hline
\end{tabular}

${ }^{* *} p \leq .01$ 
Table 8

Mean Manipulation Check Scores by Leader Training Condition Task Training Manipulation Check (Leader Knowledge)

\begin{tabular}{|c|c|c|}
\hline \multirow[b]{2}{*}{ Coordination Training } & \multicolumn{2}{|c|}{ Strategy Training } \\
\hline & Control & Experimental \\
\hline Control & $3.44(.73)$ & $3.63(.39)$ \\
\hline Experimental & $3.50(.50)$ & $3 . \dot{6} 6(.40)$ \\
\hline \multicolumn{3}{|c|}{ Task Training Manipulation Check (Flight Team Knowledge) } \\
\hline & \multicolumn{2}{|c|}{ Strategy Training } \\
\hline Coordination Training & Control & Experimental \\
\hline Control & $8.47(.72)$ & $8.59(.80)$ \\
\hline Experimental & $8.50(.87)$ & $8.78(.58)$ \\
\hline \multicolumn{3}{|c|}{ Strategy Training Manipulation Check } \\
\hline & \multicolumn{2}{|c|}{ Strategy Training } \\
\hline Coordination Training & Control & Experimental \\
\hline Control & $2.41(.78)$ & $3.75(.37)$ \\
\hline Experimental & $2.47(.74)$ & $3.81(.31)$ \\
\hline \multicolumn{3}{|c|}{ Coordination Training Manipulation Check } \\
\hline & \multicolumn{2}{|c|}{ Strategy Training } \\
\hline Coordination Training & Control & Experimental \\
\hline Control & $2.35(.81)$ & $2.41(.92)$ \\
\hline Experimental & $2.83(.88)$ & $3.13(.67)$ \\
\hline
\end{tabular}

Standard errors are in parentheses. 
Table 9

Analysis of Variance for Leader Strategy Behavior

\begin{tabular}{|c|c|c|}
\hline & $\begin{array}{l}\text { Wilks's } \\
\text { lambda }\end{array}$ & $\mathrm{F}$ \\
\hline \multicolumn{3}{|l|}{ Multivariate Model $(D F=3,60)$} \\
\hline Strategy Training & .59 & $20.70^{* *}$ \\
\hline Coordination Training & .11 & $3.49 *$ \\
\hline $\mathrm{S} \times \mathrm{C}$ Interaction & .03 & 1.02 \\
\hline \multicolumn{3}{|l|}{ Univariate Models $(D F=3,60)$} \\
\hline \multicolumn{3}{|l|}{$\begin{aligned} \mathrm{DV}= & \text { Leader strategy behavior } \\
& \text { (subordinate report) }\end{aligned}$} \\
\hline Strategy Training & & 2.00 \\
\hline Coordination Training & & $6.89^{*}$ \\
\hline S x C Interaction & & 2.01 \\
\hline \multicolumn{3}{|l|}{$\begin{aligned} \mathrm{DV}= & \text { Leader strategy behavior } \\
& \text { (expert rating) }\end{aligned}$} \\
\hline Strategy Training & & $42.10^{* *}$ \\
\hline Coordination Training & & 0.02 \\
\hline $\mathrm{S} \times \mathrm{C}$ Interaction & & 0.00 \\
\hline
\end{tabular}


Table 10

Mean Leader Strategy Ratings by Leader Training Condition

Leader Strategy Behavior (subordinate report)

\begin{tabular}{ccc}
\hline \multirow{2}{*}{ Coordination Training } & \multicolumn{2}{c}{ Strategy Training } \\
\cline { 2 - 3 } Control & $4.35(.39)$ & Experimental \\
\hline Experimental & $4.66(.31)$ & $4.57(.28)$ \\
\multicolumn{2}{c}{ Leader Strategy Behavior (expert rating) } \\
\hline \multicolumn{2}{c}{ Strategy Training } \\
\hline Coordination Training & Control & Experimental \\
\hline Control & $2.10(.96)$ & $3.66(.95)$ \\
Experimental & $2.15(.98)$ & $3.67(.90)$ \\
\hline
\end{tabular}

Standard errors are in parentheses. 
Table 11

Analysis of Variance for Inter-Team Coordination

Wilks's F

lambda

\begin{tabular}{ccl}
\hline Multivariate Model $(D F=3,60)$ & & \\
Strategy Training & .80 & $7.28^{* *}$ \\
Coordination Training & .93 & 2.21 \\
S x C Interaction & .97 & 1.02 \\
\hline
\end{tabular}

Univariate Models $(D F=3,60)$

$\mathrm{DV}=$ Inter-team coordination

(expert rating)

Strategy Training

$14.77^{* *}$

Coordination Training

S x C Interaction

1.95

$\mathrm{DV}=$ Inter-team coordination

(event-based rating)

Strategy Training

$3.49 \dagger$

Coordination Training

$4.02 *$

$\mathrm{S} \times \mathrm{C}$ Interaction

1.10

$\dagger p \leq .10 ;{ }^{*} p \leq .05 ;{ }^{* *} p \leq .01$ 
Table 12

Mean Inter-Team Coordination Ratings by Leader Training Condition Inter-Team Coordination (expert rating)

\begin{tabular}{ccc}
\hline & \multicolumn{2}{c}{ Strategy Training } \\
\cline { 2 - 3 } Coordination Training & Control & Experimental \\
\hline Control & $2.46(1.11)$ & $3.03(.93)$ \\
Experimental & $2.52(.90)$ & $3.75(.78)$ \\
\hline Inter-Team Coordination (event-based rating) \\
\cline { 2 - 3 } Coordination Training & \multicolumn{2}{c}{ Strategy Training } \\
\hline Control & $8.94(2.66)$ & Experimental \\
Experimental & $9.67(2.89)$ & $9.56(3.83)$ \\
\hline
\end{tabular}

Standard errors are in parentheses. 
Table 13

Summary of Hierarchical Regression Examining Inter-Team Coordination as Mediator in Predicting Multi-Team Performance

\begin{tabular}{lcl}
\hline Variables Entered & Step 1 & Step 2 \\
\hline Leader strategy behavior (Sub. Report) & $.25^{*}$ & .10 \\
Inter-team coordination (Expert Rating) & & $.41^{* *}$ \\
\hline R-Square & $.06^{*}$ & $.21^{* *}$ \\
R-Square Change & & $.15^{* *}$ \\
\hline Variables Entered & Step 1 & Step 2 \\
\hline Leader strategy behavior (Sub. Report) & $.25^{*}$ & .06 \\
Inter-team coordination (Event-Based Rating) & & $.61^{* *}$ \\
\hline R-Square & $.06^{*}$ & $.40^{* *}$ \\
R-Square Change & & $.34^{* *}$ \\
\hline
\end{tabular}

Values are standardized regression weights; $* p \leq .05 ;{ }^{* *} p \leq .01$ 
Table 14

Analysis of Variance for Mental Model Similarity and Accuracy

\begin{tabular}{cc}
$\mathrm{DV}=$ Mental Model Accuracy $(D F=3,60)$ & $\mathrm{F}$ \\
\hline Strategy Training & $17.96^{* *}$ \\
Coordination Training & 0.12 \\
S x C Interaction & 1.06 \\
\hline $\mathrm{DV}=$ Mental Model Similarity $(D F=3,52)$ & \\
\hline Strategy Training & 0.10 \\
Coordination Training & 1.20 \\
S x C Interaction & $4.40^{*}$ \\
\hline$* p \leq .05 ; * * \leq .01$ &
\end{tabular}

Table 15

Mean Mental Model Accuracy and Similarity Scores by Leader Training Condition Mental Model Accuracy

\begin{tabular}{ccc}
\hline & \multicolumn{2}{c}{ Strategy Training } \\
\cline { 2 - 3 } Coordination Training & Control & Experimental \\
\hline Control & $2.88(.50)$ & $3.27(.39)$ \\
Experimental & $2.80(.54)$ & $3.44(.49)$ \\
\hline & Mental Model Similarity \\
\hline Coordination Training & Strategy Training \\
\hline Control & $.50(.15)$ & Experimental \\
Experimental & $.38(.14)$ & $.43(.10)$ \\
\hline
\end{tabular}

Standard errors are in parentheses. 
Table 16

Summary of Hierarchical Regression Examining Mental Model Accuracy as a Mediator

\begin{tabular}{lcc}
\hline \multicolumn{3}{c}{ DV = Inter-team coordination (expert rating) } \\
\hline Variables Entered & Step 1 & Step 2 \\
\hline Leader strategy behavior (Sub. Report) & $.27^{*}$ & .15 \\
Leader strategy behavior (Expert Rating) & $.28^{*}$ & $.23 \dagger$ \\
Mental model accuracy & $.33^{* *}$ \\
\hline R-Square & $.19^{* *}$ & $.28^{* *}$ \\
R-Square Change & $.09^{* *}$ \\
\hline \multicolumn{1}{c}{ DV = Inter-team coordination (event-based rating) } \\
\hline Variables Entered & Step 1 & Step 2 \\
\hline Leader strategy behavior (Sub. Report) & $.29^{*}$ & $.27^{*}$ \\
Leader strategy behavior (Expert Rating) & .05 & -.02 \\
Mental model accuracy & .18 \\
\hline R-Square & $.10^{*}$ & $.12^{*}$ \\
$\quad$ R-Square Change & .03 \\
\hline Valus are standardized regrsion
\end{tabular}

Values are standardized regression weights; $\uparrow p \leq .10 ;{ }^{*} p \leq .05$ 
Table 17

Summary of Hierarchical Regression Analyses Examining Mental Model Similarity as Mediator

\begin{tabular}{lcc}
\hline \multicolumn{3}{c}{ DV = Inter-team coordination (expert rating) } \\
\hline Variables Entered & Step 1 & Step 2 \\
\hline Leader strategy behavior (Sub. Report) & $.25 \dagger$ & $.25 \dagger$ \\
Leader strategy behavior (Expert Rating) & $.24 \dagger$ & .22 \\
Mental model similarity & .06 \\
\hline R-Square & $.14^{*}$ & $.14^{*}$ \\
R-Square Change & .00 \\
\hline \multicolumn{1}{c}{ DV = Inter-team coordination (event-based rating) } \\
\hline Variables Entered & Step 1 & Step 2 \\
\hline Leader strategy behavior (Sub. Report) & $.33^{*}$ & $.33^{*}$ \\
Leader strategy behavior (Expert Rating) & -.03 & -.03 \\
Mental model similarity & $.10 \dagger$ & .10 \\
\hline R-Square & & .00 \\
\hline R-Square Change
\end{tabular}

Values are standardized regression weights; $\dagger p \leq .10 ;{ }^{*} p \leq .05$ 
Table 18

Analysis of Variance for Leader Coordinating Behavior

Wilks's F

lambda

Multivariate Model $(D F=3,60)$

Strategy Training

$.84 \quad 5.56^{* *}$

Coordination Training

$.759 .80^{* *}$

$\mathrm{S} \times \mathrm{C}$ Interaction

.96

1.21

Univariate Models $(D F=3,60)$

$\mathrm{DV}=$ Leader coordinating behavior

(subordinate report)

Strategy Training

0.52

Coordination Training

$9.29 * *$

$\mathrm{S} \times \mathrm{C}$ Interaction

0.35

DV $=$ Leader coordinating behavior

(expert rating)

Strategy Training

$10.85^{* *}$

Coordination Training

$17.84 * *$

$\mathrm{S} \times \mathrm{C}$ Interaction

1.18

** $p \leq .01$ 
Table 19

Mean Leader Coordinating Behavior Ratings by Leader Training Condition

Leader Coordinating Behavior (subordinate report)

\begin{tabular}{ccc}
\hline & \multicolumn{2}{c}{ Strategy Training } \\
\cline { 2 - 3 } Coordination Training & $3.48(.67)$ & Experimental \\
\hline Control & $3.99(.53)$ & $3.66(.49)$ \\
Experimental & $4.01(.52)$ \\
\hline Leader Coordinating Behavior (expert rating) \\
\hline \multicolumn{2}{c}{ Strategy Training } \\
\hline Coordination Training & Control & Experimental \\
\hline Control & $2.37(1.14)$ & $2.91(1.00)$ \\
Experimental & $3.13(1.00)$ & $4.20(0.70)$ \\
\hline
\end{tabular}

Standard errors are in parentheses. 
Table 20

Summary of Hierarchical Regression Analyses Examining Inter-Team Coordination as Mediator

\begin{tabular}{lcc}
\hline \multicolumn{3}{c}{ DV = Air Combat Team Performance } \\
\hline Variables Entered & Step 1 & Step 2 \\
\hline Leader coordinating behavior (Sub. Report) & $.39^{* *}$ & $.39^{* *}$ \\
Leader coordinating behavior (Expert Rating) & .03 & -.10 \\
Inter-team coordination (Expert Rating) & -.13 \\
Inter-team coordination (Event-Based Rating) & $.47^{* *}$ \\
\hline R-Square & $.17^{* *}$ & $.31^{* *}$ \\
$\quad$ R-Square Change & $.14^{* *}$ \\
\hline \multicolumn{2}{c}{ DV = Multi-Team Performance } & \\
\hline Variables Entered & Step 1 & Step 2 \\
\hline Leader coordinating behavior (Sub. Report) & $.45^{* *}$ & $.42^{* *}$ \\
Leader coordinating behavior (Expert Rating) & .07 & $-.24 \dagger$ \\
Inter-team coordination (Expert Rating) & .09 \\
Inter-team coordination (Event-Based Rating) & $.58^{* *}$ \\
\hline R-Square & $.24^{* *}$ & $.54^{* *}$ \\
$\quad$ R-Square Change & $.30^{* *}$ \\
\hline Values are standardized regression weights; $\dagger p \leq .10 ;{ }^{*} p \leq .05 ; * *$ & $p \leq .01$
\end{tabular}


Table 21

Analysis of Variance for Multi-Team Performance $(D F=3,60)$

\begin{tabular}{ll}
\hline Source & $\mathrm{F}$ \\
\hline Strategy Training & 0.05 \\
Coordination Training & $3.06 \dagger$ \\
S x C Interaction & 0.67 \\
\hline$\dagger p \leq .10$ &
\end{tabular}

Table 22

Mean Multi-Team Performance by Leader Training Condition

\begin{tabular}{ccc}
\hline & \multicolumn{2}{c}{ Strategy Training } \\
\cline { 2 - 3 } Coordination Training & Control & Experimental \\
\hline Control & $1.71(.24)$ & $1.56(.24)$ \\
Experimental & $1.93(.25)$ & $2.19(.24)$ \\
\hline
\end{tabular}

Standard errors are in parentheses. 
Table 23

Summary of Results of Hypothesis Tests

\begin{tabular}{|c|c|c|c|c|}
\hline Hypothesis & Relationship & $\begin{array}{c}\text { Full } \\
\text { Support }\end{array}$ & $\begin{array}{c}\text { Some } \\
\text { Support }\end{array}$ & $\begin{array}{l}\text { No } \\
\text { Support }\end{array}$ \\
\hline 1 & MST $\rightarrow$ Leader Strategy & $\mathrm{X}$ & & \\
\hline 2 & MST $\rightarrow$ Coordination & $\mathrm{X}$ & & \\
\hline 3 & $\begin{array}{l}\text { Leader Strategy } \rightarrow \text { Coordination } \rightarrow \text { Team } \\
\text { Performance }\end{array}$ & & & $\mathrm{X}$ \\
\hline 4 & $\begin{array}{l}\text { Leader Strategy } \rightarrow \text { Coordination } \rightarrow \text { MTS } \\
\text { Performance }\end{array}$ & & $\mathrm{X}$ & \\
\hline $5 a$ & MST $\rightarrow$ Mental Model Accuracy & $\mathrm{X}$ & & \\
\hline $5 b$ & MST $\rightarrow$ Mental Model Similarity & & & $\mathrm{X}$ \\
\hline $6 a$ & Mental Model Accuracy $\rightarrow$ Coordination & & $\mathrm{X}$ & \\
\hline $6 b$ & Mental Model Similarity $\rightarrow$ Coordination & & & $\mathrm{X}$ \\
\hline $7 a$ & $\begin{array}{l}\text { Leader Strategy } \rightarrow \text { Mental Model } \\
\text { Accuracy } \rightarrow \text { Coordination }\end{array}$ & & $\mathrm{X}$ & \\
\hline $7 b$ & $\begin{array}{l}\text { Leader Strategy } \rightarrow \text { Mental Model } \\
\text { Similarity } \rightarrow \text { Coordination }\end{array}$ & & & $\mathrm{X}$ \\
\hline 8 & $\mathrm{MCO} \rightarrow$ Leader Coordinating & $\mathrm{X}$ & & \\
\hline 9 & $\mathrm{MCO} \rightarrow$ Coordination & & $\mathrm{X}$ & \\
\hline 10 & $\begin{array}{l}\text { Leader Coordinating } \rightarrow \text { Coordination } \rightarrow \\
\text { Team Performance }\end{array}$ & & & $\mathrm{X}$ \\
\hline 11 & $\begin{array}{l}\text { Leader Coordinating } \rightarrow \text { Coordination } \rightarrow \\
\text { MTS Performance }\end{array}$ & & & $\mathrm{X}$ \\
\hline 12 & MST*MCO $\rightarrow$ Coordination & & & $\mathrm{X}$ \\
\hline 13 & MST*MCO $\rightarrow$ MTS Performance $^{*}$ & & & $X$ \\
\hline
\end{tabular}




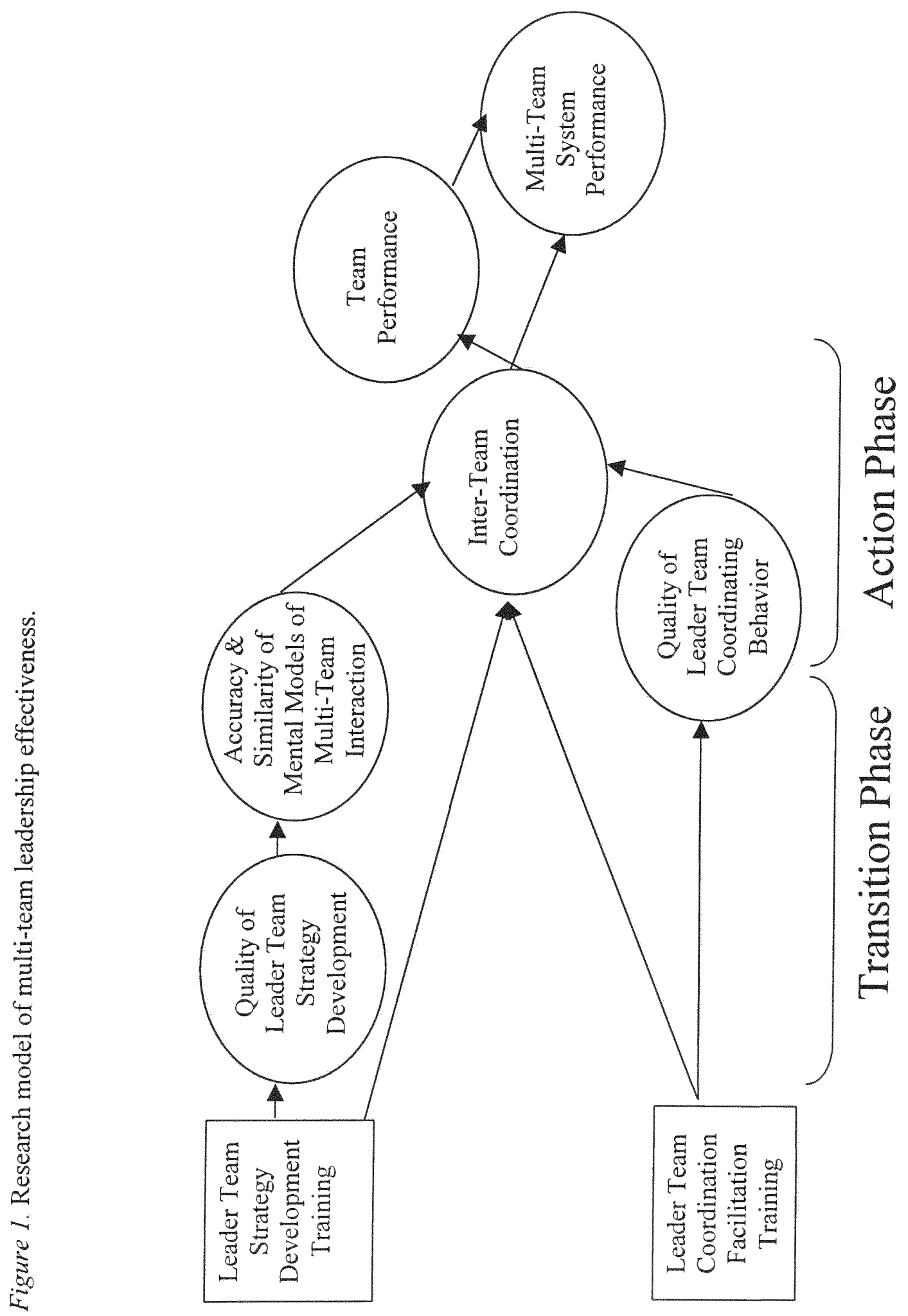



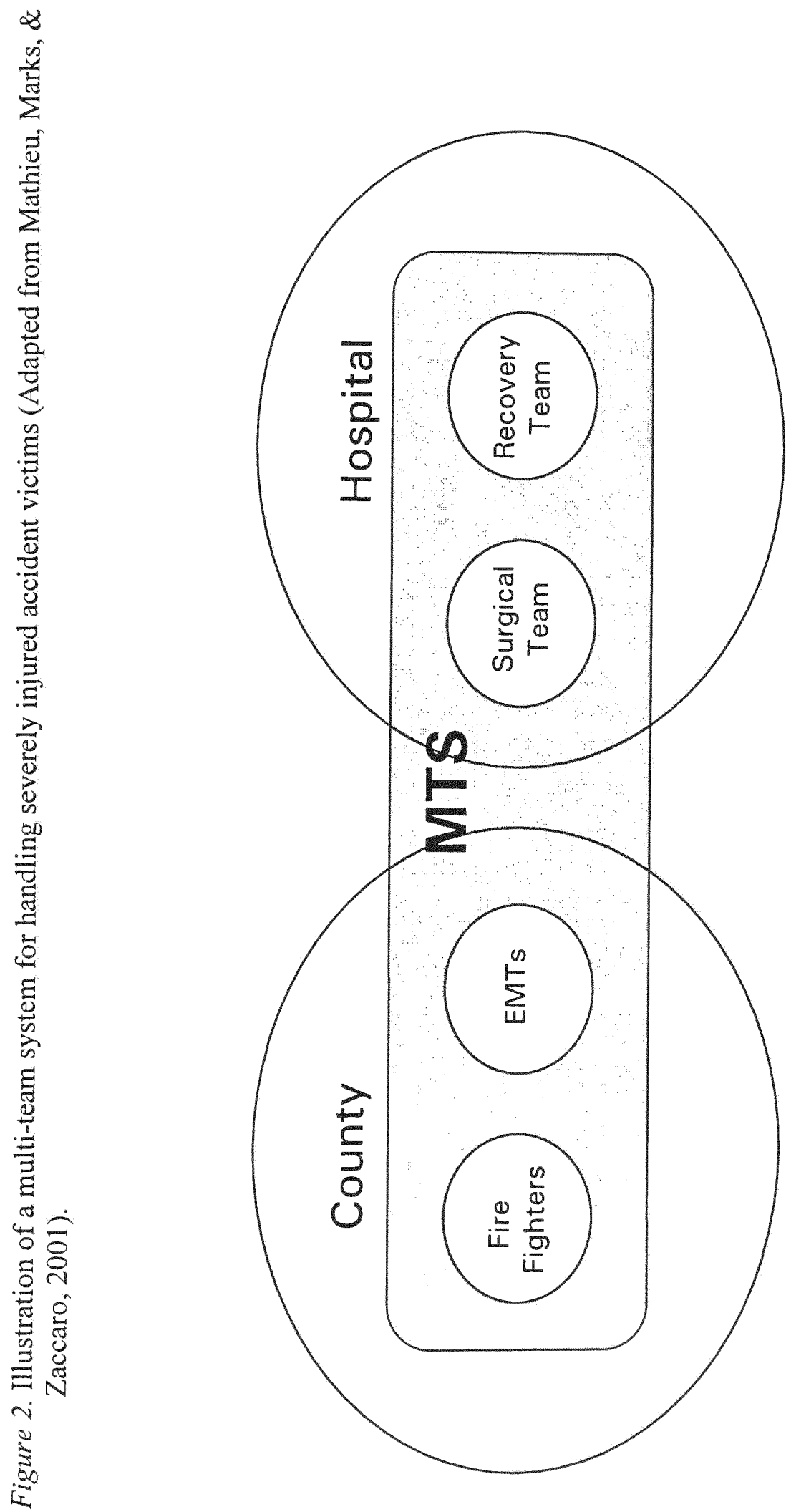


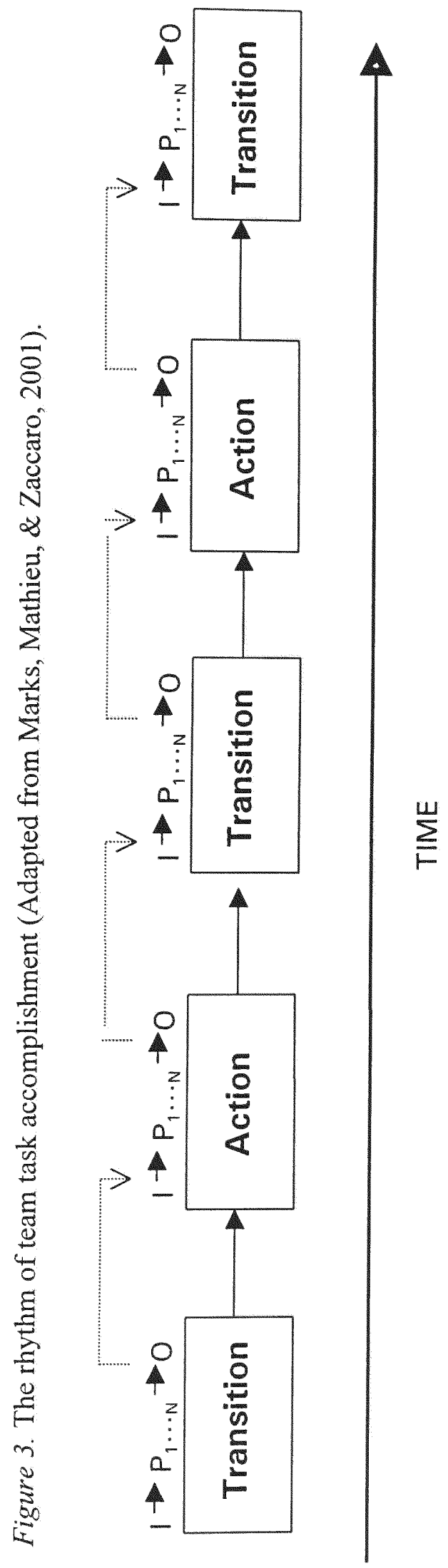




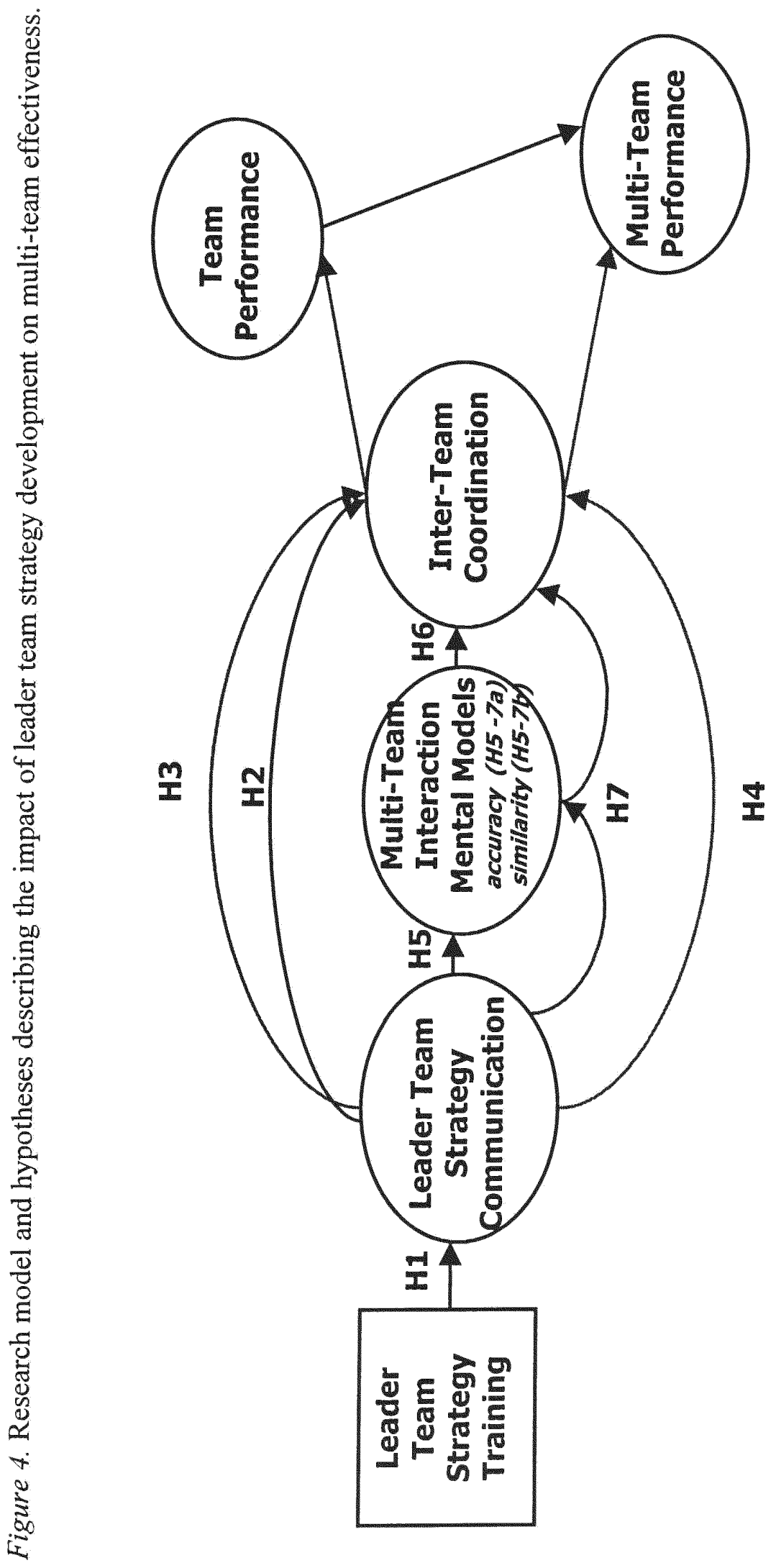

ำ 


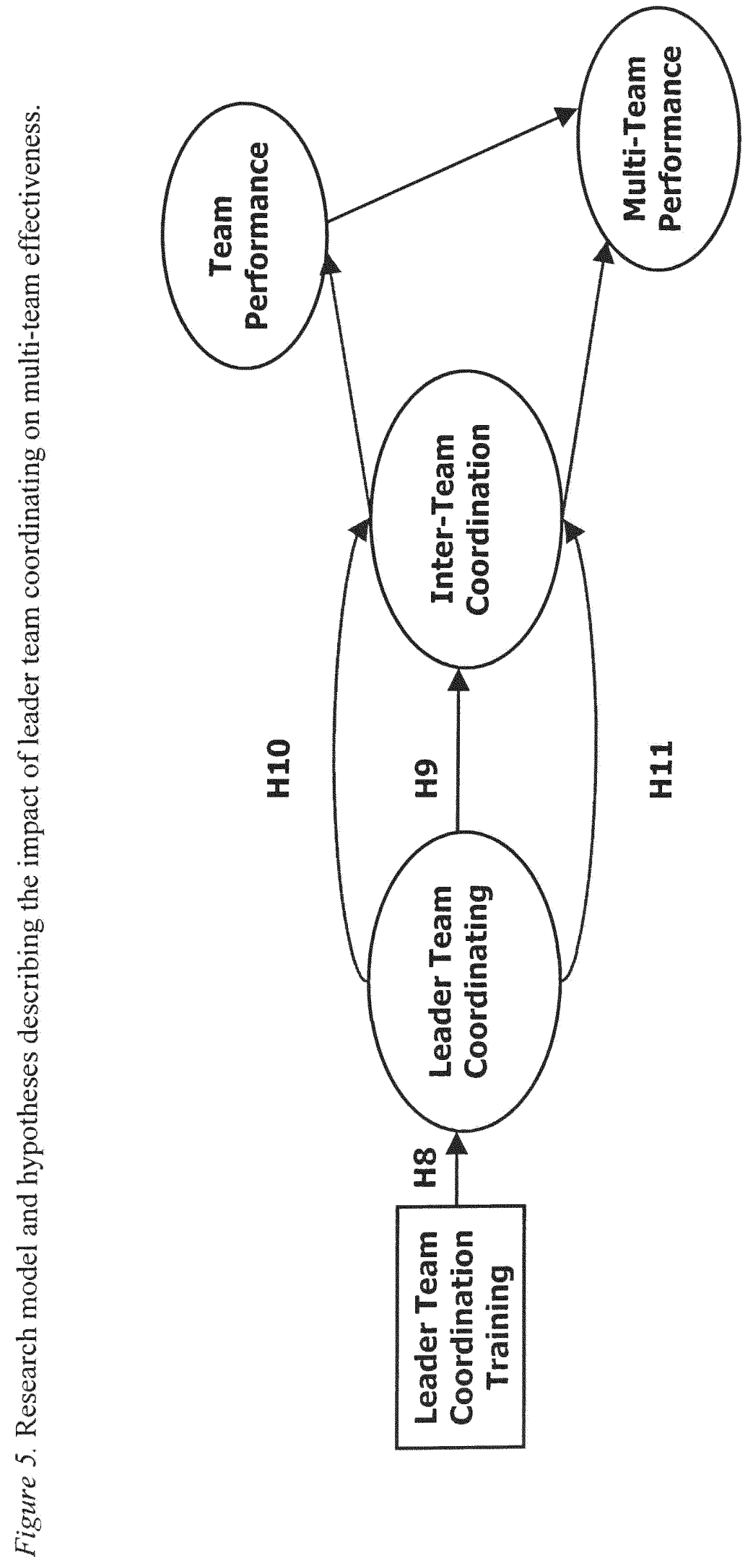



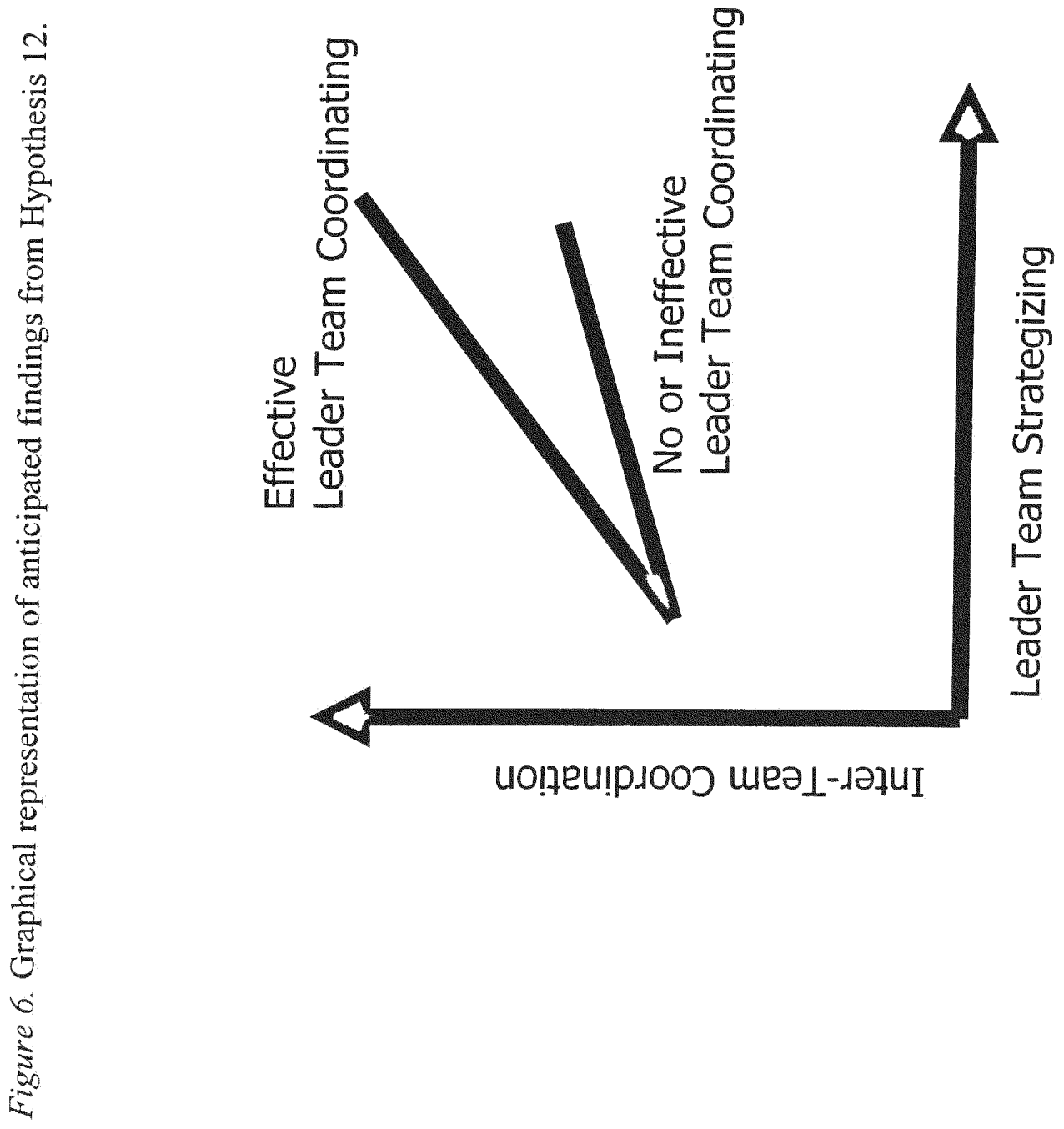


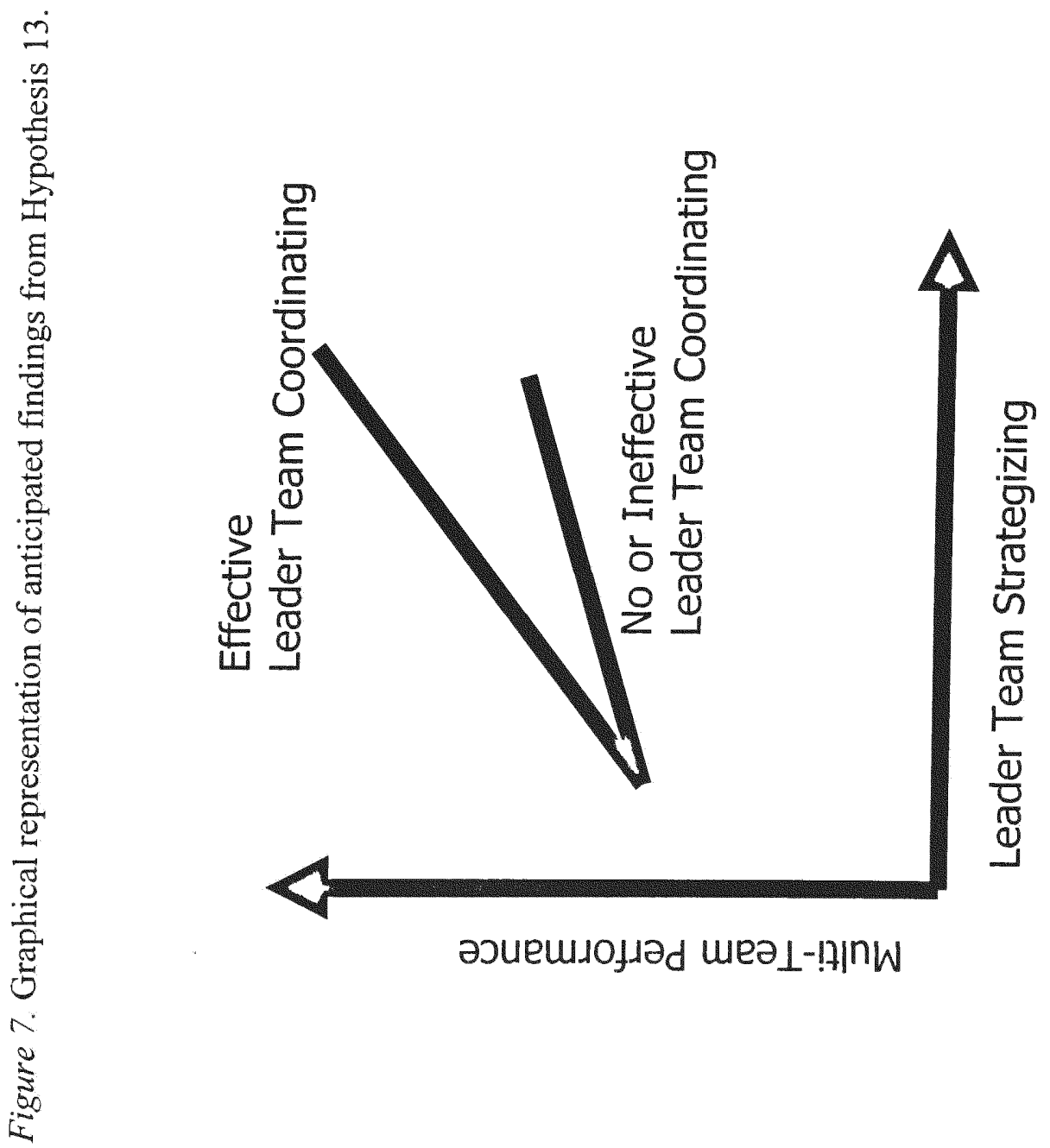




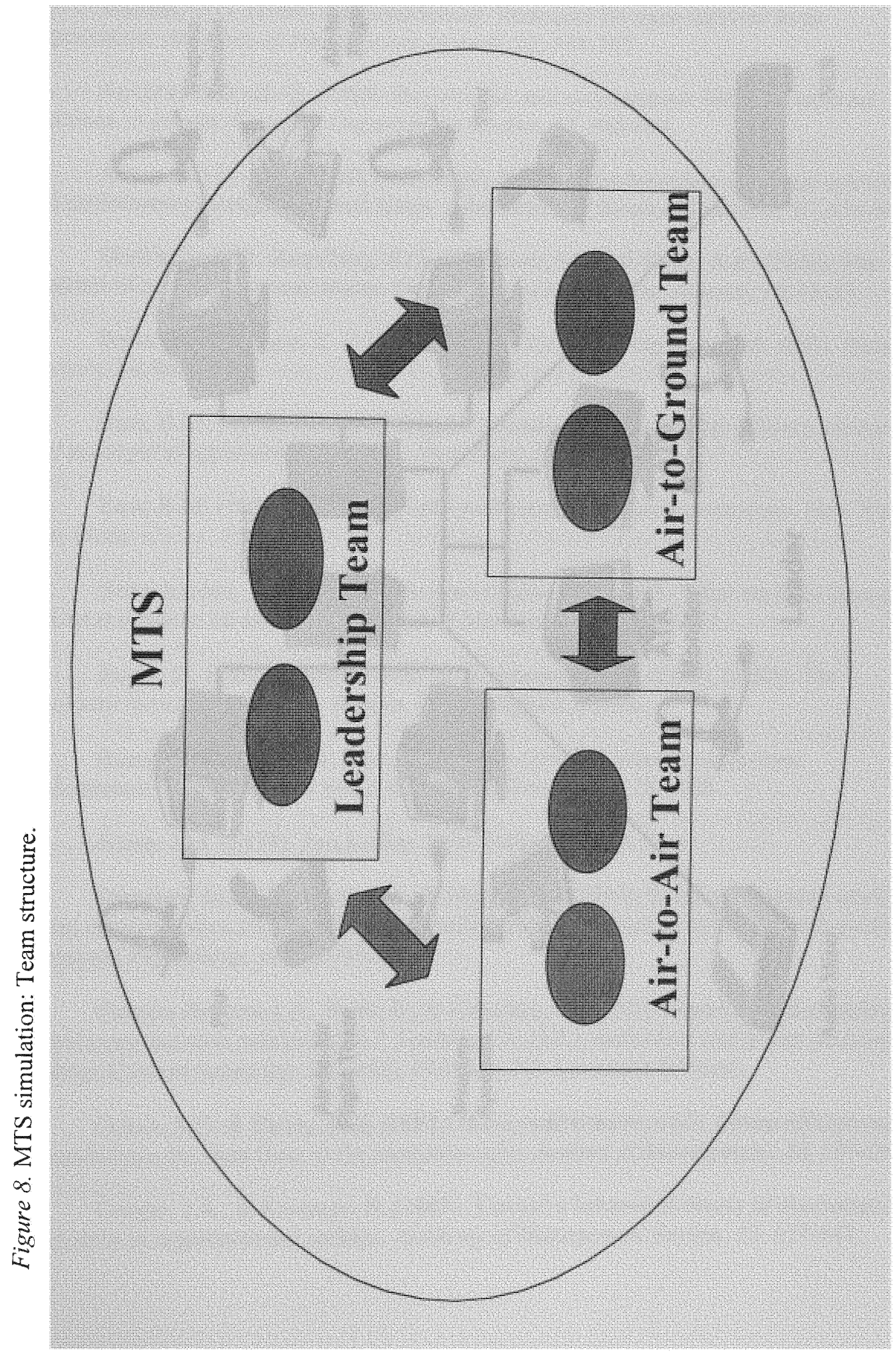

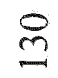




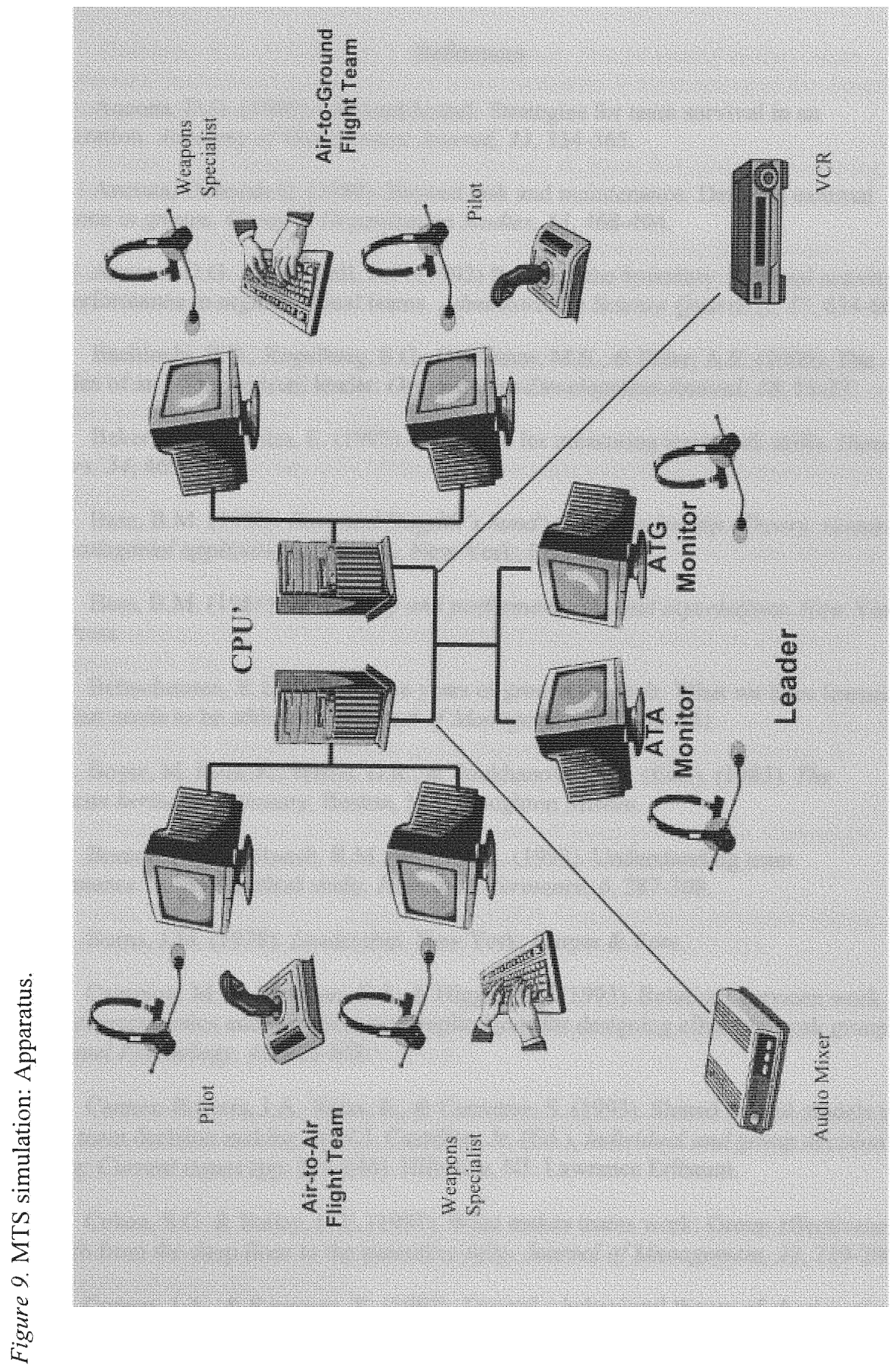


Ancona, D.G. (1990). Outward bound: Strategies for team survival in an organization. Academy of Management Journal, 33, 334-365.

Ancona, Deborah G. (1988). Beyond task and maintenance: Defining external functions in groups. Group \& Organization Studies, 13, 468-494.

Ancona, D.G. \& Caldwell, D.F. (1992) Bridging the boundary: External activity and performance in organizational teams. Administrative Science Quarterly, 37, 634-665.

Bachiochi, P.D., Rogelberg, S.G., O'Connor, M.S., \& Elder, A.E. (2000). The qualities of an effective team leader. Organization Development Journal, 18, 11-27.

Baker, D.P. \& Salas, E. (1992). Principles for measuring teamwork skills. Human Factors, 34, 469-475.

Bass, B.M. (1990). Bass and Stogdill's handbook of leadership: Theory, research, and managerial applications (3rd ed.). New York: Free Press. Free Press.

Bass, B.M. (1985). Leadership and performance beyond expectations. New York:

Bettenhausen, K.L. (1991). Five years of groups research: What we have learned and what needs to be addressed. Journal of Management, 17, 345-381.

Boyer, M. Ellis, K., Harris, D.R., \& Soukhanove, A.H. (Eds.). (1983). The American heritage dictionary. Boston, MA: Houghton Mifflin.

Brannick, M.T., Roach, R.M., \& Salas, E. (1993). Understanding team performance: A multimethod study. Human Performance, 6, 287-308.

Burns, J.M. (1978), Leadership. New York: Harper \& Row.

Campion, M.A., Medsker, G.J., \& Higgs, A.C. (1993). Relations between work group characteristics and effectiveness: Implications for designing effective work groups. Personnel Psychology, 46, 823-850.

Cannon-Bowers, J.A., Salas, E., \& Converse, S. (1993). Shared mental models in expert team decision making. In N.J. Castellan, Jr. (Ed.), Individual and group decision making: Current issues (pp. 221-246). Hillsdale, NJ: Lawrence Erlbaum.

Cohen, S.G. \& Bailey, D.E. (1997). What makes teams work: Group effectiveness research from the shop floor to the executive suite. Journal of Management, 23, 239-290.

Conger, J.A., \& Kanungo, R. (1987). Toward a behavioral theory of charismatic leadership in organizational settings. Academy of Management Review, 12, 637-647. 
Converse, S.A. \& Kahler, S.E. (1992, August). Shared mental models, team performance, and knowledge acquisition. Paper presented at the meeting of the American Psychological Association, Washington, D.C.

Cooke, N.J., Salas, E., Cannon-Bowers, J.A., \& Stout, R.J. (2000). Measuring team knowledge. Human Factors, 42, 151-173.

Denison, D.R., Hart, S.L., \& Kahn, J.A. (1996). From chimneys to crossfunctional teams: Developing and validating a diagnostic model. Academy of Management Journal, 39, 1005-1023.

Durham, C.C., Knight, D., \& Locke, E.A. (1997). Effects of leader role, team-set goal difficulty, efficacy, and tactics on team effectiveness. Organizational Behavior and Human Decision Processes, 72, 203-231.

Entin, E.E. \& Serfaty, D. (1999). Adaptive team coordination. Human Factors, $41,312-325$. Hill.

Fiedler, F.E. (1967). A theory of leadership effectiveness. New York: McGraw-

Fleishman, E.A. (1953). The description of supervisory behavior. Personnel Psychology, 37, 1-6.

Fleishman, E.A., Mumford, M.D., Zaccaro, S.J., Levin, K.Y., Korotkin, A.L., \& Hein, M.B. (1991). Taxonomic efforts in the description of leadership behavior: A synthesis and functional interpretation. Leadership Quarterly, 2, 245-287.

French, J. \& Raven, B.H. (1959). The bases of social power. In D. Cartwright (Ed.), Studies of social power. Ann Arbor, MI: Institute for Social Research.

Gist, M.E., Locke, E.A., Taylor, M.S. (1987). Organizational behavior: Group structure, process, and effectiveness. Journal of Management, 13, 237-257.

Goren, H. \& Borenstein, G. (2000). The effects of intragroup communication on intergroup cooperation in the repeated intergroup prisoner's dilemma (IPD) game. Journal of Conflict Resolution, 44, 700-719.

Griffin, A. \& Hauser, J.R. (1992). Patterns of communication among marketing engineering and manufacturing-a comparison between two new product teams. Management Science, 38, 360-373.

Guastello, S.J. \& Guastello, D.D. (1998). Origins of coordination and team effectiveness: A perspective from game theory and nonlinear dynamics. Journal of Applied Psychology, 83, 423-437. 
Hackman, J.R. (1987). The design of work teams. In J. Lorsch (Ed.), Handbook of organizational behavior (pp. 315-342). Englewood Cliffs, NJ: Prentice Hall.

Hackman, J.R., Brousseau, K.R., \& Weiss, J.A. (1976). The interaction of task design and group performance strategies in determining group effectiveness. Organizational Behavior and Human Performance, 16, 350-365.

Hackman, J.R. \& Walton, R.E. (1986). Leading groups in organizations. In P.S. Goodman \& Associates, Designing effective work groups (pp. 72-119). San Francisco: Jossey-Bass.

Harris, T.C. \& Barnes-Farrell, J.L. (1997). Components of teamwork: Impact on evaluations of contributions to work team effectiveness. Journal of Applied Social Psychology, 27, 1694-1715.

House, R.J. (1971). A path-goal theory of leader effectiveness. Administrative Science Quarterly, 16, 321-339.

House, R.J. (1977). A 1976 theory of charismatic leadership. In J.G. Hunt \& L.L. Larson (Eds.). Leadership: The cutting edge. Carbondale: Southern Illinois University Press.

James, L. R., Demaree, R. G., \& Wolf, G. (1984). Estimating within-group interrater reliability with and without response bias. Journal of Applied Psychology, 69, 85-98.

Janis, I.L., Deutsch, M., Krauss, R.M., Goktepe, J.R., Scheier, C.E., (1991). Group behavior. In W.A. Lesko, (Ed.), Readings in social psychology: General, classic, and contemporary selections (pp. 317-341). Needham Heights, MA: Allyn \& Bacon.

Janz, B.D., Colquitt, J.A., \& Noe, R.A. (1997). Knowledge worker team effectiveness: The role of autonomy, interdependence, team development, and contextual support variables. Personnel Psychology, 50, 877-904.

Jehn, K.A., Northcraft, G.B., \& Neale, M.A. (1999). Why differences make a difference: A field study of diversity, conflict, and performance in workgroups. Administrative Science Quarterly, 44, 741-763.

Jehn, K.A. \& Shah, P.P. (1997). Interpersonal relationships and task performance: An examination of mediating processes in friendship and acquaintance groups. Journal of Personality and Social Psychology, 72, 775-790.

Kabanoff, B. \& O'Brien, G.E. (1979). The effects of task type and cooperation upon group products and performance. Organizational Behavior and Human Performance, 23, 163-181. 
Kanfer, R., Ackerman, P.L., Murtha, T.C., \& Dugdale, B. (1994). Goal setting, conditions of practice, and task performance: A resource allocation perspective. Journal of Applied Psychology, 79, 826-835.

Katz, R. \& Tushman, M. (1979). Communication patterns, project performance, and task characteristics: An empirical evaluation and integration in an R\&D setting. Organizational Behavior and Human Performance, 23, 139-162.

Klimoski, R. \& Mohammed, S. (1994). Team mental model: Construct or metaphor? Journal of Management, 20, 403-437.

Komaki, J.L., Desselles, M.L., \& Bowman, E.D. (1989). Definitely not a breeze: Extending an operant model of effective supervision to teams. Journal of Applied Psychology, 74, 522-529.

Kozlowski, S.W.J. \& Bell, B.S. (in press). Work groups and teams in organizations. In W.C. Borman, D.R. Ilgen, \& R.J. Klimoski (Eds.), Comprehensive handbook of psychology: Vol. 12. Industrial and organizational psychology. New York: Wiley.

Kozlowski, S.W.J., Gully, S.M., McHugh, P.P., Salas, E., \& Cannon-Bowers, J.A. (1996). A dynamic theory of leadership and team effectiveness: Developmental and task contingent roles. In G. Ferris (Ed.), Research in personnel and human resource management (Vol. 14, pp. 253-305). Greenwich, CT: JAI Press.

LePine, J.A., Hollenbeck, J.R., Ilgen, D.R., \& Hedlund, J. (1997). Effects of individual differences on the performance of hierarchical decision-making teams: Much more than g. Journal of Applied Psychology, 82, 803-811.

Levine \& Moreland (1990). Progress in small group research. Annual Review of Psychology, 41, 585-634.

Locke, E.A., Durham, C.C., Poon, J.M.L., \& Weldon, E. (1997). Goal setting, planning, and performance on work tasks for individuals and groups. In S.L. Friedman \& E.K. Scholnick (Eds.), The developmental psychology of planning: Why, how, and when do we plan? Mahwah, NJ: Lawrence Erlbaum.

Lord, R.G. (1976). Group performance as a function of leadership behavior and task structure: Toward an exploratory theory. Organizational Behavior and Human Performance, 17, 76-96.

Lord, R.G. \& Rowzee, M. (1979). Task interdependence, temporal phase, and cognitive heterogeneity as determinants of leadership behavior and behavior-performance relations. Organizational Behavior and Human Performance, 23, 182-200. 
Marks, M.A., Mathieu, J.E., \& Zaccaro, S.J. (2001). A temporally based framework and taxonomy of team processes. Academy of Management Review, 26, 356376.

Marks, M.A., Zaccaro, S.J. \& Mathieu, J.E. (2000). Performance implications of leader briefings and team-interaction training for team adaptation to novel environments. Journal of Applied Psychology, 85, 971-986.

Mathieu, J.E., Heffner, T.S., Goodwin, G.F., Salas, E., \& Cannon-Bowers, J.A. (2000). The influence of shared mental models on team process and performance. Journal of Applied Psychology, 85, 273-283.

Mathieu, J.E., Marks, M.A., \& Zaccaro, S.J. (2001). Multiteam systems. In N. Anderson, D.S. Ones, H.K. Sinangil, \& C. Viswesvaran (Eds.), Organizational psychology: Vol. 2. Handbook of industrial, work and organizational psychology (pp. 289-313). London: Sage.

McGrath, J.E. (1984). Groups: Interaction and performance. Englewood Cliffs, NJ: Prentice-Hall.

McGrath, J.E. (1962). Leadership behavior: Some requirements for leadership training. Washington, DC: U.S. Civil Service Commission [Mimeographed].

Mitchell, T.R. \& Silver, W.S. (1990). Individual and group goals when workers are interdependent: Effects on task strategies and performance. Journal of Applied Psychology, 75, 185-193.

Mohammed, S. Klimoski, R. \& Rentch, J.R. (2000). The measurement of team mental models: We have no shared schema. Organizational Research Methods, 3, 123165.

Morgeson, F.P. (1997, April). Leading as event management: Toward a new conception of team leadership. Poster session presented at meeting of the Society of Industrial and Organizational Psychology, St. Louis, MO.

Mossholder, K.W. \& Bedeian, A.G. (1983). Group interactional processes: Individual and group level effects. Group and Organization Studies, 8, 187-202.

Mullen, B. \& Copper, C. (1994). The relation between group cohesiveness and performance: An integration. Psychological Bulletin, 115, 210-227.

Pinkley, R.L. \& Northcraft, G. B. (1992). Conflict frames of reference: Implication for dispute processes and outcomes. Academy of Management Journal, 37, 193-205.

Pinto, M.B., Pinto, J.K., \& Prescott, J.E. (1993). Antecedents and consequences of project team cross-functional cooperation. Management Science, 39, 1281-1297. 
Podsakoff, P.M., Ahearne, M. \& MacKenzie, S.B. (1997). Organizational citizenship behavior and the quantity and quality of work group performance. Journal of Applied Psychology, 82, 262-270.

Rawlings, D. (2000). Collaborative leadership teams: Oxymoron or new paradigm? Consulting Psychology Journal: Practice and Research, 52, 36-48.

Rouse, W.B. \& Morris, N.M. (1986). On looking into the black box: Prospects and limits in the search for mental models. Psychological Bulletin, 100, 349-363.

Ryska, T.A., Yin, Z.., Cooley, D. \& Ginn, R. (1999). Developing team cohesion: A comparison of cognitive-behavioral strategies of U.S. and Australian sport coaches. The Journal of Psychology, 133, 523-539.

Saavedra, R., Earley, P.C., \& Van Dyne, L. (1993). Complex interdependence in task-performing groups. Journal of Applied Psychology, 78, 61-72.

Salas, E., Dickinson, T.L., Converse, S.A., \& Tannenbaum, S.L. (1992). Toward an understanding of team performance and training. In R.W. Swezey \& E. Salas (Eds.), Teams: Their training and performance (pp. 3-29). Norwood, NJ: Ablex.

Schriesheim, C.A., Castro, S.L., \& Cogliser, C.C. (1999). Leader-member exchange (LMX) research: A comprehensive review of theory, measurement, and data analytic practices. Leadership Quarterly, 10, 63-113.

Seers, A. (1989). Team-member exchange quality: A new construct for rolemaking research. Organizational Behavior and Human Decision Processes, 43, 118-135.

Sherif, M. (1966). In common predicament: Social psychology of intergroup conflict and cooperation. Boston: Houghton Mifflin.

Smith, K.G., Carroll, S.J., \& Ashford, S.J. (1995). Intra- and interorganizational cooperation: Toward a research agenda. Academy of Management Journal, 38, 7-23.

Stout, R.J., Salas, E., \& Carson, R. (1993). Individual task proficiency and team process behavior: What's important for team functioning. Military Psychology, 6, 177192.

Stout, R.J., Cannon-Bowers, J.A., Salas, E. \& Malanovich. (1999). Planning, shared mental models, and coordinated performance: An empirical link is established. Human Factors, 41, 61-71.

Stout, R.J., Cannon-Bowers, J.A, \& Salas, E. (1996). The role of shared mental models in developing team situational awareness: Implications for training. Training Research Journal, 2, 86-116. 
Thompson, J.D. (1967). Organizations in action. New York: McGraw-Hill.

Tjosvold, D. (1990). Flight crew collaboration to manage safety risks. Group and Organization Studies, 15, 177-191.

Tjosvold, D. (1984). Cooperation theory and organizations. Human Relations, 37 , 743-767.

Van de Ven, A.H., Delbecq, A.L., \& Koenig, R.J., Jr. (1976). Determinants of coordination modes within organizations. American Sociological Review, 41, 322-338.

Wagner, J.A. III. (1995). Studies of individualism-collectivism: Effects on cooperation in groups. Academy of Management Journal, 38, 152-172.

Webber, S.S., Chen, G., Payne, S.C., Marsh, S.M., \& Zaccaro, S.J. (2000). Enhancing team mental model measurement with performance appraisal practices. Organizational Research Methods, 3, 307-322.

Weingart, L.R. (1992). Impact of group goals, task component complexity, effort, and planning on group performance. Journal of Applied Psychology, 77, 682-693.

Weldon, E., Jehn, K.A., \& Pradhan, P. (1991). Processes that mediate the relationship between a group goal and improved group performance. Journal of Personality and Social Psychology, 61, 555-569.

Weldon, E. \& Weingart, L.R. (1988, August). A theory of group goals and group performance. Paper presented at the meeting of the Academy of Management, Anaheim, CA.

West, M.A. \& Anderson, N.R. (1996). Innovation in top management teams. Journal of Applied Psychology, 81, 680-693.

Wonderlic, Inc. (2000). Wonderlic personnel test and scholastic level exam user's manual. Libertyville, IL: Author.

Zalesny, M.D., Salas, E., \& Prince, C. (1995). Conceptual and measurement issues in coordination: Implications for team behavior and performance. Research in Personnel and Human Resources Management, 13, 81-115. 
APPENDICES 


\section{LIST OF APPENDICES}

APPENDIX

PAGE

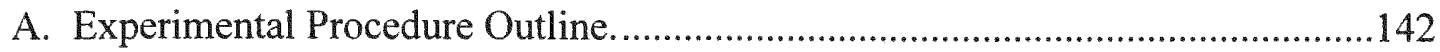

B. Task Training Script - Air to Air Flight Team ...............................................148

C. Task Training Script - Air to Ground Flight Team ….......................................153

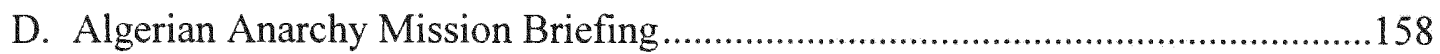

E. Botswana Battle Mission Briefing ...................................................................161

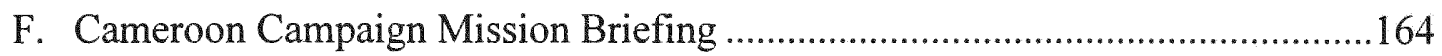

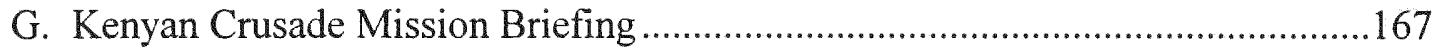

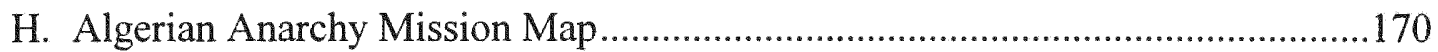

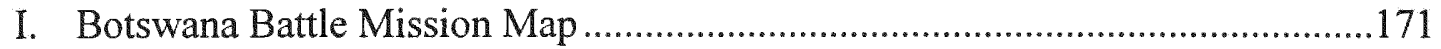

J. Cameroon Campaign Mission Map …….......................................................172

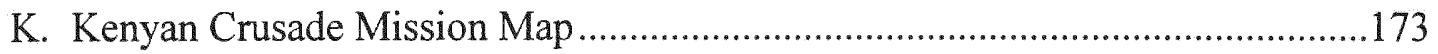

L. Experimental Procedure Outline - Leader Team Training Phase.........................174

M. Leader Strategy Training Overview - Experimental ..........................................175

N. Leader Strategy Training Overview - Control...................................................176

O. Leader Team Strategy Training Presentation - Experimental .............................177

P. Leader Team Strategy Training Presentation - Control.......................................179

Q. Leader Team Strategy Training - Botswana Expert Strategy Key.......................180

R. Leader Coordination Training Overview - Experimental .................................181

S. Leader Coordination Training Overview - Control ..............................................184

T. Leader Team Coordination Training - Botswana Feedback Key ........................187

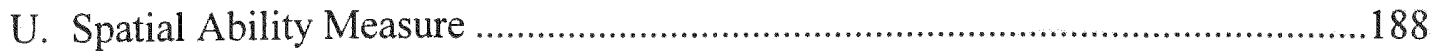


V. Leader Task Knowledge Measure

W. Leader Team Strategy Manipulation Check........................................................193

X. Leader Team Coordination Manipulation Check ..............................................195

Y. Leader Team Strategy Communication...............................................................197

Z. Leader Team Strategy Communication BARS ..................................................198

AA. Leader Team Coordinating Behavior ...............................................................199

BB. Leader Team Coordinating Behavior BARS ….............................................200

CC. Multi-Team Interaction Mental Model Measure .............................................201

DD. MTS Mental Model Accuracy Scoring Key ...................................................202

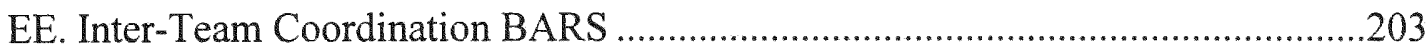

FF. Inter-Team Coordination Objective Measure Scoring Key ...............................204

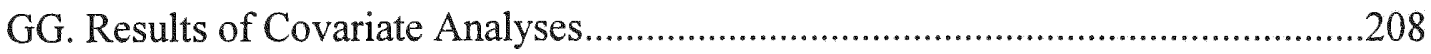




\section{Appendix A}

\section{ACES Experimental Procedure Outline (11/18/01)}

\section{Before Participants Arrive:}

1. Turn on all computers ( 2 simulation computers, the destination, 2 green computers)

2. Label and cue tape in VIDEO CAMERA (GREEN)

3. Label and cue tapes in main VCR's (BLUE)

4. Label and cue audio tape in cassette recorder

5. Make sure you have:

- 6 informed consent forms

- 6 pre-measures 1 packets

- 6 pre-measures 2 packets (DO NOT WRITE ON THESE)

- 6 pre-measures 2 answer sheets

- 6 participant packets (one for each role)

- 6 scoring sheets

- 4 Q sort forms

- For each mission: mission brief, 3 copies of the maps, \& Intel/sit-reps

- 3 SME packets

- 2 Leader SME packets

- 3 video tapes

GENERAL NOTE: When participants are in the Green room filling out measures, an experimenter needs to be standing right at the table at all times.

\section{Start in the Green Room}

- Administer Informed Consent

- Administer pre-measures 1

Divide subjects into pairs and alternate the following:

- (lead trainer) Administer spatial ability test (Remind them not to write on these) go over the instructions and all examples, then time them for 5 minutes

- (flight trainers) Administer Balloon test - RECORD SCORES ON CLIP BOARD

\section{Move to Blue Room}

- Give verbal introduction.

- Give position \& team assignments

\section{Spatial Ability Test Key}

\begin{tabular}{llllllll}
\hline 1) & $\mathrm{D}$ & 2) & $\mathrm{A}$ & $3)$ & $\mathrm{E}$ & $4)$ & $\mathrm{B}$ \\
5) & $\mathrm{A}$ & $6)$ & $\mathrm{B}$ & $7)$ & $\mathrm{E}$ & $8)$ & $\mathrm{B}$
\end{tabular}

- Administer task training (target 30 minutes for this, 10 minutes for each module).

- Flight team train on simulation, leader team trains in green room 
Flight Teams - Move to Green Room

Leader Team - Move to Blue Room

Flight Teams - Green Room

- Hand out participant packets (different for all 4 positions!) Instruct them to:

- fill out the cover

- turn to first page and fill out familiarity items

- complete the "After Training" competency check questions using the HUD mode diagrams

\section{Leader Team - Blue Room}

- Administer leader team task training on simulation

- Administer treatment leader training (strategy control or strategy \& coordination control or coordination

\section{ALGERIAN ANARCHY (Flight Team Practice Mission)}

\section{Flight Teams - Green Room}

- Read the first paragraph of the mission brief to them

- Next lay the materials in the center of the table and explain what they are, what information they contain, etc. You should point out the following:

- Mission brief (the larger battle, targets, points, strategic information, timing guidelines)

- Sit/Rep (additional intelligence that's gathered that ranges from irrelevant to critical in importance level)

- Maps of the mission.

- Q-sort form (give instruction on how to fill this out).

- Tell them they'll have 10 minutes to plan for their mission \& they can only take the maps into their mission, so they'll need to make notes of other information on the maps.

- Start video camera and stopwatch (make sure no one has their back to the camera).

- Cue up the simulation in the blue room.

Leader Team - Move to Green Room

Flight Teams - Move to Blue Room

Flight Teams - Blue Room

- Press RECORD on both VCR's

- Have them say their call signs - start with AA Pilot

- Start the simulation

- Press "ALT" + "R" on both computers 
- The flight team trainers stand to the side and make SME ratings (performance by position and MTS process) in REAL time

- If one team is shot down have them wait $\&$ ask them not to talk, turn off their audio mixer but DO NOT STOP THE GAME until both teams are finished

- If either team is destroyed in less than 3 minutes, restart the game

- During the practice mission, the task trainers/SME's should coach the team on anything they learned in task training that they are still deficient on. Also, the ground team trainer needs to teach the pop up maneuver.

- IMPORTANT: There can be absolutely no process training done. For instance, telling the wiso to "inform the pilot when he's too low" is training back up behavior; telling the pilot "you are too low when you hear the warning" is training the task. We can only train the task.

- After the mission, save both ACMI files.

Filenames:

$\overline{\mathrm{E} / \mathrm{P}} \overline{\#}-\mathrm{A} / \overline{\mathrm{B} / \mathrm{C}} / \mathrm{K}-\overline{\mathrm{W} / \mathrm{E}}$

(Experimental/Piloting)

(Algeria/Botswana/Cameroon/Kenya)

(Wolf/Eagle)

- Compute the AA team, AG team, \& MTS scores. (see scoring sheet)

- Cue the next mission.

Leader Team - Green Room

- Administer practice session on simulation.

- BREAK (maximum of 10 minutes; NO FOOD OR DRINK IN THE LAB ROOMS).

\section{Flight Teams - Move to Green Room}

- Have them fill out the "After Algeria" measures.

- BREAK (maximum of 10 minutes; NO FOOD OR DRINK IN THE LAB ROOMS).

\section{BOTSWANA BATTLE (Flight Team Experimental Mission)}

Leader Team - Return to Blue Room after break

- Administer leader practice session - Botswana materials and pre-recorded mission

Flight Teams - Return to Green Room after Break

- Have them fill out the "Before Botswana" measures.

- Introduce the second mission briefing in the same way... read the introduction...place materials on the table

- Set the stopwatch. 


\section{Flight Teams - Move to Blue Room BOTSWANA BATTLE (Experimental Mission)}

- Press RECORD on both VCR's

- Have them say their call signs - start with AA Pilot (the leader)

- Start the game

- Press "ALT" + "R" on both computers

- The flight team task trainers stand to the side and make SME ratings (performance by position and MTS process) in REAL time

- If one team is shot down have them wait $\&$ ask them not to talk, turn off their audio mixer but DO NOT STOP THE GAME until both teams are finished

- If either team is destroyed in less than 3 minutes, restart the game

- During this mission there is ABSOLUTELY NO coaching.

- After the mission, save both ACMI files.

- Compute the AA team, AG team, \& MTS scores.

- Cue the next mission.

\section{Flight Teams - Blue Room}

- Write scores (team \& MTS) on the top of the first measure in the packet.

- Have them fill out the "After Mission 1" measures \& the "Before Mission 2" measures.

\section{CAMEROON CAMPAIGN (MTS Experimental Mission)}

\section{Leader Team - Green Room}

- Press "Record" on camera.

- Introduce the mission and provide materials to the leaders.

- Give them 10 minutes to develop a strategy.

- Set the stopwatch.

- When time has elapsed, have leaders fill out strategy manipulation check.

- Escort flight teams to Green Room

\section{Flight Teams \& Leader Team - Green Room}

- Read the following: "For the final missions you will have a leader team. The leader team is responsible for developing a plan for the mission, making sure all team members understand the plan, and then assisting the teams in working together during the missions. Leader team you will now have 10 minutes to instruct your flight teams on the upcoming mission."

- Set the stopwatch.

- Have flight teams \& leader team fill out Before Cameroon Measures.

- Escort all teams to Blue room.

\section{Flight Teams and Leader Team - Blue Room}

- Press RECORD on both VCR's

- Have them say their call signs - start with the leader team 
- Start the game

- Press "ALT" + "R" on both computers

- The flight team task trainers stand to the side and make SME ratings (performance by position and MTS process) in REAL time

- The leader team trainer stands behind the leader team and rates

- If one team is shot down have them wait \& ask them not to talk, turn off their audio mixer but DO NOT STOP THE GAME until both teams are finished

- If either team is destroyed in less than 3 minutes, restart the game

- During this mission, there is ABSOLUTELY NO coaching.

- After the mission, save both ACMI files.

- Compute the AA team, AG team, \& MTS scores.

- Cue the next mission.

\section{Flight Teams remain in Blue Room}

- Write scores (team \& MTS) on the top of the first measure in the packet.

- Have them fill out the "After Cameroon" measures.

\section{KENYAN CRUSADE (MTS Experimental Mission)}

\section{Move Leader Team to Green Room}

- Press "record" on the camera.

- Introduce the mission and provide materials to the leaders.

- Give them 10 minutes to develop a strategy.

- Set the stopwatch.

- When time has elapsed, have leaders fill out strategy manipulation check.

- Escort flight teams to green room.

\section{Flight Teams \& Leader Team - Green Room}

- Read the following: "This is the final mission. As before, the leader team is responsible for developing a plan for the mission, making sure all team members understand the plan, and then assisting the teams in working together during the mission. Leader team you will now have 10 minutes to instruct your flight teams on the upcoming mission."

- Set the stopwatch.

- Have flight teams \& leader team fill out "Before Kenya" Measures.

- Escort all teams to Blue room.

Flight Teams \& Leader Team - Blue Room

- Press RECORD on both VCR's

- Have them say their call signs - start with leader team

- Start the simulation

- Press "ALT" + "R" on both computers 
- The flight team task trainers stand to the side and make SME ratings (performance by position and MTS process) in REAL time

- The leader trainer stands behind leader team making ratings

- If one team is shot down have them wait \& ask them not to talk, turn off their audio mixer but DO NOT STOP THE GAME until both teams are finished

- If either team is destroyed in less than 3 minutes, restart the game

- During this mission, there is ABSOLUTELY NO coaching.

- After the mission, save both ACMI files.

- Compute the AA team, AG team, \& MTS scores.

Flight Teams \& Leader Team - Move to Green Room

- Write scores (team \& MTS) on the top of the first measure in the packet.

- Have them fill out the "After Kenya" measures (finish the participant packet).

- Debrief participants. 


\title{
Appendix B
}

\section{Task Training Script - Air to Air Flight Team}

\section{ACES Task Training Protocol (Air-to-Air)}

\author{
Last Updated: 10/22/01
}

Note: Italicized type is notes to the experimenter. Plain type is what should be told to the participants. It is not necessary to follow the scripted parts word for word although it is important that the participants do receive this information. The important point is that participants attain the competencies listed on the task training competency checklists.

I. In this training segment, you will learn the basics of how to fly the F22 simulator.

II. Begin Basic Maneuvering

In the first part of this mission you will learn the basic operations of the joystick, throttle, and how to read information on the Heads-up-Display, or HUD. Then you will learn how to perform the following maneuvers with the joystick: 1) climbing and diving; 2) rolling from side to side; and 3 ) turning left and right. You will also learn how to speed up and slow down the plane. Finally, you will learn how to look around in the cockpit.

A. Click on "Basic Maneuvering" to begin the simulation.

B. Pause the game as it begins, and point out the following (use pictures of the HUD to point these out):

1. Point out the roles of the Weapons Specialist and the Pilot:

The Pilot is responsible for maneuvering the aircraft, controlling its speed, and firing weapons.

The Weapons Specialist is responsible for the aircraft's radar settings, choosing the appropriate weapons, releasing chaffs and flares, and communication system.

2. As the simulation begins, ask participants to push "SHIFT and PILOT AIDS." This brings up two radar screens. The screen on the bottom left shows your plane in relation to other planes in the sky. The second screen, on the bottom right shows your plane in relation to the flight plan. Notice that on the latter of these, there are lines with numbered circles on them. These are waypoints. You will be starting each mission headed for waypoint one. You should keep the flight path in view so that you can navigate. The waypoints serve as reference points that are helpful in locating targets. The pilot is responsible for watching the display on the left. The Weapons Specialist is responsible for watching the display on the right. The W.S. should routinely update the pilot on their relation to the flight route. It is also the W.S. responsibility to control the range of the pilot aids, i.e., zoom-in, zoom-out.

3. Altitude Display, right of the HUD's center.

4. Speed Display, just left of the HUD's center.

5. The Horizon bars. These are two long "L" shaped bars. When these are in the middle of the screen, the plane is flying level.

6. The Pitch Ladder. These are smaller " $L$ " shaped bars above and below the Horizon bar. They have numbers to the left of them. The numbers tell you what angle the plane is pointed up or down.

7. The HUD mode. At the top of the HUD display it currently reads "AA HUD." This stands for Air-to-air HUD. In this mode you can obtain information about, target and fire at enemy aircraft. You can switch the HUD mode by pressing "HUD MODE" on the keyboard. Press "HUD MODE" now. Notice that it now reads "AG HUD." This stands for Air-to-ground HUD. In this mode you can target and fire at enemy ground targets. Explain to them how they will not be responsible for air-to-ground because they are the air-to-air team. 
8. The clock. There is a clock at the bottom left of the screen. In later missions, you will use this clock to accomplish certain goals within a given amount of time. The weapon specialist will have to take responsibility for watching this clock.

C. Release pause on the game. Allow the participants to practice maneuvering the plane.

D. Demonstrate the following, using a toy plane as visual aid:

1. Climbing - Pull the joystick back. Notice that the pitch ladder moves. Identify the angle you are flying at. Notice the altimeter rising and the speed falling. Pull back until the pitch ladder reads " 80 " for an eighty degree angle of ascent. Point out that the speed is rapidly falling. Allow the participants to fly nearly straight up until their planes loose momentum and stall. If your plane should stall, you need to point the nose down to gain speed. As the plane tumbles, it will gain speed, and at around 200 knots it will gain maneuverability again. Level the plane off.

2. Diving - Now push the joystick forward. Notice the pitch ladder is now displaying negative numbers for a negative angle from level flight. Notice that the altimeter is falling and the speed is rising.

3. Straighten the plane out so that you are flying level.

4. Pull the joystick to the right. Hold it to the right. Notice that the plane is rolling but is still flying in the same direction. Straighten the plane out again. Simply pushing the joystick to the left or right will not allow you to turn the plane.

5. Turning - To turn the plane requires two steps. We will first practice a right turn. First, pull the joystick to the right until the plane is on its side or perpendicular to the ground. Now, pull back on the joystick. Straighten the plane and turn to the left.

6. Speed Control - To accelerate, push the throttle all the way forward. Notice that the Engine Power display in the bottom right of the HUD now reads "ENG 140\%." You are now flying at 140 percent of the engine's capacity, the aircraft's maximum throttle. This is the F22's fastest setting, but flying at $140 \%$ for too long could cause you to run out of fuel and crash. Notice that the speed is increasing. Now, pull the throttle all the way back. Notice the Engine Power now reads "ENG 51\%." This is the engine's lowest setting. Notice that your air speed is decreasing. At this setting, the aircraft will soon loose momentum and tumble towards the ground. The normal setting is at $100 \%$ power. The F-22 performs best when flying at between 400 and 550 knots per hour.

7. Braking - You've just seen how to slow the plane down using the throttle, another way to quickly slow the plane down is by using an airbrake. Using your pinky finger, push the maroon button on the bottom side of the joystick that is facing away from you. Notice that when you push it "ABK ON" appears at the bottom right side of the screen. Notice that the plane is slowing down. Now push the button again. Notice that the HUD now reads "ABK OFF."

8. Looking around - You can use a switch on the joystick to simulate head moverment. You can use this switch to "look around" in the cockpit and out of the plane. Using your thumb, move the round gray knob on the joystick. Notice that its movement parallels that of your virtual head. You can push the red button, next to the gray knob, to snap back to the front view.

9. Now, fly towards the ground. At 2500 feet, level off and fly straight. Attempt to fly as close as you can to the ground. Make sure they notice the "ground proximity warning" and PULL UP on the HUD. When you hear this warning, you should pull up quickly to avoid crashing. Notice that you need to anticipate changes in the altitude of the ground.

E. Basic Maneuvering Competencies:

Here, we want to make sure the participants have learned the important task competencies for this mission. The experimenter should ask them to do the following. If the participants cannot do so, show them how and quiz them again later.

1. Now I would like you to climb to 25,000 feet.

2. W.S. zoom in and zoom out pilot aids

3. Now dive to 15,000 feet.

4. Accelerate to 550 knots. 
5. Slow down to 300 knots.

6. Look to the left of your plane...and now look straight ahead.

Then ask them, "What is your..."

7. Altitude.

8. Speed.

Grab the joystick and put the plane at a 30 degree angle.

9. Are you flying up or down...and at what angle?

10. Stall out their plane and have them recover.

III. Navigating a Flight Route.

The second practice mission builds upon the skills that you have developed during your previous mission and introduces you to new concepts: 1) following a flight plan and waypoints; and; 2) identifying other aircraft.

Click on "Navigating a Flight Route" to begin the simulation.

Push "shift" and "pilot aids."

Release the pause on the game. Instruct the participants to fly towards waypoint two at 20,000 feet.

Pause the game. When you fly directly over a waypoint, your computer will automatically switch the HUD settings to the next waypoint. However, in later missions, you may not be able to fly directly over a waypoint due to the need to attack a target or if you are under attack. In these cases, you can manually switch to the next waypoint by pressing ADVANCE WAYPOINT. Point out how the circle around the next waypoint changes on the right pilot's aid. If you goof and press W more than once and accidentally advance to the wrong waypoint, you can press "WAYPOINT BACK" to move the waypoint back one. Have them press WAYPOINT BACK and watch the waypoint indicators.

Have the subjects drop to 2000 feet and fly towards waypoint three at exactly 500 knots. When it looks like the participants have the hang of it, end the mission.

F. Navigating a Flight Route Competencies.

1. Take the stick and put the participants off course. Turn off their pilot aids and switch the HUD to $A G$. Fly towards waypoint two.

2. If the participants did not demonstrate how to do so in finding their way back to waypoint two, ask them to:

a. Switch to AA HUD.

b. Advance the waypoint.

c. Move the waypoint back.

3. If the participants are on course, ask them how they know that.

4. Ask them:
a. What is your speed?
b. What is your altitude?
c. What do you look at to find the next waypoint?

IV. Basic Air-to-Air.

In this part of the training, you will learn air-to-air combat tactics including: 1) How to identify enemy air targets; 2) How to target them and 3) How to fire air-to-air weapons.

A. Click on "Basic Air- to-Air" to begin the simulation and put EMCON to level 4.

B. Remind participant to press "shift" and "pilot aids". Since your objective here is to destroy air targets, you must be in the AA HUD mode.

C. When the mission starts, pause the game and increase the range of the pilot aid (zoom out) to about 50 miles. This makes it possible to see and point out the planes. There are several types of enemy air targets. In this mission, you will attack enemy planes called Su-27s and enemy helicopters called M124 's. The enemy planes and helicopters are displayed on the HUD as triangles and on your radar screen as red triangles. The enemy planes are threatening because they can shoot at you. You also will encounter the enemy helicopters on your missions and these are non-threatening (they cannot shoot at you). However you should still try to shoot them down to clear the airspace. Notice that there are also 
green and blue triangles. The blue triangles signify neutral air units such as civilian planes. Do not shoot these planes.

D. Unpause the game. Add targets to the shoot list by pressing "ADD TARGET." Targets that aren't in the shoot list cannot be fired at. Identify the type of plane that is approaching by looking at the infrared display just below the HUD. Use Pictures on the wall to show what they look like to the players. There will also be neutral aircraft in the area. You must not fire at any of these neutral units. Any plane that's name begins with SU is a threatening enemy target meaning that these planes will attempt to shoot you down. Therefore, you must try to destroy them before they destroy you. Any helicopter that begins with $\mathrm{MI}$ is a non threatening target. All other planes such as the 767 , the 747 , and the Learjet are neutral.

E. Now that the plane is targeted, notice that a circle has appeared around it on the HUD display. When you fire missiles, they will only lock onto this target. If you have more than one target on your screen and you push "ADD TARGET", the computer automatically selects the one closest to you. If you do not want to fire at the target, you must push "CYCLE TARGET" to cycle to another target.

F. The distance to the air target is displayed next to a vertical bar near the bottom right side of the HUD. Next to this bar, the distance is displayed in nautical miles.

G. We want to shoot the air target, so we have three choices of weapons. (As you discuss their weapons choices, have them cycle the weapons by pressing backspace so that the appropriate weapon appears on the screen. Point out in the HUD where the weapon's name and number available are displayed Also, remind them that each time they switch weapons they must press "Add Target" again.) The first is CANNONs. These are basically bullets. To use CANNONs you must be perfectly lined up with the target and within two miles. These should be used only as a last resort. Another choice is to use the AIM9xs. These are heat-seeking missiles. They are lethal within about 10 miles. The third weapon is the AIM-120C AMRAAM. This is a long-range radar guided missile. It has a range of 31 miles. You can switch between these missiles by pressing the "CHANGE AA WEAPONS" key. Do that now several times. Watch the HUD display to see what weapons you have selected.

H. Select the AIM9x. A heat seeking box will appear on the screen. This box will enclose the circle representing the enemy aircraft on the HUD display when you have "locked on" to the target. When within firing range, a circle will appear in the middle of the HUD. The larger the circle is, the better the chances are of hitting the target with an AIM9X. Also, when you are within the optimum range, the words "SHOOT" will appear on the HUD and you will hear "SHOOT SHOOT." To fire the AIM9x, pull the trigger on the joystick.

I. After you fire a missile at a plane, an " $X$ " will appear over the circle. That means that the missile is on its way to the target. Do not fire any additional missiles unless the " $\mathrm{X}$ " disappears. If it does, that means that the plane has outmaneuvered the missile. You will have a limited number of missiles in these missions and should not waste them.

J. Have participants try using both the AIM-120C and the AIM9x missiles.

$K$. Instruct participants to continue along the waypoints. Have them add, cycle through and identify targets as they go. If they haven't already done so, ask participants to fly towards an enemy plane. To the left of waypoint four, there should be two SU27's. Also, at waypoint 5, 2 SU27s will appear. Remember to point out the threat rings of the plane's radar to the participants. Tell them that within these circles, the enemy can "see you" and if they can see you they can shoot at you. When a plane fires a missile at them, demonstrate evasive maneuvering techniques.

1) Turning away from enemy plane

2) Launching chaffs and flares.

K.. Allow participants to practice as needed.

L. Basic Air-to-Air Competencies Ask participants to:

1. Point out an enemy air target on the HUD and the pilot aids.

2. Point out a targeted enemy air target.

3. Which targets are the threatening targets? Non threatening?

4. Where are you in relation to the target?

5. Identify the range of the target.

6. Which weapon should be used to fire at the target? 
7. How many missiles do you have left?

8. Are you on course? If not, get back on course.

9. What is your speed?

10 . What is your altitude? 


\section{Appendix C}

\section{Task Training Script - Air to Ground Flight Team}

\section{ACES Task Training Protocol (Air-to-Ground)}

Last Updated: 10/22/01

Note: Italicized type is notes to the experimenter. Plain type is what should be told to the participants. It is not necessary to follow the scripted parts word for word although it is important that the participants do receive this information. The important point is that participants attain the competencies listed on the task training competency checklists.

I. In this training segment, you will learn the basics of how to fly the F22 simulator.

II. Begin Basic Maneuvering

In the first part of this mission you will learn the basic operations of the joystick, throttle, and how to read information on the Heads-up-Display, or HUD. Then you will learn how to perform the following maneuvers with the joystick: 1) climbing and diving; 2) rolling from side to side; and 3) turning left and right. You will also learn how to speed up and slow down the plane. Finally, you will learn how to look around in the cockpit.

A. Click on "Basic Maneuvering" to begin the simulation.

B. Pause the game as it begins, and point out the following (use pictures of the HUD to point these out):

1. Point out the roles of the Weapons Specialist and the Pilot:

The Pilot is responsible for maneuvering the aircraft, controlling its speed, and firing weapons.

The Weapons Specialist is responsible for the aircraft's radar settings, choosing the appropriate weapons, releasing chaffs and flares, and communication system.

2. As the simulation begins, ask participants to push "SHIFT and PILOT AIDS." This brings up two radar screens. The screen on the bottom left shows your plane in relation to other planes in the sky. The second screen, on the bottom right shows your plane in relation to the flight plan. Notice that on the latter of these, there are lines with numbered circles on them. These are waypoints. You will be starting each mission headed for waypoint one. You should keep the flight path in view so that you can navigate. The waypoints serve as reference points that are helpful in locating targets. The pilot is responsible for watching the display on the left. The Weapons Specialist is responsible for watching the display on the right. The W.S. should routinely update the pilot on their relation to the flight route. It is also the W.S. responsibility to control the range of the pilot aids, i.e., zoom-in, zoom-out.

3. Altitude Display, right of the HUD's center.

4. Speed Display, just left of the HUD's center.

5. The Horizon bars. These are two long "L" shaped bars. When these are in the middle of the screen, the plane is flying level.

6. The Pitch Ladder. These are smaller "L" shaped bars above and below the Horizon bar. They have numbers to the left of them. The numbers tell you what angle the plane is pointed up or down.

7. The HUD mode. At the top of the HUD display it currently reads "AA HUD." This stands for Air-to-air HUD. Explain to them how they will not be responsible for air-toair because they are the air-to-ground team. In this mode you can obtain information about, target and fire at enemy aircraft. You can switch the HUD mode by pressing "HUD MODE" on the keyboard. Press "HUD MODE" now. Notice that it now reads "AG HUD." This stands for Air-to-ground HUD. In this mode you can target and fire at enemy ground targets. 
8. The clock. There is a clock at the bottom left of the screen. In later missions, you will use this clock to accomplish certain goals within a given amount of time. The weapon specialist will have to take responsibility for watching this clock.

C. Release pause on the game. Allow the participants to practice maneuvering the plane.

D. Demonstrate the following, using a toy plane as visual aid:

1. Climbing - Pull the joystick back. Notice that the pitch ladder moves. Identify the angle you are flying at. Notice the altimeter rising and the speed falling. Pull back until the pitch ladder reads " 80 " for an eighty degree angle of ascent. Point out that the speed is rapidly falling. Allow the participants to fly nearly straight up until their planes loose momentum and stall. If your plane should stall, you need to point the nose down to gain speed. As the plane tumbles, it will gain speed, and at around 200 knots it will gain maneuverability again. Level the plane off.

2. Diving - Now push the joystick forward. Notice the pitch ladder is now displaying negative numbers for a negative angle from level flight. Notice that the altimeter is falling and the speed is rising.

3. Straighten the plane out so that you are flying level.

4. Pull the joystick to the right. Hold it to the right. Notice that the plane is rolling but is still flying in the same direction. Straighten the plane out again. Simply pushing the joystick to the left or right will not allow you to turn the plane.

5. Turning - To turn the plane requires two steps. We will first practice a right turn. First, pull the joystick to the right until the plane is on its side or perpendicular to the ground. Now, pull back on the joystick. Straighten the plane and turn to the left.

6. Speed Control - To accelerate, push the throttle all the way forward. Notice that the Engine Power display in the bottom right of the HUD now reads "ENG 140\%." You are now flying at 140 percent of the engine's capacity, the aircraft's maximum throttle. This is the F22's fastest setting, but flying at $140 \%$ for too long could cause you to run out of fuel and crash. Notice that the speed is increasing. Now, pull the throttle all the way back. Notice the Engine Power now reads "ENG 51\%." This is the engine's lowest setting. Notice that your air speed is decreasing. At this setting, the aircraft will soon loose momentum and tumble towards the ground. The normal setting is at $100 \%$ power. The F-22 performs best when flying at between 400 and 550 knots per hour.

7. Braking - You've just seen how to slow the plane down using the throttle, another way to quickly slow the plane down is by using an airbrake. Using your pinky finger, push the maroon button on the bottom side of the joystick that is facing away from you. Notice that when you push it "ABK ON" appears at the bottom right side of the screen. Notice that the plane is slowing down. Now push the button again. Notice that the HUD now reads "ABK OFF."

8. Looking around - You can use a switch on the joystick to simulate head movement. You can use this switch to "look around" in the cockpit and out of the plane. Using your thumb, move the round gray knob on the joystick. Notice that its movement parallels that of your virtual head. You can push the red button, next to the gray knob, to snap back to the front view.

9. Now, fly towards the ground. At 2500 feet, level off and fly straight. Attempt to fly as close as you can to the ground. Make sure they notice the "ground proximity warning" and PULL UP on the HUD. When you hear this warning, you should pull up quickly to avoid crashing. Notice that you need to anticipate changes in the altitude of the ground.

E. Basic Maneuvering Competencies:

Here, we want to make sure the participants have learned the important task competencies for this mission. The experimenter should ask them to do the following. If the participants cannot do so, show them how and quiz them again later.

1. Now I would like you to climb to 25,000 feet.

2. W.S. zoom in and zoom out pilot aids

3. Now dive to 15,000 feet.

4. Accelerate to 550 knots. 
5. Slow down to 300 knots.

6. Look to the left of your plane... and now look straight ahead.

Then ask them, "What is your..."

7. Altitude.

8. Speed.

Grab the joystick and put the plane at a 30 degree angle.

9. Are you flying up or down...and at what angle?

10. Stall out their plane and have them recover.

III. Navigating a Flight Route.

This practice mission builds upon the skills that you have developed during your previous mission and introduces you to new concepts: 1) following a flight plan and waypoints; and; 2) identifying other aircraft.

A. Click on "Navigating a Flight Route" to begin the simulation.

$B$. Push "shift" and "pilot aids."

C. Release the pause on the game. Instruct the participants to fly towards waypoint two at 20,000 feet. Pause the game. When you fly directly over a waypoint, your computer will automatically switch the HUD settings to the next waypoint. However, in later missions, you may not be able to fly directly over a waypoint due to the need to attack a target or if you are under attack. In these cases, you can manually switch to the next waypoint by pressing ADVANCE WAYPOINT. Point out how the circle around the next waypoint changes on the right pilot's aid. If you goof and press W more than once and accidentally advance to the wrong waypoint, you can press "WAYPOINT BACK" to move the waypoint back one. Have them press WAYPOINT BACK and watch the waypoint indicators. Have the subjects drop to 2000 feet and fly towards waypoint three at exactly 500 knots. When it looks like the participants have the hang of it, end the mission.

D. Navigating a Flight Route Competencies.

1. Take the stick and put the participants off course. Turn off their pilot aids and switch the HUD to AA. Fly towards waypoint two.

2. If the participants did not demonstrate how to do so in finding their way back to waypoint two, ask them to:

a. Switch to AG HUD.

b. Advance the waypoint.

c. Move the waypoint back.

3. If the participants are on course, ask them how they know that.

4. Ask them:

a. What is your speed?

b. What is your altitude?

c. What do you look at to find the next waypoint?

IV. Basic Air-to-Ground.

In the first part of this mission you will learn air-to-ground combat tactics including: 1) how to identify enemy ground targets; 2) how to target enemy ground vehicles; 3) how to fire air-toground weapons; and 4) how to identify surface-to-air weapons, or SAMS and the importance of avoiding them.

A. Click on "Basic Air-to-Ground" to begin the simulation and switch EMCON to level 4.

B. Push "shift" and "pilot aids." Since your objective here is to destroy ground targets, you must be in the AG HUD mode. Switch to this mode by pressing "CHANGE AG WEAPONS" or the "HUD MODE" key until you see "AG HUD" at the top of the HUD.

C. Have participants follow the waypoints. At waypoint 3, point out the friendly ground forces and have participants cycle through them and try to identify them. Then, move on to waypoint 4. As the subjects approach the first enemy ground target, pause the game. There are several types of enemy ground targets. Targets will include tanks, and SAM sites. The tanks are displayed on the HUD as crosses and are non threatening targets This means they cannot 
shoot at you. The SAM sites are displayed as pentagons They are threatening targets which means they are surface to air weapons that can fire at you. So you must destroy them before they destroy you. These are the only type of ground target that can also fire at you.

D. Notice that we are approaching a ground target that has not been targeted. The dotted lines indicate that this target hasn't been added to our shoot list. Targets that aren't in the shoot list cannot be fired at. Add it to the shoot list by pressing "Add Targets,". Identify the type of ground target we are approaching by looking at the infrared display just below the HUD. Your mission will be to destroy enemy ground units. Use pictures of these to show what they look like to the players. Have participants approach and target the SAM that is at waypoint 4. When you fire missiles, they will only lock onto this target. If you have more than one target on your screen and you push "ADD TARGET" to target, the computer automatically selects the one closest to you. If you do not want to fire at the target because it may be a jeep, you must push "CYCLE TARGET" to cycle to another target.

E. The distance to the ground target is displayed next to a vertical bar near the bottom right side of the HUD. Next to this bar, the distance is displayed in nautical miles.

F. We want to shoot the ground target, so we have three choices of weapons. (As you discuss their weapons choices, have them cycle the weapons by pressing backspace so that the appropriate weapon appears on the screen. Point out in the HUD where the weapon's name and number available are displayed. Also, remind them that each time they switch weapons they must press "Add Target" again) The first is CANNONs. This is the same weapon we discussed in the last practice mission. To use CANNONs you must be perfectly lined up with the target and within two miles. These should be used only as a last resort. Another choice is the AGM 88's. These are specially designed to lock onto SAM sites. Our other choice is the AGM65's. These are heat-seeking missiles lethal within about 10 miles. You should use these weapons for the tanks. They can however shoot SAMS at a closer range. Emphasize that they should save the AGM 88 's for SAM sites and use the AGM 65 's for the tanks.

G. Select the AGM65. When you are within the optimum range, the words "SHOOT" will appear on the HUD and you will hear "SHOOT SHOOT." To fire the AGM88, pull the trigger on the joystick. After you fire at one target, the computer will automatically select the next closest ground target. You should check your infrared screen every time you fire to make sure that a ground target objective is what is targeted. Every time you fire, the computer will automatically advance to the next target in the shoot list. Sometimes, when a group of tanks are right next to each other, it appears that you are firing at the same target. If you pulled the trigger, heard the missile fire, or saw the missile leave the plane then the target in the infrared display will not be the same that you just fired at.

H. An " $X$ " will appear over a ground target after it has been fired at. Do not waste missiles firing at the same target because you only have a limited number of missiles.

1. Instruct participants to continue along the waypoints. Have them add, cycle through and identify targets as they go along. If they haven't already done so, ask them to fly towards a SAM site. There are SAM sites at waypoint 5. Point out the threat rings of the SAM's radar to the participants. Within these circles, the SAM can "see" you. And if they can see you, they can shoot at you. When a SAM fires a missile at them, demonstrate evasive maneuvering techniques

1. Turning away from the SAM, moving erratically.

2. Launching chaffs and flares.

J. Allow participants to practice as needed.

$K$. Basic Air-to-Ground Competencies

1. What weapon is currently selected?

2. How many do you have?

3. Where are the enemy ground targets in relation to you?

4. Pick one of the ground targets on the HUD and ask them "What kind of target is that (e.g., a tank, fuel truck, threatening non threatening, etc.)?" Participants should use their MFD (or infrared display) to ID the target. 
5. Hit the "C" key a number of times to cycle through the ground targets. Ask them where the threatening and non threatening targets are. They should look for the target with the circle around it on the HUD and pilot aids.

6. Ask them to pick the appropriate weapon and to fire at the target when ready. They should pick a AGM 88 if it is a SAM site and a AGM 65 if it is anything else. They should wait until they here and see "SHOOT SHOOT" to fire.

7. After firing, ask them how they know a missile is heading towards the target. (An "X" will appear over the target.)

8. Tell them to pretend that a missile has been fired at them. Ask them to show you how they would keep the missile from hitting them. (They should turn and launch chaffs and flares. 


\section{Appendix D}

\section{Algerian Anarchy Mission Briefing}

\section{ALGWRIMN ANALCIVY}

\section{YOUR MISSION}

Rebels are attempting to over throw the Algerian government The government has recuested $U$ is. intervention to stop the revolt and restore order to the nation. The rebels have fortified Fue areas of the Algerian desert critcal to thet occupation of the capitol Your mission is to destroy rebel air and ground forces in these key locations while ensuring the safaly of you strike teami.

\section{FLIGHT INFORMATION}

* Wolf team should descend from their initial atitude of $5000 \mathrm{ft}$ to an alitude $2000 \mathrm{ft}$. Woll should generally maintain an airspeed of approximately 450 knots

- In order to destroy targets, Wolf team should climb to an altitude of $5000 \mathrm{ft}$ but should then return to $2000 \mathrm{ft}$ when enemy targets or threats have been destroyed.

- Eagle team should generally maintain their initial altitude of $10,000 \mathrm{ft}$ and airspeed of approximately $450 \mathrm{knots}$ throughout the mission:

YOU HAVE 20 MINUTES TO COMPLETE THIS MISSION 


\section{ALGERIAN ANARCHY}

\section{YOUR MISSION OBNECTUES AND SCORING}

\section{Objective 1: Ensure the survival of your F-22 strike team.}

Wolf and Eagle foach):

$$
\begin{aligned}
& \text { Dead }=0 \text { points } \\
& \text { Damaged }=20 \text { points } \\
& \text { Undamaged }=30 \text { points }
\end{aligned}
$$

POUTS POSSIBLE FOR FIRST OBUECTIE $=60$

Obiective 2: Destroy enemy targets near twe bases of operstion:

Wolf Team Targets $(120$ points possible): $\quad$ SANts $=20$ points each

Tanks $=10$ points each

Eagle Team Targets (120 points possible): $3 U-27 \mathrm{~s}=20$ points each $M 4-24 s=15$ points each

Eneny Base Destrustion (100 points possible): . Destroy Alt targets at a base

\begin{tabular}{|c|c|}
\hline WP2 & 3 Tanks 2 Mi-24s \\
\hline WP3: & $1 \sin ,+\sin 27$ \\
\hline WP4 & BTanks, 1 SAM \\
\hline Ps & $1 \mathrm{su}-27,2 \mathrm{M} 1 \mathrm{2}-\mathrm{s}$ \\
\hline P6 & IsAM, I SU-27 \\
\hline
\end{tabular}
and you will receive an additional 20 points per base

POINTS POSSIBLE FOR SECOND OBJECTIV $=340$

TOTAL POSSIBLE MTS MISSION SCOFE= AN0 


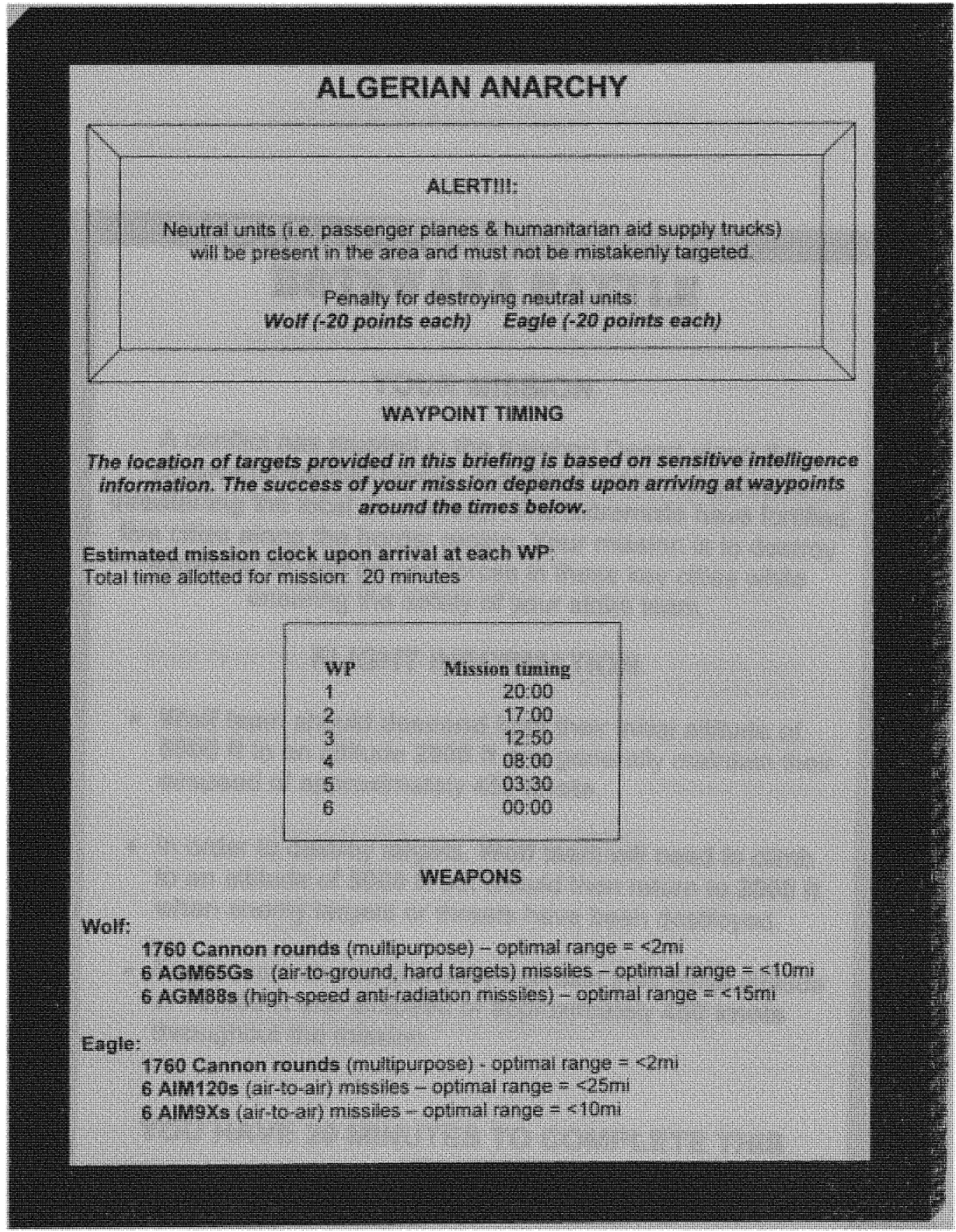


Appendix E

Botswana Battle Mission Briefing

\section{BOTSWANA BATTLI?}

\section{YOUR MISSION}

A conflict has erupted in the Kalahari Desert along the Botswana/Nambia border. A political extremist group is threatening the local democracy. The extremists have fortified five cities along the border region. Your mission is to destroy extremist air and ground forces in these key cities while ensuring the safety of your strike team

\section{FLIGHT INFORMATION}

- Wolf team should descend from their initial altitude of $5000 \mathrm{ft}$ to an altitude $2000 \mathrm{ft}$ and generally maintain their airspeed of approximately 450 knots.

- In order to destroy targets, Wolf team will need to climb to an altitude of $5000 \mathrm{ft}$ but should then return to $2000 \mathrm{ft}$ when enemy targets or threats have been destroyed.

- Eagle team should generally maintain their initial altitude of $10,000 \mathrm{ft}$ and airspeed of approximately $450 \mathrm{knots}$ throughout the mission.

YOU HAVE 20 MINUTES TO COMPLETE THIS MISSION 


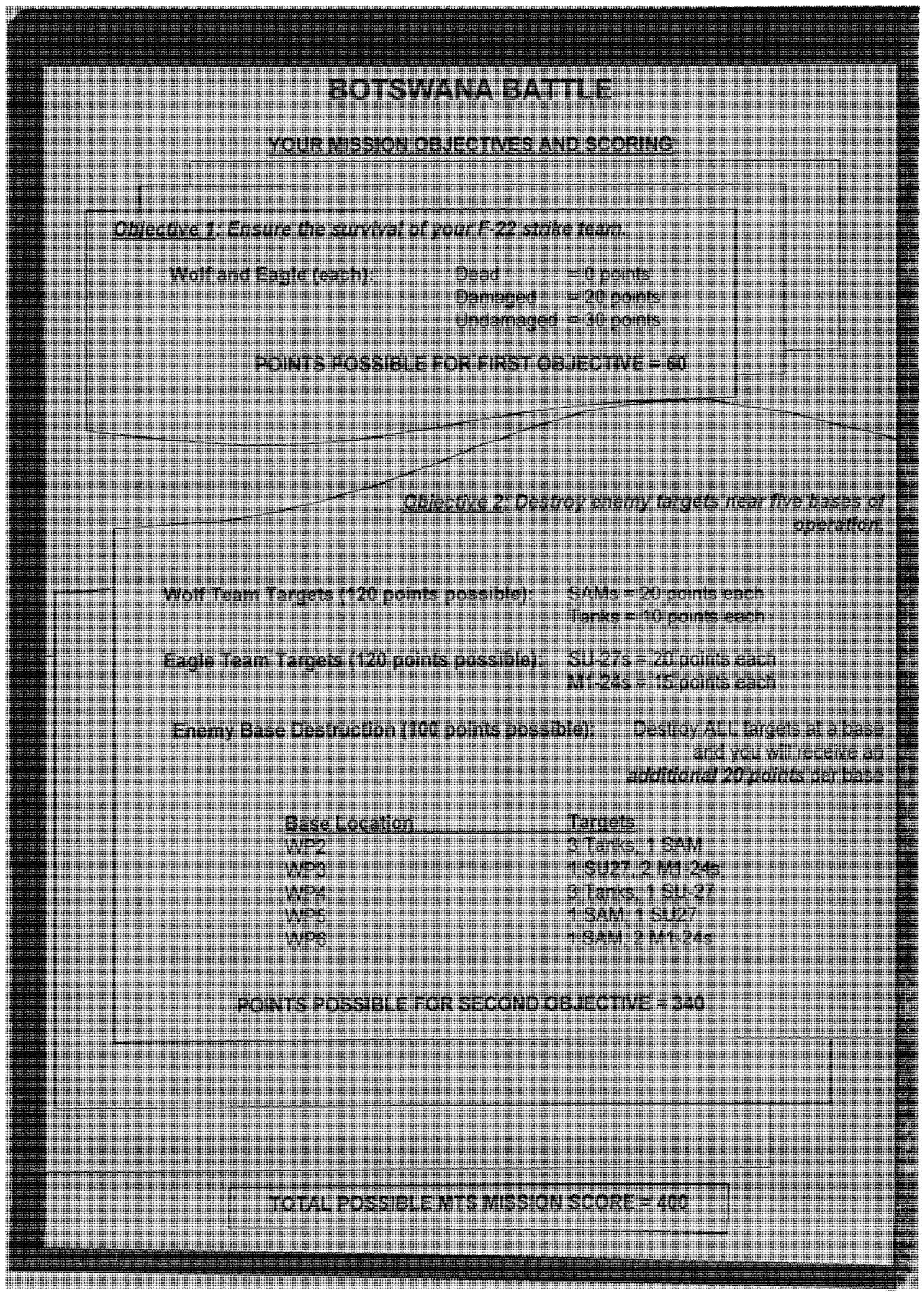




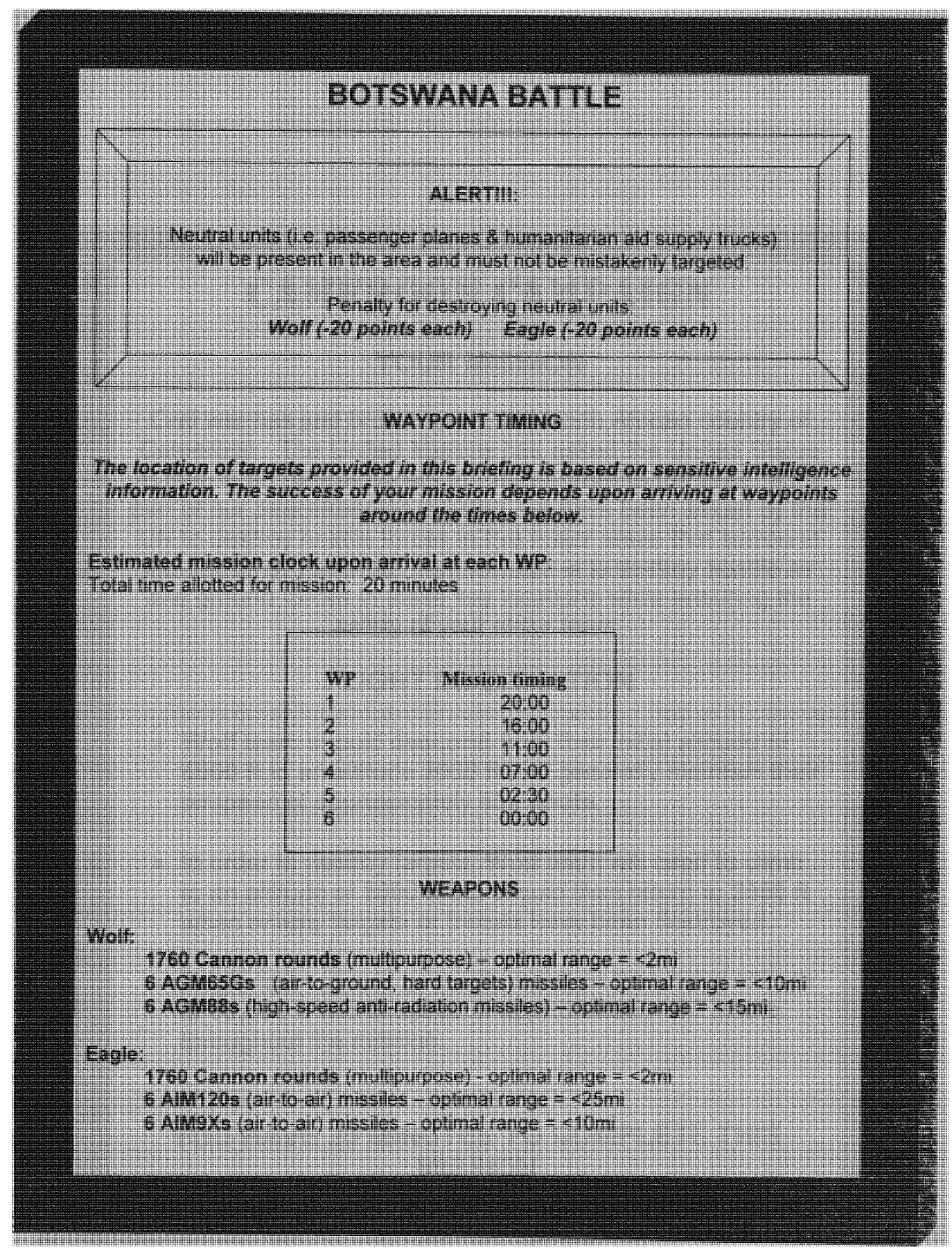




\section{Appendix F}

\section{Cameroon Campaign Mission Briefing}

\section{CAMEROON CAMPAIGN}

\section{YOUR MISSION}

Civil war has just broken out in the North African country of Cameroon. The United Nations has asked the United States to step in as peacekeepers to restore order to the area. As a part of our peacekeeping mission, we have been asked by the UN to destroy hostile forces in five major areas that surround the capitol of Yaounde. Your mission is to destroy hostile air and ground forces in these key locations while ensuring the safety of your strike team.

\section{FLIGHT INFORMATION}

- Wolf team should descend from their initial altitude of $5000 \mathrm{ft}$ to an aititude $2000 \mathrm{ft}$ and generally maintain their airspeed of approximately 450 knots

- In order to destroy targets, Wolf team will need to climb to an altitude of $5000 \mathrm{ft}$ but should then return to $2000 \mathrm{ft}$ when enemy targets or threats have been destroyed.

- Eagle team should generally maintain their initial altitude of $10,000 \mathrm{ft}$ and airspeed of approximately 450 knots throughout the mission

YOU HAVE 20 MINUTES TO COMPLETE THIS MISSION 


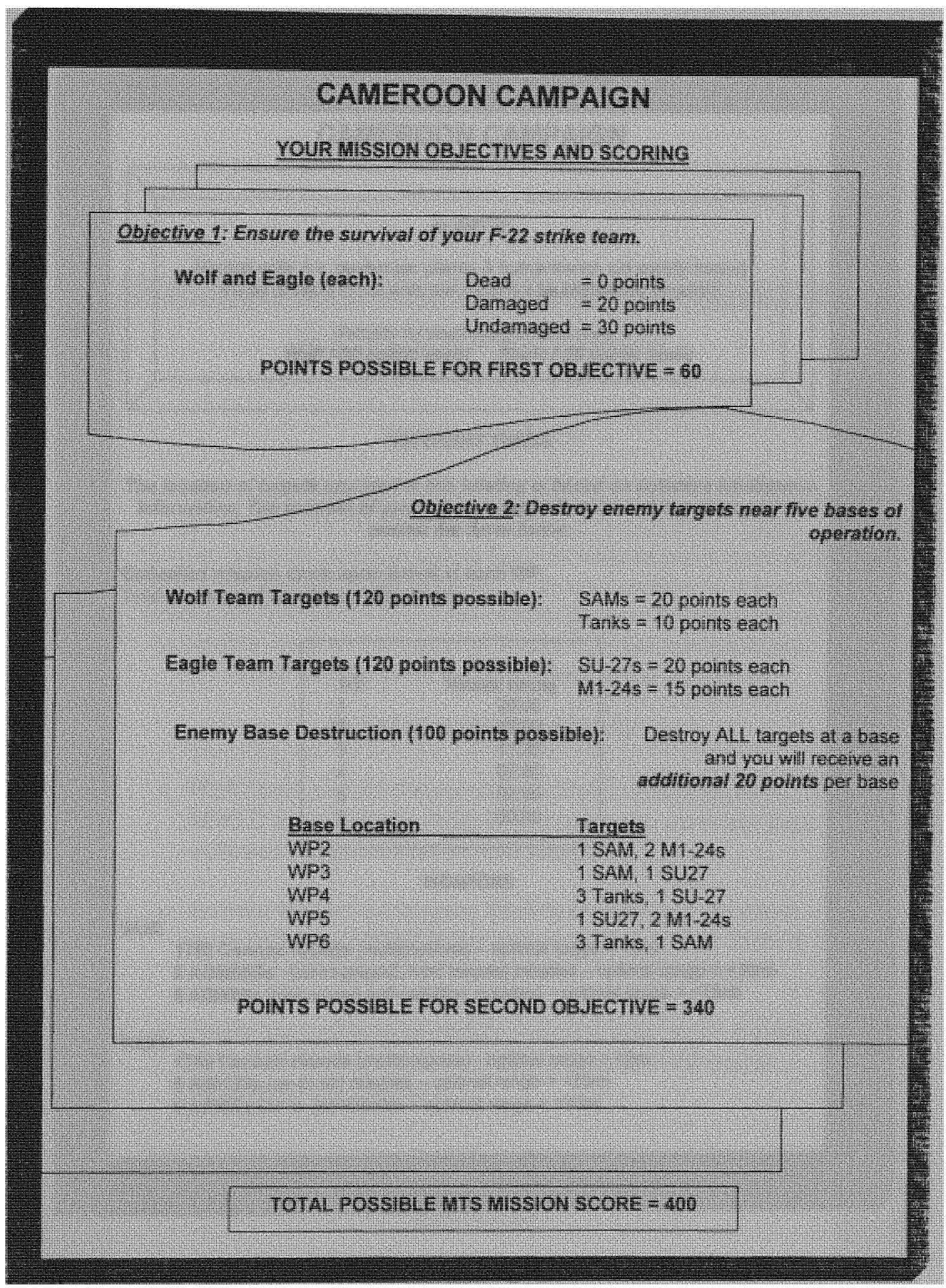




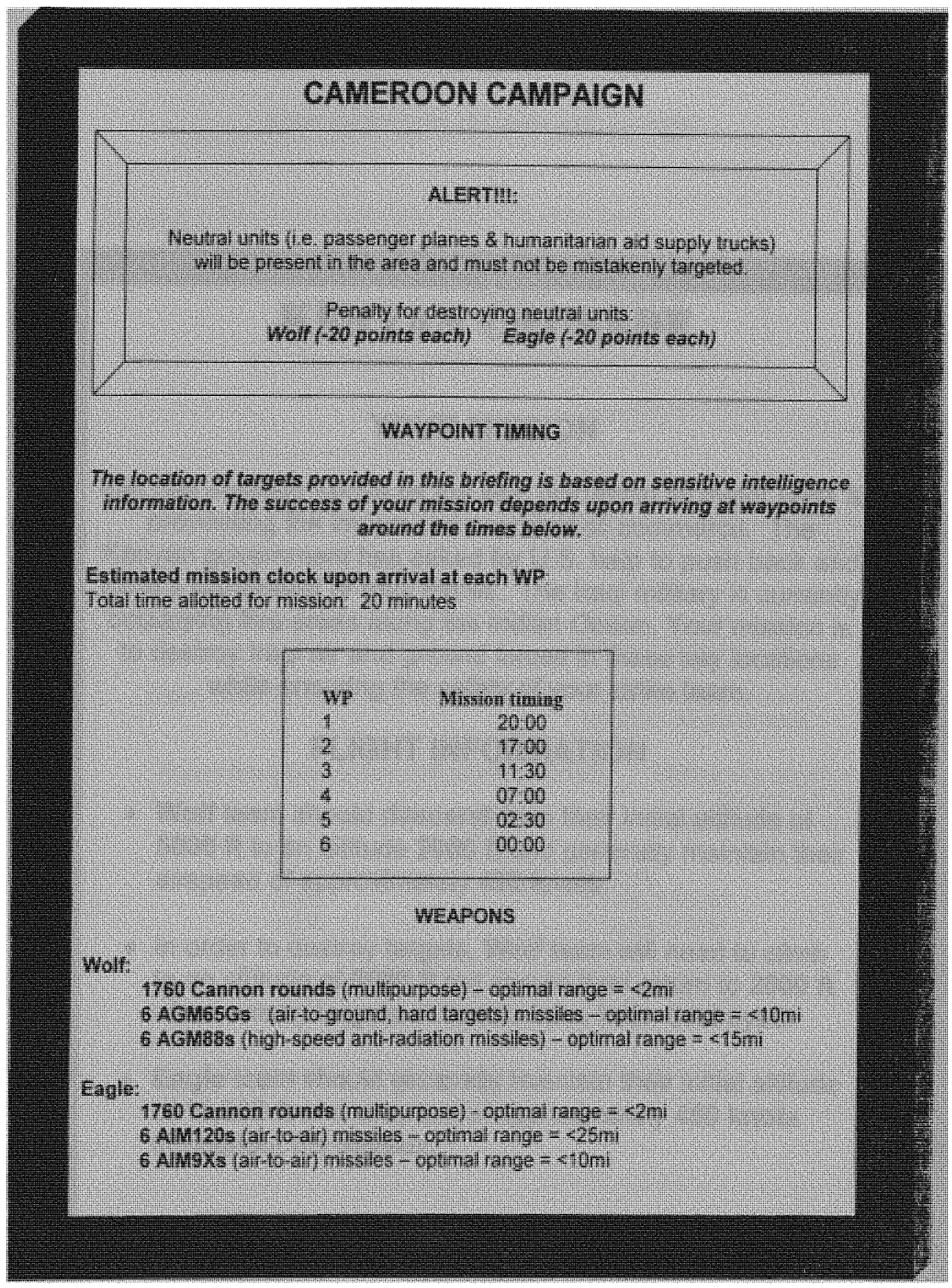




\section{Appendix G}

\section{Kenyan Crusade Mission Briefing}

\section{IKNYAN CRUSADI}

\section{YOUR MISSION}

Iraq has invaded Kenya by the sea, disrupting all major ports \& preventing the import and export of all commerce. The Kenyan government has asked for U.S. help to push back and force a withdrawal of lragi forces. The tragi military is currently occupying five areas along the Indian Ocean. Your mission is to destroy Iraqi air and ground forces in these key locations while ensuring the safety of your strike team.

\section{FLIGHT INFORMATION}

- Wolf team should descend from their initial altitude of $5000 \mathrm{ft}$ to an altitude $2000 \mathrm{ft}$ and generally maintain their airspeed of approximately 450 knots

- In order to destroy targets, Wolf team will need to climb to an altitude of $5000 \mathrm{ft}$ but should then return to $2000 \mathrm{ft}$ when enemy targets or threats have been destroyed.

- Eagle team should generally maintain their initial altitude of $10,000 \mathrm{ft}$ and airspeed of approximately 450 knots throughout the mission

YOU HAVE 20 MINUTES TO COMPLETE THIS MISSION 


\section{KENYAN CRUSADE}

\section{YQUR MISSION OBJECTIVES AND SCORING}

Obiective 1: Ensure the surwival of your F-22 strike team.

\begin{tabular}{|c|c|c|}
\hline Wolf end Eagle (oach): & Dead & trits \\
\hline & Dameged & $=20$ points \\
\hline
\end{tabular}

POINTS POSSIBLE FOR FIRST OEJECTVE $=$ to

Objective 2: Destroy enemy targets near five basts of aperation

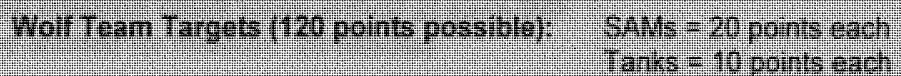

Eagle Team Targets (120 points possible): $\quad$ SU-27 $=20$ points each MAt-24s = 15 points each

Enemy Sase Destruction (tô points possibie): Destroy Alt targets of a base and you will receive an actitional 20 points per wase

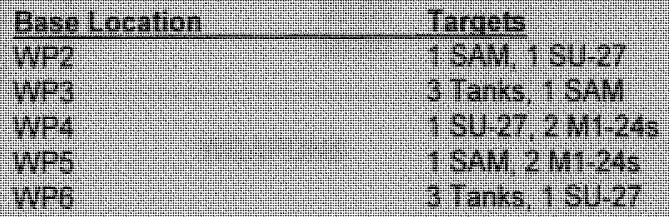

PONTS POSSIBLE FOR SECOND OBUECTVE $=340$

TOTAL POSSISLE ATS HISSION SCORE $=400$ 


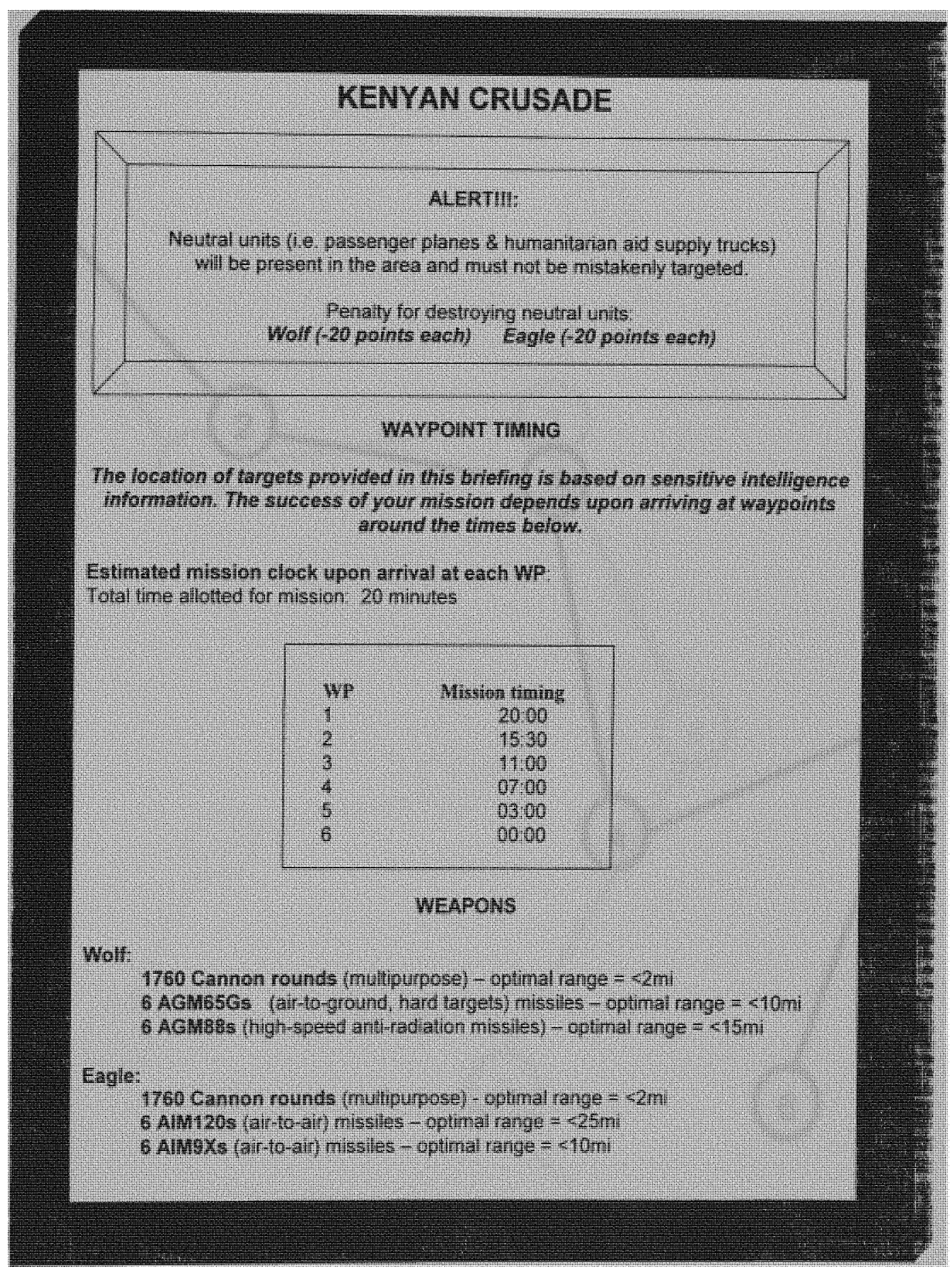


Appendix $\mathbf{H}$

Algerian Anarchy Mission Map

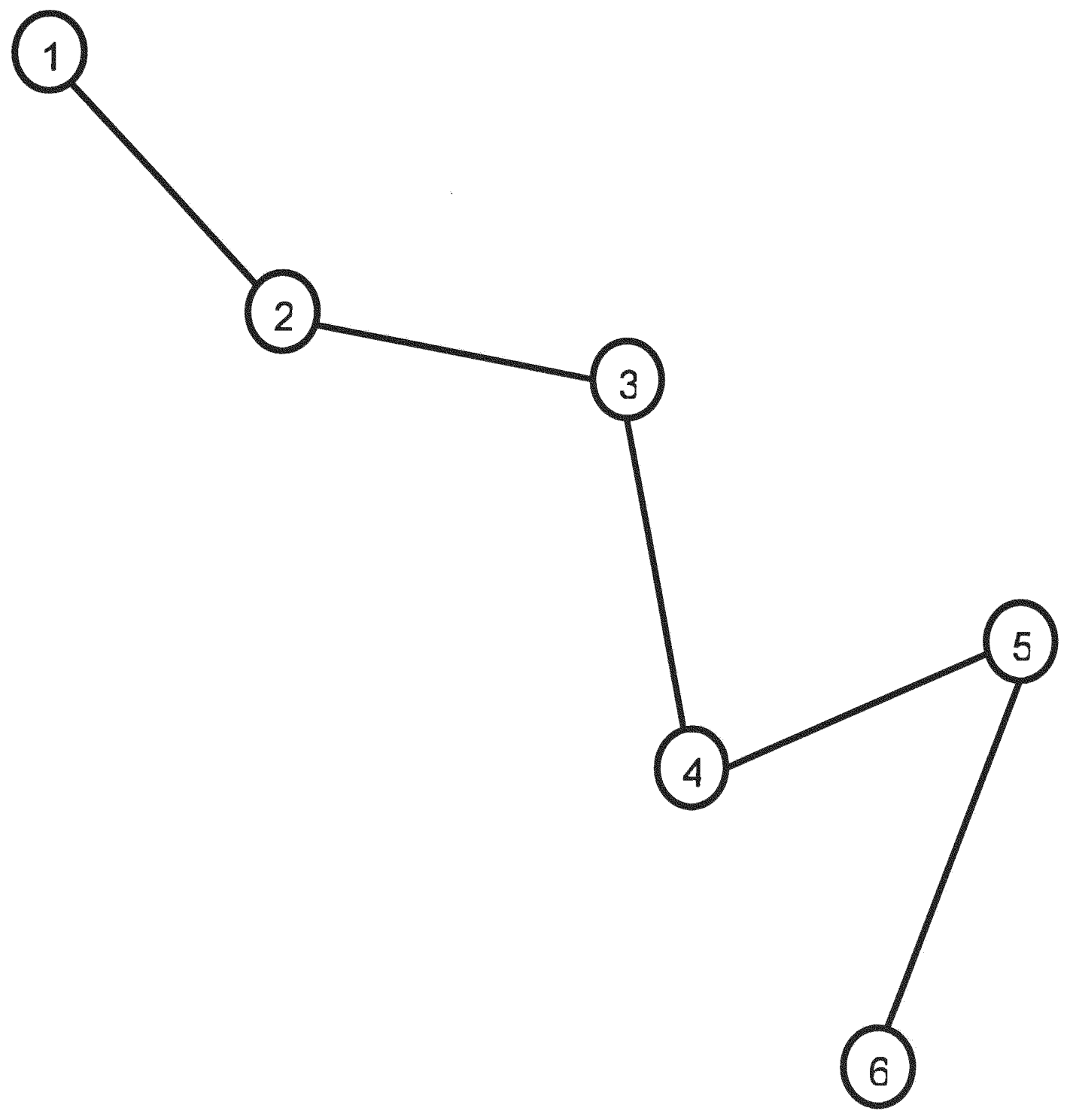




\section{Appendix I}

Botswana Battle Mission Map

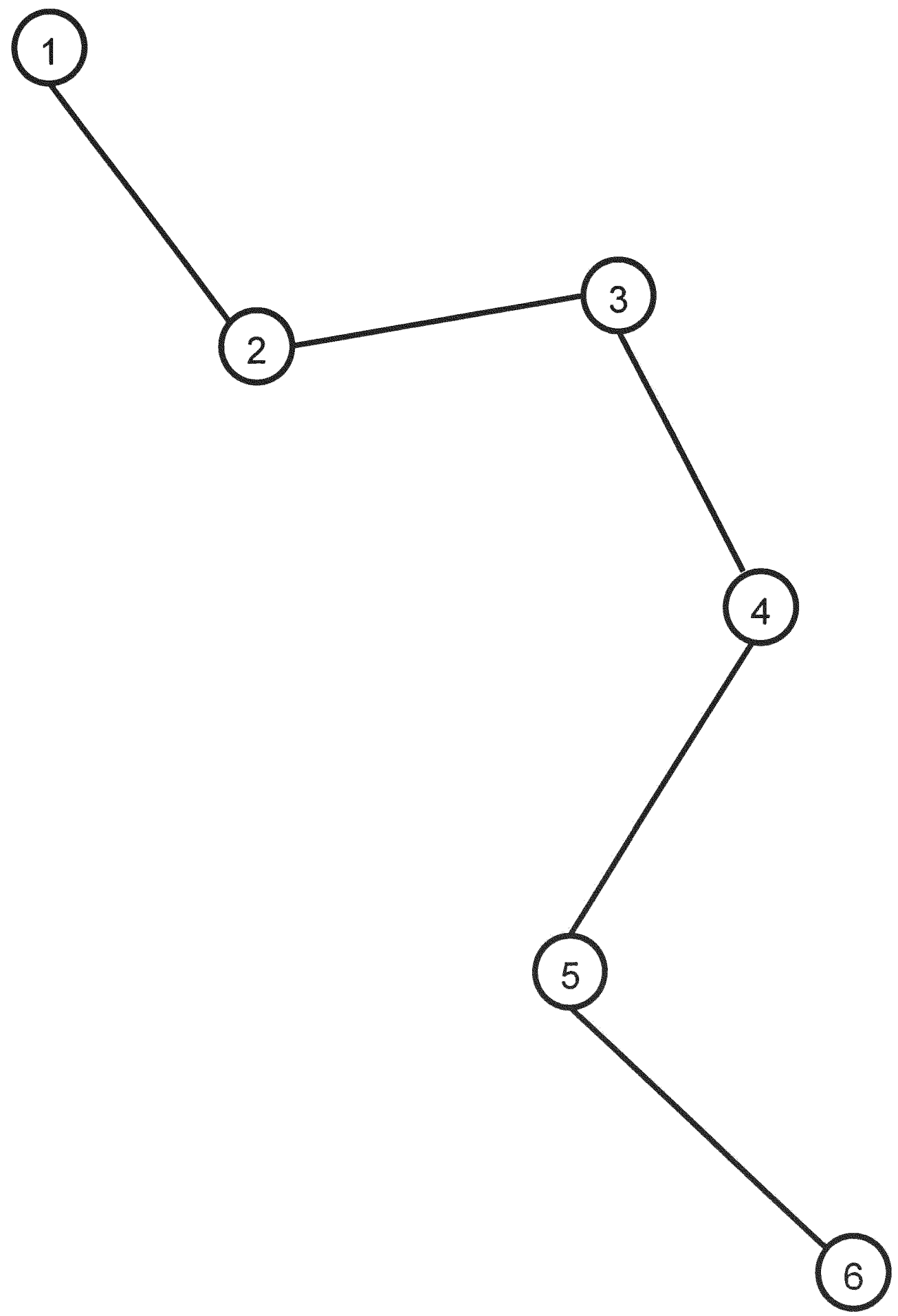


Appendix $\mathbf{J}$

Cameroon Campaign Mission Map

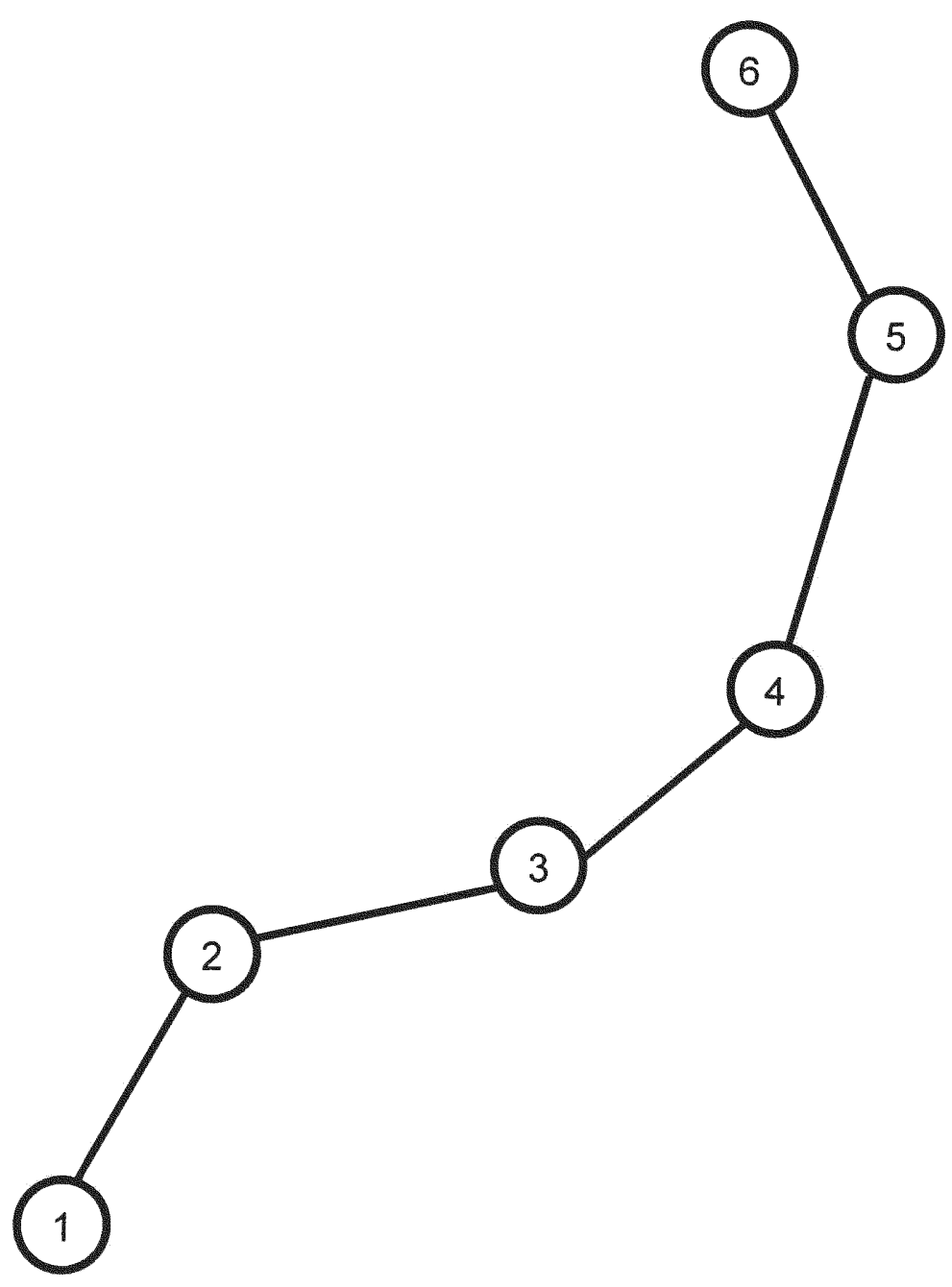


Appendix K

Kenyan Crusade Mission Map

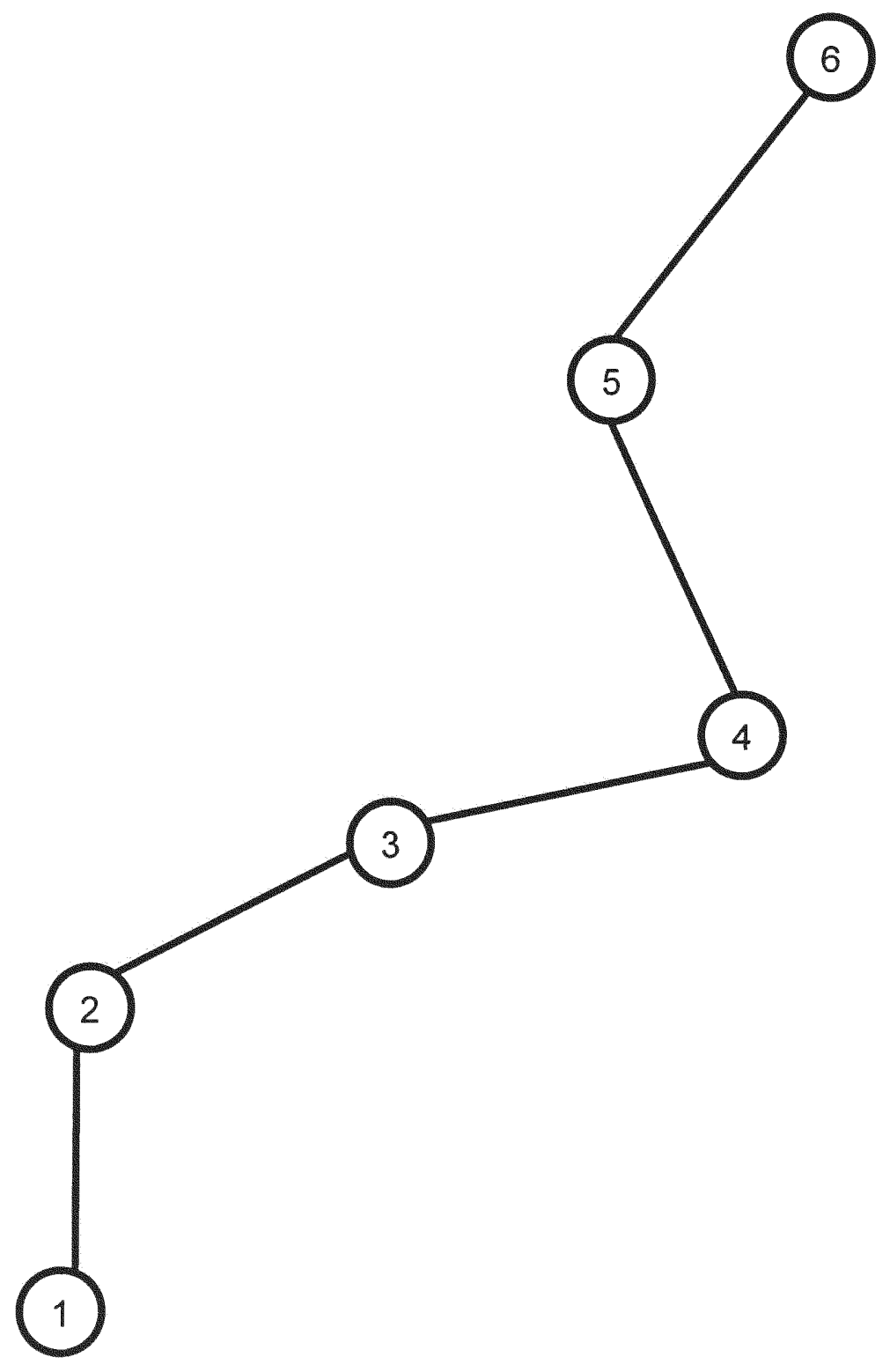




\section{Appendix L}

\section{Experimental Procedure Outline - Leader Team Training Phase}

Begin this sequence once all pre-measures are complete, and the flight teams begin task training in the simulation room.

\section{Green Room}

A. Task Training - randomly designate one leader team member to be the pilot and one to be the weapons specialist. First go through the Air to Ground Task Training. Next go through the Basic Air to Air combat module of the Air to Air Task Training.

B. Strategy Training - administer either experimental or control training.

C. Coordination Facilitation Training - administer either experimental or control training

D. Administer Measures (Task Competency Check, Strategy Training Manipulation Check, Coordination Training Manipulation Check)

\section{Break}




\section{Appendix M}

\section{Leader Strategy Training Overview - Experimental}

In this training you will learn to develop an overall mission plan that specifies how teams should proceed to achieve their goals so that the multi-team is successful.

First, you should look at the locations of the enemy targets and decide on the appropriate tactics. You will then want to develop a strategy that specifies:

1. The flight path of each team

2. The order in which teams should fly at each part of the mission

\section{Training Inter-Team Coordination Tactics}

There are four types of situations you will face in the coming missions. During your planning session, you need to evaluate the situation your team will face and determine the appropriate tactic given the situation.

Situation 1: Targets are not located near one another.

Tactic 1: Eagle and Wolf work independently to destroy isolated targets and then meet up after.

Situation 2: Enemy planes and tanks located near one another.

Tactic 2: Eagle engages enemy plane while wolf reduces speed and altitude and waits, once enemy plane is destroyed Eagle leaves the area and Wolf destroys remaining ground targets.

Situation 3: Enemy planes and SAM's located near one another.

Tactic 3: Wolf and Eagle approach targets from opposite directions. First Eagle engages the enemy plane, then Wolf fires at SAM sites \& turns around. Eagle heads away from SAMs until destroyed.

Situation 4: SAM's and enemy helicopter's located near one another.

Tactic 4: Wolf attacks SAM sites while Eagle reduces speed and altitude and waits, once SAMs are destroyed Wolf leaves the area and Eagle destroys helicopters.

For each situation (a) show what the situation looks like on a map (b) explain how the teams should proceed (c) show video clip of an mts approaching a situation using the appropriate tactic.

Next give leader team practice mission information and time to practice planning. Then provide feedback on the appropriateness of the tactics chosen. 


\section{Appendix N}

\section{Leader Strategy Training Overview - Control $^{1}$}

\section{In this training you will learn to develop an overall mission plan that specifies how} teams should proceed to achieve their goals so that the multi-team is successful.

First, you should look at the locations of the enemy targets and decide on the appropriate tactics. You will then want to develop a strategy that specifies:

3. The flight path of each team

4. The order in which teams should fly at each part of the mission

Training Inter-Team Coordination Tactics

There are four types of situations you will face in the coming missions. During your planning session, you need to evaluate the situation your team will face and determine the appropriate tactic given the situation.

Situation 1: Targets are not located near one another.

Tactic 1: Eagle and Wolf work independently to destroy isolated targets and then meet up after.

Situation 2: Enemy planes and tanks located near one another.

Tactic 2: Eagle engages enemy plane while wolf reduces speed and altitude and waits, once enemy plane is destroyed Eagle leaves the area and Wolf destroys remaining ground targets.

Situation 3: Enemy planes and SAM's located near one another.

Tactic 3: Wolf and Eagle approach targets from opposite directions. First Eagle engages the enemy plane, then Wolf fires at SAM sites \& turns around. Eagle heads away from SAMs until destroyed.

Situation 4: SAM's and enemy helicopter's located near one another.

Tactic 4: Wolf attacks SAM sites while Eagle reduces speed and altitude and waits, once SAMs are destroyed Wolf leaves the area and Eagle destroys helicopters.

For each situation (a) show what the situation looks like on a map (b) explain how the teams should proceed (c) show video clip of an mts approaching a situation using the appropriate tactic.

Next give leader team practice mission information and time to practice planning. Then provide feedback on the appropriateness of the tactics chosen.

\footnotetext{
${ }^{1}$ Text is shown in two styles so that the content of the experimental and control versions of the strategy training can be compared. While experimental teams will receive the full training, control teams will only receive the training segments in regular non-italicized text.
} 


\section{Appendix O}

\section{Leader Team Strategy Training - Experimental}

\section{Leader Team Strategy Training}

\section{Overview:}

- You will face four types of situations in each mission

- You must evaluate the information you'll be given to determine the best tactic given the situation
Training Objective:

- At the conclusion of this training, you should be able to develop a mission plan that specifies:

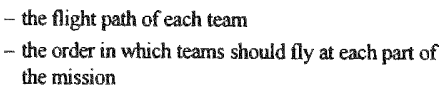

Situation 1:

- SITUATION: Eagle \& Wolf targets are NOT located near one another.

- TACTIC: Eagle \& Wolf should go after their own targets separately, but should approach the targets so they remain out of enemy SU-27 \& SAM radar.

Situation 1: Example
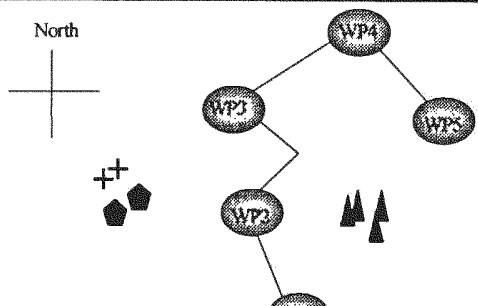

wo

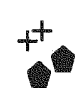

EAST

- Eagle approaches SU-27s \& Ml's from the WEST

\section{Situation 2:}

- SITUATION: Enemy planes and tanks located near one another.

- TACTIC: Eagle flies ahead to engage the planes while Wolf slows down and decreases altitude until the planes have been destroyed. Then Wolf destroys the tanks.
Situation 2: Example

- Briefing Information:

- 3 Tanks EAST of WP2

-1 SU.27 EAST of WP2

- Tactic:

- Wolf slows down and decreases altitude

- Eagle flies ahead and destroys the SU-27

- Once the SU-27 is destroyed, Wolf flies ahead and destroys the Tanks 
Situation 2: Example
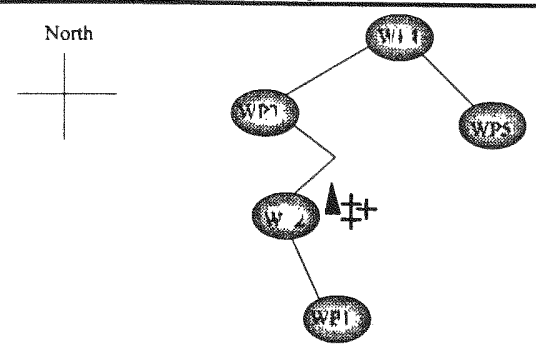

Situation 3: Example

- Briefing Information:

-2 SAMS WEST of WP2

- 1 SU-27s WEST of WP2

- Tactic

- Eagle \& Wolf approach area together.

- Wolf approaches SAMs first.

- Eagle targets SU-27 but does not enter SAM's location until they are destroyed.

Situation 4:

- SITUATION: SAMs and enemy M1-24s (helicopters) located near one another

- TACTIC: Wolf flies ahead and attacks SAMs while Eagle slows down and reduces altitude. Once SAMs are destroyed Eagle flies ahead and destroys M1-24s (helicopters).

Situation 4: Example
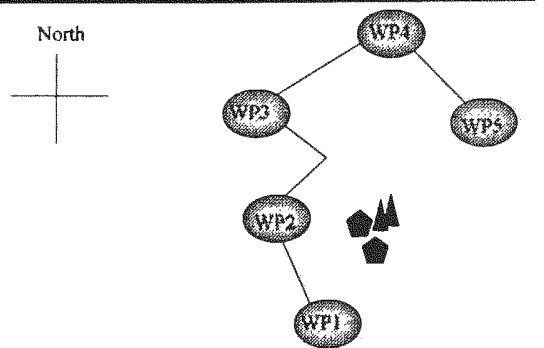

Situation 3:

- SITUATION: Enemy SU-27 \& SAMs

located near one another

- TACTIC: Eagle \& Wolf should approach targets together. As they near the SAMs, Wolf should fly slightly ahead to destroy the SAMs and then fly away from the SU. 27. Eagle should target the SU-27 while staying out of the SAMs radar.

\section{Situation 3: Example}

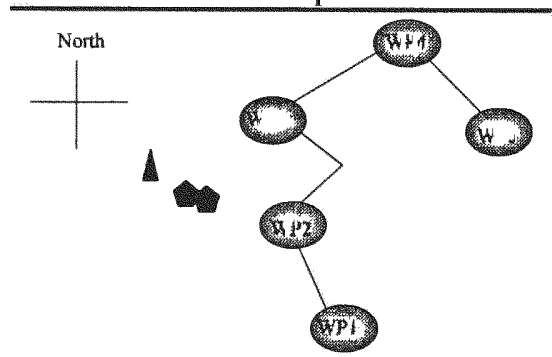

Situation 4: Example

- Briefing Information:

- 2 SAMs EAST of WP2

$-2 \mathrm{Ml}-24 \mathrm{~s}$ (helicopters) EAST of WP2

- Tactic:

- Wolf flies ahead and destroys SAMs.

- Eagle slows down and lowers altitude until SAMs are destroyed.

- Once SAMs are destroyed, Eagle flies ahead and destroys M1-24s (helicopters)

Review:

- Each mission contains four basic types of situations

- During your planning session, you should identify the type of situation and the appropriate tactic to use at each waypoint.

- Write down your strategy on the map provided and then inform the flight teams of the mission plan you have developed. 


\section{Appendix P}

\section{Leader Team Strategy Training - Control}

\section{Leader Team Strategy Training}

\section{Training Objective:}

- At the conclusion of this training, you will be able to develop a mission plan.

\section{Information:}

- You will fly two missions with your flight teams

- Before each mission you must evaluate the information provided and decide how the teams will proceed during the mission

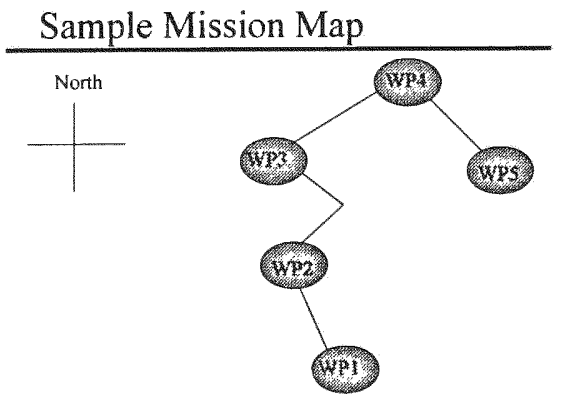

- Before each mission you will be provided with:

- mission briefing "location of targets (e.g., "2 SU.27s EAST of WP2") - mission map

Review:

- Before each mission you will have ten minutes to evaluate the information and develop a mission plan.

- Write down your strategy on the map provided and then inform the flight teams of the mission plan you have developed. 


\section{Appendix Q}

Leader Team Strategy Training - Botswana Expert Strategy Key

\begin{tabular}{|l|l|l|l|}
\hline & MTS Strategy & Wolf Behavior & Eagle Behavior \\
\hline WP2 & $\begin{array}{l}\text { approach at same time } \\
\text { from opposite } \\
\text { directions }\end{array}$ & $\begin{array}{l}\text { approach from West; } \\
\text { destroy SAMs then } \\
\text { Tanks }\end{array}$ & $\begin{array}{l}\text { approach from East; } \\
\text { destroy SU-27s then } \\
\text { M1-24s }\end{array}$ \\
\hline $\begin{array}{l}\text { While wolf slows } \\
\text { down and lowers } \\
\text { altitude }\end{array}$ & $\begin{array}{l}\text { wait for eagle to } \\
\text { destroy SU-27, then } \\
\text { destroy tanks }\end{array}$ & $\begin{array}{l}\text { fly ahead to destroy } \\
\text { SU-27 }\end{array}$ \\
\hline WP4 & $\begin{array}{l}\text { approach together with } \\
\text { wolf slightly ahead }\end{array}$ & $\begin{array}{l}\text { target SAMs first, then } \\
\text { fly away from the SU- } \\
\text { 27 }\end{array}$ & $\begin{array}{l}\text { target SU-27, but do } \\
\text { not enter SAM radar } \\
\text { range }\end{array}$ \\
\hline WP6 & $\begin{array}{l}\text { wolf flies ahead while } \\
\text { eagle slows down and } \\
\text { lowers altitude }\end{array}$ & $\begin{array}{l}\text { fly ahead to destroy } \\
\text { SAMs }\end{array}$ & $\begin{array}{l}\text { wait for wolf to } \\
\text { destroy SAMs, then } \\
\text { destroy M1-24s }\end{array}$ \\
\hline
\end{tabular}




\section{Appendix R}

\section{Leader Coordination Training Overview - Experimental}

\section{In this training you will learn to assist the teams in working together during the}

mission so that the multi-team is successful.

During the missions you will need to:

1. Monitor the location and status of both enemy targets and the teams

2. Continuously inform all MTS members of the location/status of targets and of the location of the other team

\section{Training Inter-Team Coordination Facilitation}

The success of your MTS depends on your coordinating the efforts of Eagle and Wolf team. This can be done by monitoring where enemies are, and where the teams are, and then relaying this information to the team members.

Monitoring Eagle Team:

The monitor on the left shows the cockpit of the Eagle team. Eagle team will be destroying enemy planes and helicopters. Enemy planes are very dangerous as they can fire missiles at both the Eagle and Wolf team. Enemy helicopters are not dangerous to the Wolf and Eagle teams since they cannot fire missiles, however, they are threatening to ground troops and so they need to be destroyed in order for your mission to be successful.

You can monitor Eagle team's location using the lower right pilot aid that shows where the plane is in relation to the waypoints. You can monitor the location of Eagle in relation to Wolf team by looking for the green triangle in the lower right or left screen, this is the Wolf team.

Communicating Eagle Team Information to Wolf Team:

Wolf team needs to know where the Eagle team is located throughout the mission. This is especially critical when the Eagle team is engaged with an enemy plane since the plane could destroy the Wolf team if they are in the area. Tell Wolf team where the Eagle team is located:

1. Throughout Eagle's engagement with an enemy plane

2. As Eagle team passes each waypoint

Monitoring Wolf Team:

The monitor on the right shows the cockpit of the Wolf team. Wolf team will be destroying enemy SAM sites and tanks. Enemy SAM sites are very dangerous as they can fire missiles at both the Eagle and Wolf team. Enemy tanks are not dangerous to the Wolf 
and Eagle teams since they cannot fire missiles, however, they are threatening to ground troops and so they need to be destroyed in order for your mission to be successful.

You can monitor Wolf team's location using the lower right pilot aid that shows where the plane is in relation to the waypoints. You can monitor the location of Wolf in relation to Eagle team by looking for the green triangle in the lower right or left screen, this is the Wolf team.

Communicating Wolf Team Information to Eagle Team:

Eagle team needs to know where the Wolf team is located throughout the mission. This is especially critical when either team is near an enemy SAM site since the SAM could destroy either plane. Tell Eagle team where the Wolf team is located:

1. When either team is approaching a SAM site

2. As Wolf team passes each waypoint

Monitoring Enemies:

During the mission it is your job to monitor the location of all enemies and the teams' progress in destroying them. Enemy planes and helicopters will show up as triangles on the radar. When they have been fired at, an " $\mathrm{X}$ " will appear over them. They are still alive until they disappear from the screen and you see \& hear the message, "Eagle splash." Enemy SAM sites appear as pentagons on the screen. When they have been fired at, an " $X$ " will appear over them. They are still alive until they disappear from the screen and you see \& hear the message, "Wolf splash." Enemy tanks appear as crosses "+" on the screen. When they have been fired at, an "X" will appear over them. They are still alive until they disappear from the screen and you see $\&$ hear the message, "Wolf splash."

Communicating Enemy Information to Eagle \& Wolf Team:

Both Eagle and Wolf teams needs to know where the enemies are located throughout the mission, and their status (e.g. dead, alive). Again, this is especially critical for enemy planes and SAM sites, since the planes and SAM sites can destroy both the Eagle and Wolf team. Tell Eagle and Wolf team where enemies are located:

1. As they approach a target

2. As each team passes each waypoint

Review:

During the missions you need to constantly be aware of where each team is, where all enemies are located and their status, and where the teams and enemies are in relation to one another. In addition, the success of your mission depends on your relaying this information to the teams. 
Therefore, as the teams pass a waypoint tell them:

1. Where the other team is

2. What enemies are in the area

When Eagle team is engaged with an enemy plane, inform Wolf team. When there are SAM sites near the teams, inform Eagle team.

3. Monitor the location (e.g. near wp2) and status (e.g. fired upon but still alive) of all enemies

4. Monitor the location and progress of each team (e.g. Eagle is just left of WP 3 and is engaged with an SU; Wolf is just right of WP 3 and just fired at a SAM)

Show a video of a mission and point out (a) leader team vocalizing as they monitor the location of teams \& enemies (b) leader team informing teams of other team's location (b) leader team informing wolf team when enemy planes are near (c) leader team informing Eagle team when enemy SAM's are near.

Next give leader team a practice session. Play a prerecorded mission $\&$ have leader team monitor and inform as instructed. Coach leader team and provide feedback on any training objectives not achieved. 


\section{Appendix S}

\section{Leader Coordination Training Overview - Control ${ }^{1}$}

In this training you will learn to assist the teams in working together during the mission so that the multi-team is successful.

\section{During the missions you will need to:}

1. Monitor the location and status of both enemy targets and the teams

2. Continuously inform all MTS members of the location/status of targets and of the location of the other team

\section{Training Inter-Team Coordination Facilitation}

The success of your MTS depends on your coordinating the efforts of Eagle and Wolf team. This can be done by monitoring where enemies are, and where the teams are, and then relaying this information to the team members.

Monitoring Eagle Team:

The monitor on the left shows the cockpit of the Eagle team. Eagle team will be destroying enemy planes and helicopters. Enemy planes are very dangerous as they can fire missiles at both the Eagle and Wolf team. Enemy helicopters are not dangerous to the Wolf and Eagle teams since they cannot fire missiles, however, they are threatening to ground troops and so they need to be destroyed in order for your mission to be successful.

You can monitor Eagle team's location using the lower right pilot aid that shows where the plane is in relation to the waypoints. You can monitor the location of Eagle in relation to Wolf team by looking for the green triangle in the lower right or left screen, this is the Wolf team.

\section{Communicating Eagle Team Information to Wolf Team:}

Wolf team needs to know where the Eagle team is located throughout the mission. This is especially critical when the Eagle team is engaged with an enemy plane since the plane could destroy the Wolf team if they are in the area. Tell Wolf team where the Eagle team is located:

1. Throughout Eagle's engagement with an enemy plane

2. As Eagle team passes each waypoint

\footnotetext{
${ }^{1}$ Text is shown in two styles so that the content of the experimental and control versions of the coordination training can be compared. While experimental teams will receive the full training, control teams will only receive the training segments in regular non-italicized text.
} 
Monitoring Wolf Team:

The monitor on the right shows the cockpit of the Wolf team. Wolf team will be destroying enemy SAM sites and tanks. Enemy SAM sites are very dangerous as they can fire missiles at both the Eagle and Wolf team. Enemy tanks are not dangerous to the Wolf and Eagle teams since they cannot fire missiles, however, they are threatening to ground troops and so they need to be destroyed in order for your mission to be successful.

You can monitor Wolf team's location using the lower right pilot aid that shows where the plane is in relation to the waypoints. You can monitor the location of Wolf in relation to Eagle team by looking for the green triangle in the lower right or left screen, this is the Wolf team.

Communicating Wolf Team Information to Eagle Team:

Eagle team needs to know where the Wolf team is located throughout the mission. This is especially critical when either team is near an enemy SAM site since the SAM could destroy either plane. Tell Eagle team where the Wolf team is located:

1. When either team is approaching a SAM site

2. As Wolf team passes each waypoint

Monitoring Enemies:

During the mission it is your job to monitor the location of all enemies and the teams' progress in destroying them. Enemy planes and helicopters will show up as triangles on the radar. When they have been fired at, an "X" will appear over them. They are still alive until they disappear from the screen and you see \& hear the message, "Eagle splash." Enemy SAM sites appear as pentagons on the screen. When they have been fired at, an "X" will appear over them. They are still alive until they disappear from the screen and you see \& hear the message, "Wolf splash." Enemy tanks appear as crosses "+" on the screen. When they have been fired at, an "X" will appear over them. They are still alive until they disappear from the screen and you see $\&$ hear the message, "Wolf splash."

Communicating Enemy Information to Eagle \& Wolf Team:

Both Eagle and Wolf teams needs to know where the enemies are located throughout the mission, and their status (e.g. dead, alive). Again, this is especially critical for enemy planes and SAM sites, since the planes and SAM sites can destroy both the Eagle and Wolf team. Tell Eagle and Wolf team where enemies are located:

1. As they approach a target

2. As each team passes each waypoint 
Review:

During the missions you need to constantly be aware of where each team is, where all enemies are located and their status, and where the teams and enemies are in relation to one another. In addition, the success of your mission depends on your relaying this information to the teams.

Therefore, as the teams pass a waypoint tell them:

1. Where the other team is

2. What enemies are in the area

When Eagle team is engaged with an enemy plane, inform Wolf team. When there are SAM sites near the teams, inform Eagle team.

3. Monitor the location (e.g. near wp2) and status (e.g. fired upon but still alive) of all enemies

4. Monitor the location and progress of each team (e.g. Eagle is just left of WP 3 and is engaged with an SU; Wolf is just right of WP 3 and just fired at a SAM)

Show a video of a mission and point out (a) leader team vocalizing as they monitor the location of teams \& enemies (b) leader team informing teams of other team's location (b) leader team informing wolf team when enemy planes are near (c) leader team informing Eagle team when enemy SAM's are near.

Next give leader team a practice session. Play a prerecorded mission $\&$ have leader team monitor and inform as instructed. Coach leader team and provide feedback on any training objectives not achieved. 


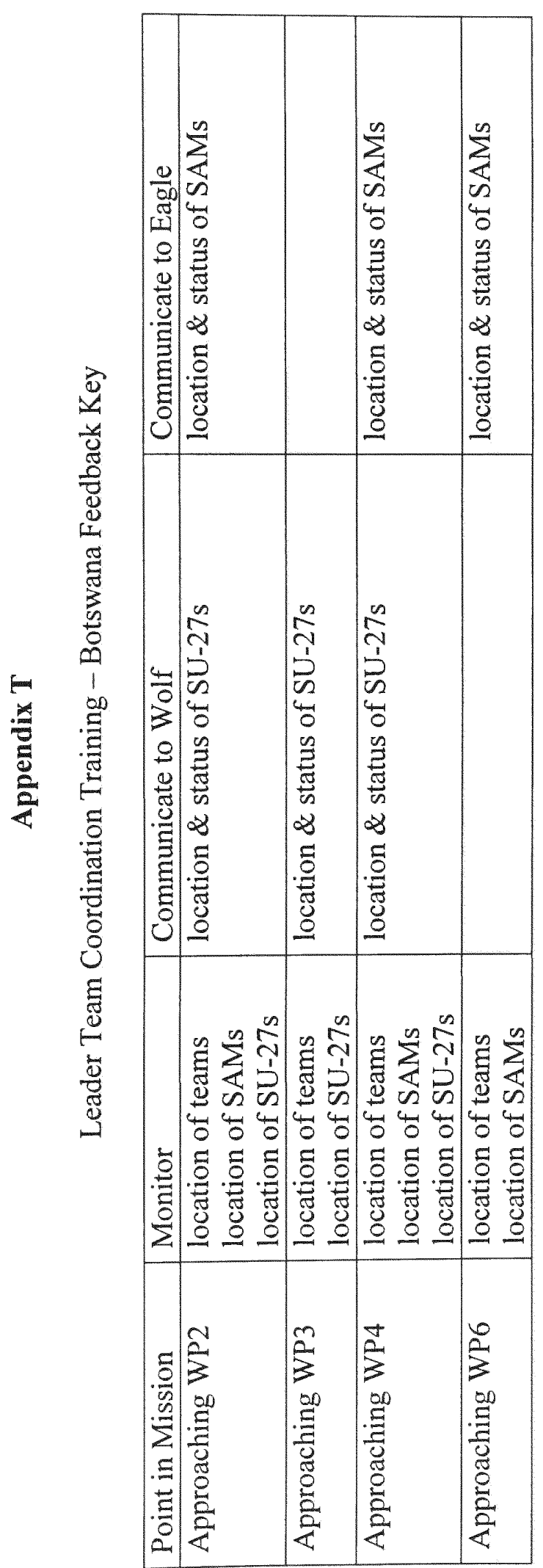




\title{
Appendix U
}

\author{
Spatial Ability Measure
}

\section{ACES Spatial Orienation Test}

Instructions. - This is a test of your ability to see changes in direction and position. In each item you are to note how the position of the plane has changed in the second picture from its original position in the first picture.

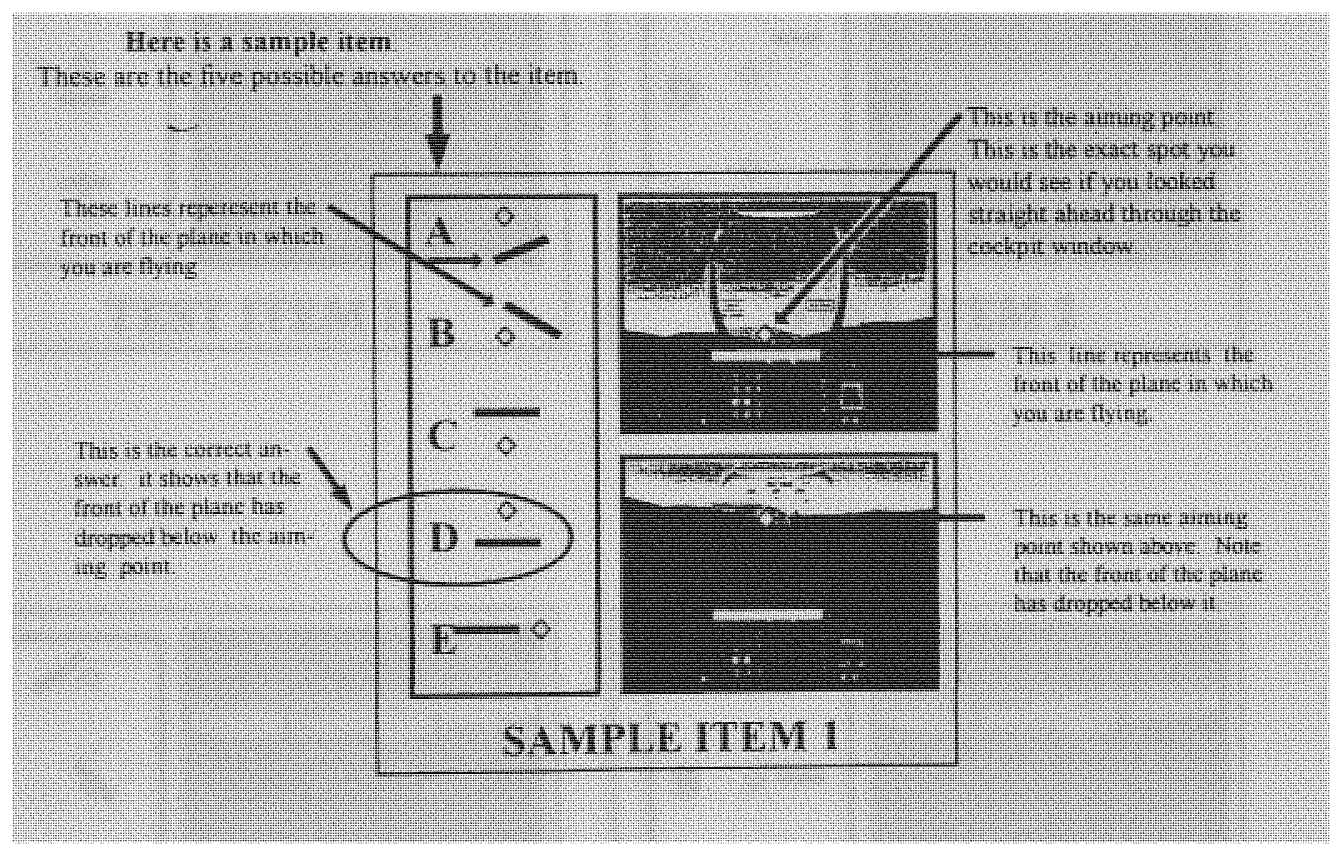

(If the front of the plane had risen, instead of dropped, the correct answer would have been $C$, instead of $D$.)

Other items in the test are very similar to SAMPLE ITEM 1. To work each item: First, look at the top picture. See where the plane is headed. Second, look at the bottom picture and note the CHANGE in the plane's heading. Third, mark the answer that shows the same change. 

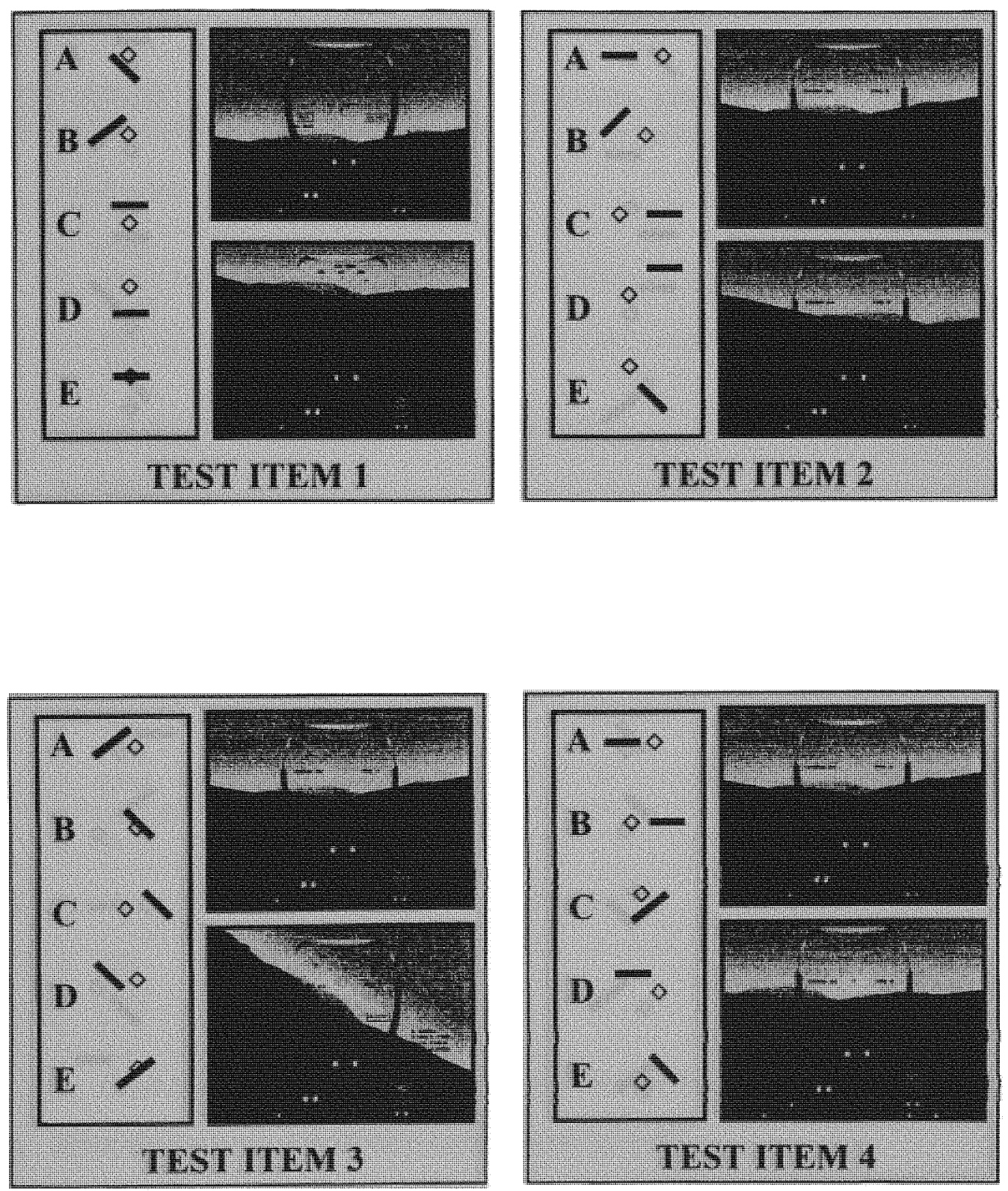

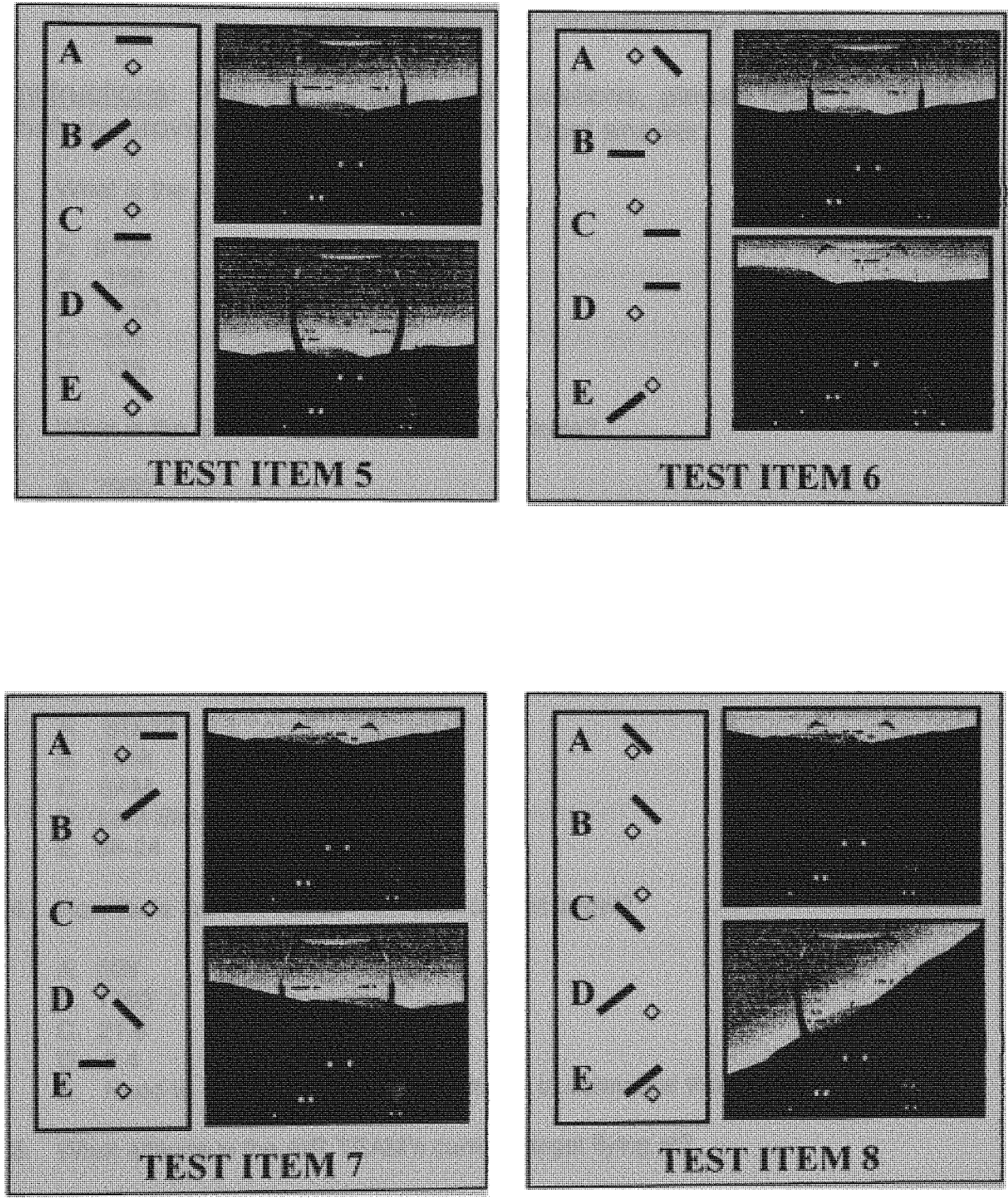


\section{Appendix V \\ Leader Task Knowledge Measure \\ Task Training Competency Check}

Instructions: For the following ten questions, please refer to the HUD displays that are provided. Please choose the best answer.

1. What is the AIR TEAM's current speed?
A. 9700
A. 138
B. 6180
C. 508
D. 138

2. What is the GROUND TEAM's current altitude?
A. 7900
B. 9700
C. 6180
D. 508
E. 389

3. What target does the AIR TEAM currently have selected?
A. SU-27
B. Tank
C. SAM
D. Lant Slaved
E. MI-24

4. How far is the AIR TEAM from their current target?
A. 508
B. 1760
C. 21.6
D. 8.4
E. Need to switch to another HUD mode to determine the answer.

5. What altitude is the AIR TEAM's current target flying at?
A. 7900
B. 9700
C. 6180
D. 508
E. 389 
6. What target does the GROUND TEAM currently have selected?
A. SU-27
B. Tank
C. SAM
D. Lant Slaved
E. $\mathrm{MI}-24$

7. How far is the GROUND TEAM from their current target?
A. 389
B. 6
C. 21.6
D. 9100
E. Need to switch to another HUD mode to determine the answer.

8. What is the next waypoint the GROUND TEAM will pass?
A. 3
B. 1
C. 4
D. 2
E. Need to switch to another HUD mode to determine the answer.

9. What weapon does the GROUND TEAM have selected?
A. AGM65G
B. EMCON M1
C. SINGLE FIRE
D. $A B K$
E. FRQ 3

10. What weapon does the AIR TEAM have selected?
A. CANNON
B. EMCON A5
C. SINGLE FIRE
D. $A B K$
E. FRQ 3 


\section{Appendix W}

\section{Leader Team Strategy Manipulation Check \\ Strategy Questionnaire - Botswana Battle}

1. Briefly describe what each team will be doing as you approach each waypoint:

\begin{tabular}{|l|l|l|}
\hline & Eagle Team & Wolf Team \\
\hline WP2 & & \\
\hline WP3 & & \\
\hline WP4 & & \\
\hline WP6 & & \\
\hline
\end{tabular}

2. How do you want the flight teams to approach WP2?

a. Eagle first, Wolf behind

b. Wolf first, Eagle behind

c. Eagle \& Wolf approach together from same direction

d. Eagle \& Wolf approach together from opposite directions (correct answer)

3. How do you want the flight teams to approach WP3?

a. Eagle first, Wolf behind (correct answer)

b. Wolf first, Eagle behind

c. Eagle \& Wolf approach together from same direction

d. Eagle \& Wolf approach together from opposite directions

4. How do you want the flight teams to approach WP4?

a. Eagle first, Wolf behind

b. Wolf first, Eagle behind

c. Eagle \& Wolf approach together from same direction (correct answer)

d. Eagle \& Wolf approach together from opposite directions

5. How do you want the flight teams to approach WP6?

a. Eagle first, Wolf behind

b. Wolf first, Eagle behind (correct answer)

c. Eagle \& Wolf approach together from same direction

d. Eagle \& Wolf approach together from opposite directions 
Question 1: Coding Guide

Assign one point for each action that is mentioned in the correct box. Score range: 0-12.

\begin{tabular}{|c|c|c|c|}
\hline \multicolumn{4}{|c|}{ Botswana Battle Expert Strategy } \\
\hline & MTS Strategy & Wolf Behavior & Eagle Behavior \\
\hline WP2 & $\begin{array}{l}\text { approach at same time } \\
\text { from opposite } \\
\text { directions }\end{array}$ & $\begin{array}{l}\text { approach from West; } \\
\text { destroy SAMs then } \\
\text { Tanks }\end{array}$ & $\begin{array}{l}\text { approach from East; } \\
\text { destroy SU-27s then } \\
\text { M1-24s }\end{array}$ \\
\hline WP3 & $\begin{array}{l}\text { eagle targets SU- } 27 \\
\text { while wolf slows } \\
\text { down and lowers } \\
\text { altitude }\end{array}$ & $\begin{array}{l}\text { wait for eagle to } \\
\text { destroy SU-27, then } \\
\text { destroy tanks }\end{array}$ & $\begin{array}{l}\text { fly ahead to destroy } \\
\text { SU-27 }\end{array}$ \\
\hline WP4 & $\begin{array}{l}\text { approach together with } \\
\text { wolf slightly ahead }\end{array}$ & $\begin{array}{l}\text { target SAMs first, then } \\
\text { fly away from the SU- } \\
27\end{array}$ & $\begin{array}{l}\text { target SU-27, but do } \\
\text { not enter SAM radar } \\
\text { range }\end{array}$ \\
\hline WP6 & $\begin{array}{l}\text { wolf flies ahead while } \\
\text { eagle slows down and } \\
\text { lowers altitude }\end{array}$ & $\begin{array}{l}\text { fly ahead to destroy } \\
\text { SAMs }\end{array}$ & $\begin{array}{l}\text { wait for wolf to } \\
\text { destroy SAMs, then } \\
\text { destroy M1-24s }\end{array}$ \\
\hline
\end{tabular}




\section{Appendix X}

\section{Leader Team Coordination Manipulation Check}

\section{Mission Questionnaire}

1. During the mission, the leader team can best monitor the Wolf Team cockpit information by watching the:

a. Monitor on the left

b. Monitor on the right (correct answer)

c. Either Monitor

d. The leader team cannot monitor the Wolf Team cockpit information directly

2. During the mission, it is most important for the leader team to monitor:

a. Weapons available to the flight teams

b. Speed \& altitude of the flight teams

c. Location \& status of targets (correct answer)

d. Time remaining in the mission

3. During the mission, the leader team can best monitor waypoint information by watching the:

a. Lower right pilot aid (correct answer)

b. Lower left pilot aid

c. Center of HUD (heads up display)

d. The leader team cannot monitor waypoint information directly

4. During the mission, it is most important for the leader team to communicate to the flight teams:

a. Weapons available

b. Speed \& altitude

c. Location \& status of targets (correct answer)

d. Time remaining in the mission

5. During the mission, the leader team can best monitor when flight teams are in an enemy's radar range by watching the:

a. Lower right pilot aid

b. Lower left pilot aid (correct answer)

c. Center of HUD (heads up display)

d. The leader team cannot monitor enemy radar information directly 
6. During the mission, you should inform the Wolf Team when:

a. Eagle Team is engaged with SU-27s (correct answer)

b. Eagle Team is engaged with M1-24s

c. Eagle Team is engaged with any target

d. It is not necessary to inform Wolf Team about Eagle Team targets

7. During the mission, the leader team can best monitor the time remaining by watching the:

a. Lower right mission clock

b. Lower left mission clock (correct answer)

c. Center of HUD (heads up display)

d. The leader team cannot monitor time remaining directly

8. During the mission, you should inform the Eagle Team when:

a. Wolf Team is engaged with tanks

b. Wolf Team is engaged with SAMs (correct answer)

c. Wolf Team is engaged with any target

d. It is not necessary to inform Eagle Team about Wolf Team targets

\section{Manipulation Check Key}

Monitoring Knowledge Scale

Q1

Q3

Q5

Q7

Coordination Knowledge Scale

Q2

Q4

Q6

Q8 


\section{Appendix Y}

\section{Leader Team Strategy Communication}

Response Anchors

$1=$ Strongly Disagree

$2=$ Disagree

$3=$ Neutral

$4=$ Agree

5 - Strongly Agree

Subordinate Report Items

1. The leader team clearly informed us of our mission strategy.

2. The leader team got us all on the same page.

3. The leader team left us confused about how to fly the mission.*

4. The leader team came up with a specific mission plan.

5. We know how we are to work together throughout the mission.

6. We all know our parts and our team's part in the coming mission.

7. We're not sure how to approach this mission.*

*reverse scored item 


\section{Appendix Z}

\section{Leader Team Strategy Communication BARS}

\section{STRATEGY COMMUNICATION}

Definition: Communicating a plan that specifies the sequence and timing of team actions.

Examples: - Specifying which team should approach each waypoint first

- Specifying the order of target destruction

Complete skill

Very much skill

4

The leader team very clearly articulates a plan to MTS members that specifies 1) the order in which teams should fly throughout the mission, 2) the order in which targets should be destroyed. The plan is very specific and is made clear to all MTS members.

Adequate skill

The leader team communicates a plan to MTS members that sometimes specifies 1) the order in which teams should fly and 2) the order in which targets should be destroyed. The plan is either somewhat vague or does not include team actions at each part of the mission. The plan is relatively clear to all members.

Some skill

2

Hardly any skill
The leader team does not specify a coherent plan. Either the plan is totally vague or the leader team does not make its plan clear. There is no mention of 1) the order in which teams should fly or 2) the order in which targets should be destroyed. 


\section{Leader Team Coordinating Behavior}

Response Anchors

$1=$ Strongly Disagree

$2=$ Disagree

$3=$ Neutral

$4=$ Agree

5 - Strongly Agree

Subordinate Report Items

1. The leader team frequently informed us of the other team's location.

2. The leader team kept us aware of the location of all targets.

3. The leader team did a good job of helping us work with the other team.

4. We rarely knew if the other team was taking out their targets.*

5. The leader team rarely told us when we entering enemy radar.*

6. The leader team informed us of all hostile targets as we approached each waypoint.

*reverse scored item 


\title{
Appendix BB
}

\section{Leader Team Coordinating Behavior BARS}

\section{COORDINATING BEHAVIOR}

\author{
Definition: Monitoring and communicating cross-team information. \\ Examples: $\quad$ - Informing Wolf team of Eagle team's location \\ - Informing Eagle team of a SAM site's location
}

Complete skill

The leader team is aware of the location of both teams and enemies at all times. The leader team informs each team of the other team's location as the teams approach each waypoint and as each is engaged with a threatening target (i.e. SU or SAM).

Very much skill

4

Adequate skill

Some skill

Hardly any skill
2

1
The leader team is aware of the location of both teams and enemies much of the time. The leader team informs each team of the other team's location as the teams approach some of the waypoints and during most of the engagements with threatening targets (i.e. SUs or SAMs). The leader team may need to be asked for critical information; or may not report it some of the time.

The leader team is generally unaware of the location of either team or enemies most of the time. The leader team almost never informs each team of the other team's location. Even when/if asked, leader teams do not relay critical information. 


\section{Appendix CC}

\section{Multi-Team Interaction Mental Model Measure \\ Mission Strategy Questionnaire}

INSTRUCTIONS: Below are some situations you may encounter during your missions. Each is followed by a list of behaviors that your two teams could engage in. Read the entire list first, then order the list beginning with the first action that should be taken (first action $(s)=1$ ) and ending with the final action that should be taken in order to be effective.

- If two actions should be done AT THE SAME TIME, give both the same number.

\begin{tabular}{|l|l|}
\hline \multicolumn{2}{|c|}{$\begin{array}{c}\text { SITUATION: } \\
\text { Your two teams are instructed to destroy an enemy installation that } \\
\text { includes an SU-27 (enemy plane) flying in the general vicinity of two } \\
\text { enemy tanks. }\end{array}$} \\
\hline ACTION & ORDER \\
\hline Wolf decreases speed \& altitude & \\
\hline Wolf increases speed \& altitude & \\
\hline Wolf flies toward enemies & \\
\hline Eagle flies toward the enemies & \\
\hline Wolf flies away from the enemies & \\
\hline Eagle flies away from the enemies & \\
\hline Wolf targets \& destroys the first tank & \\
\hline Wolf targets \& destroys the second tank & \\
\hline Eagle targets \& destroys the SU-27 & \\
\hline
\end{tabular}




\section{Appendix DD}

MTS Mental Model Accuracy Scoring Key

\begin{tabular}{|cl|}
\hline ACTION \\
\hline 1. & Wolf decreases speed \& altitude \\
\hline 2. & Wolf increases speed \& altitude \\
\hline 3. & Wolf flies toward enemies \\
\hline 4. & Eagle flies toward the enemies \\
\hline 5. & Wolf flies away from the enemies \\
\hline 6. & Eagle flies away from the enemies \\
\hline 7. & Wolf targets \& destroys the first tank \\
\hline 8. & Wolf targets \& destroys the second tank \\
\hline 9. & Eagle targets \& destroys the SU-27 \\
\hline
\end{tabular}

$$
\begin{aligned}
& 4=\text { completely accurate } \\
& 3=\text { mostly accurate } \\
& 2=\text { partially accurate } \\
& 1=\text { inaccurate }
\end{aligned}
$$

Assign a 4:

IF $9<7$ AND 8

AND

IF 1 AND $5<9$

Assign a 3:

IF $9 \leq 7$ AND 8

AND

IF 1 OR $5<9$

Assign a 2:

IF $9 \leq 7$ AND 8

AND

IF 1 AND $5>9$

Assign a 1:

IF $9>7$ AND 8

AND

IF 1 AND $5>9$ 


\section{Appendix EE}

\section{Inter-Team Coordination BARS}

\section{INTER-TEAM COORDINATION}

Definition: Orchestrating the sequence and timing of interdependent MTS actions.

Examples: $\quad$ - Organizing how and when teams will synchronize

actions that require the efforts of more than one team in multi-team situations

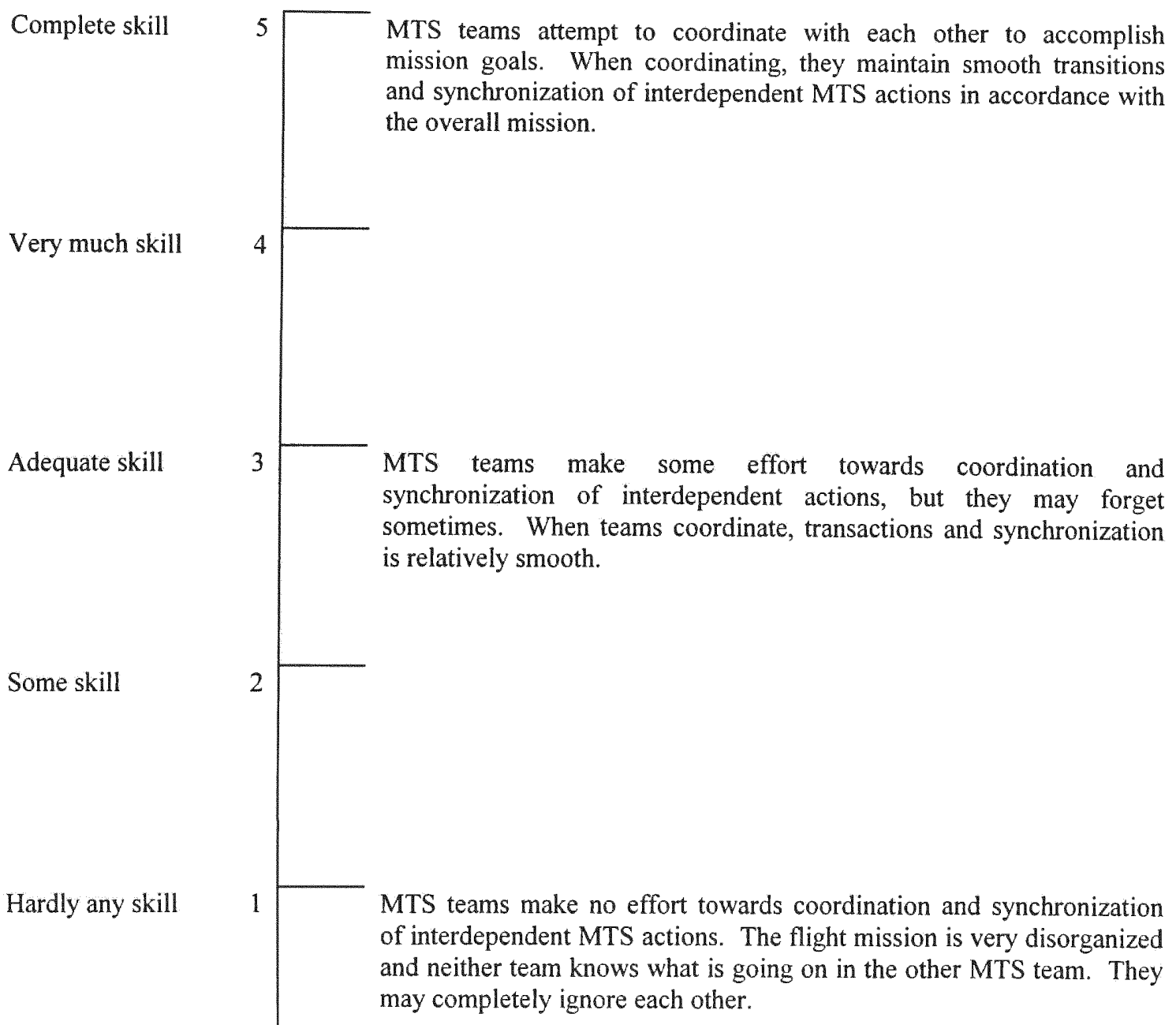




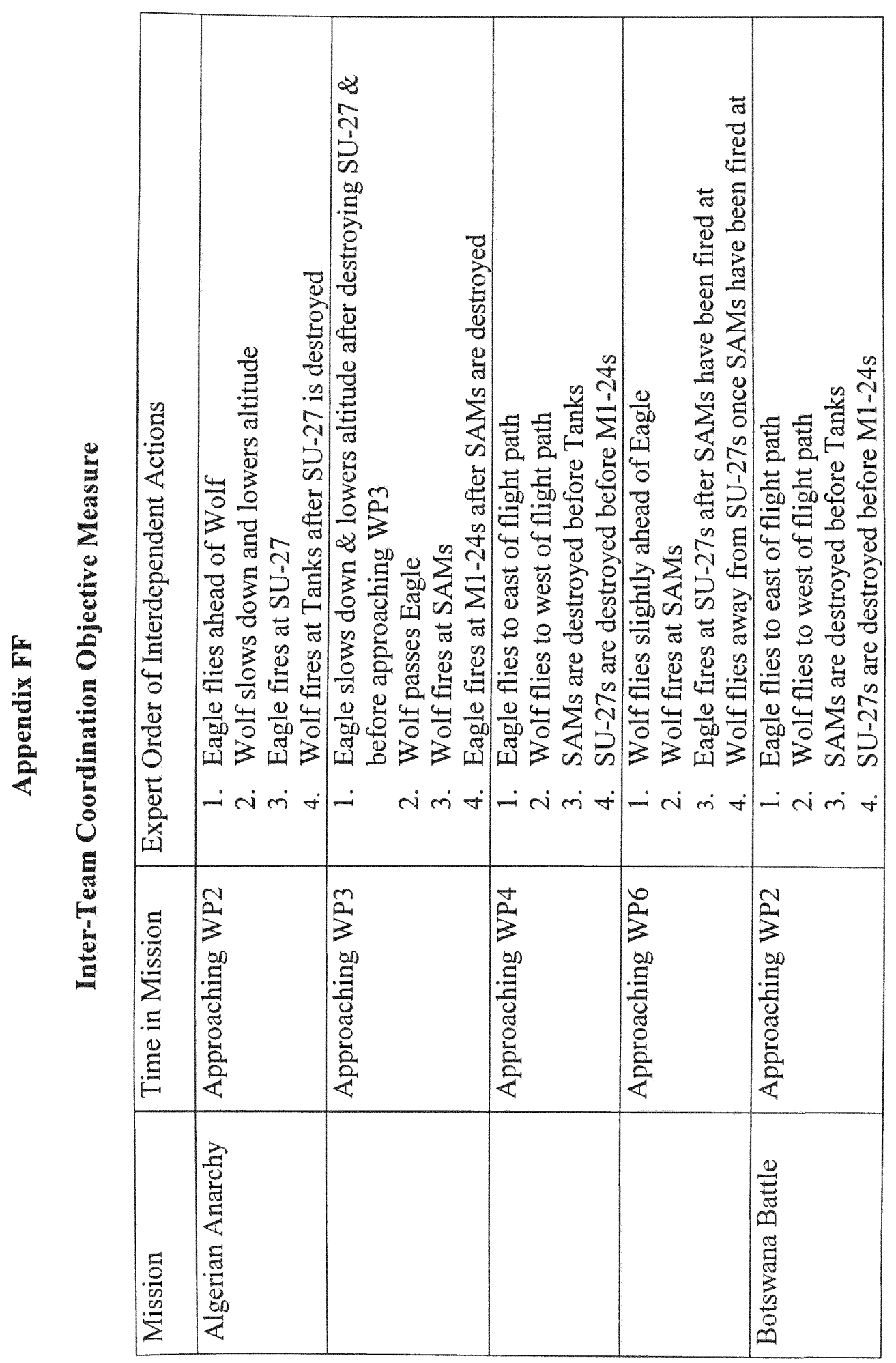




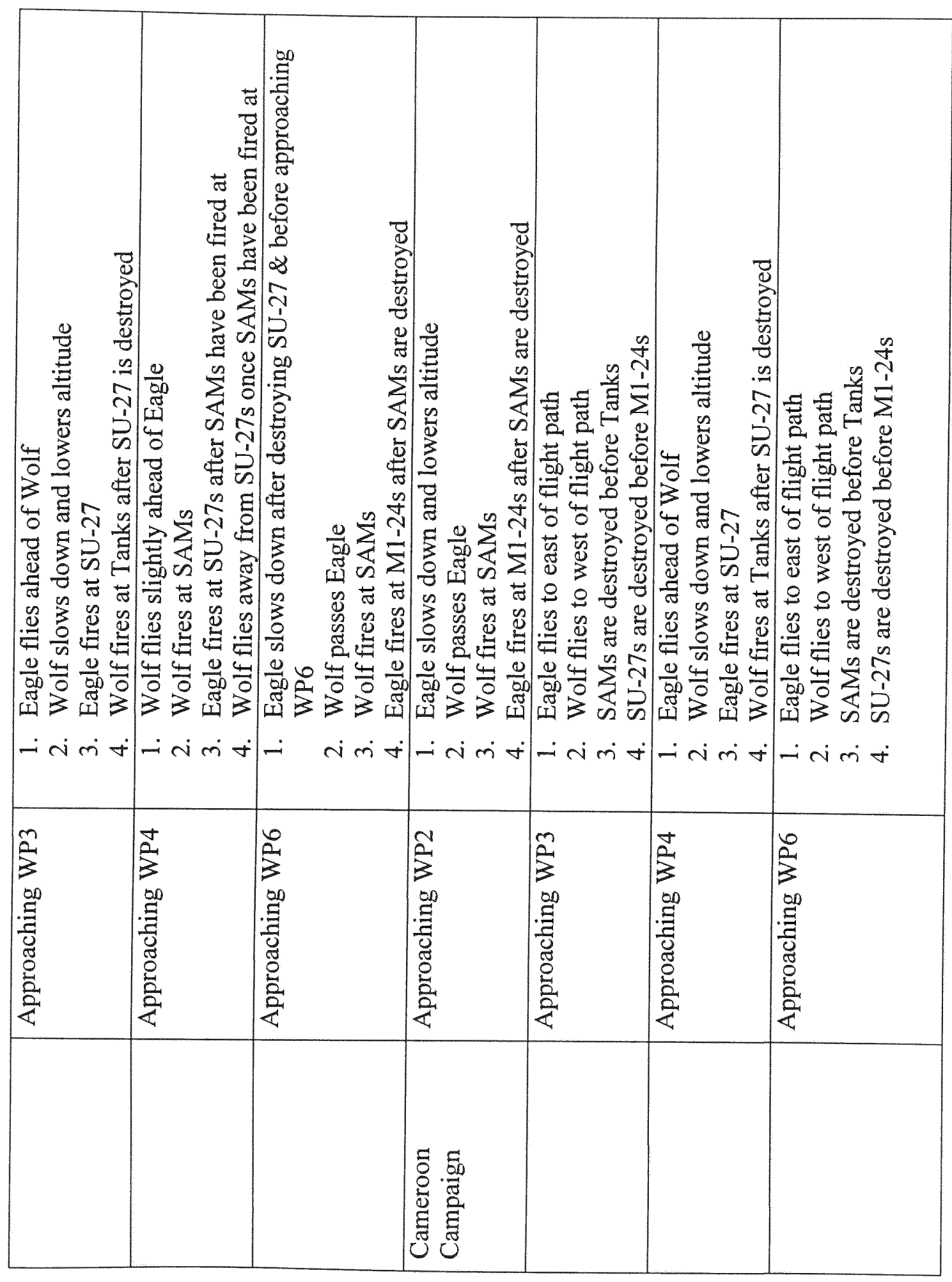

용 


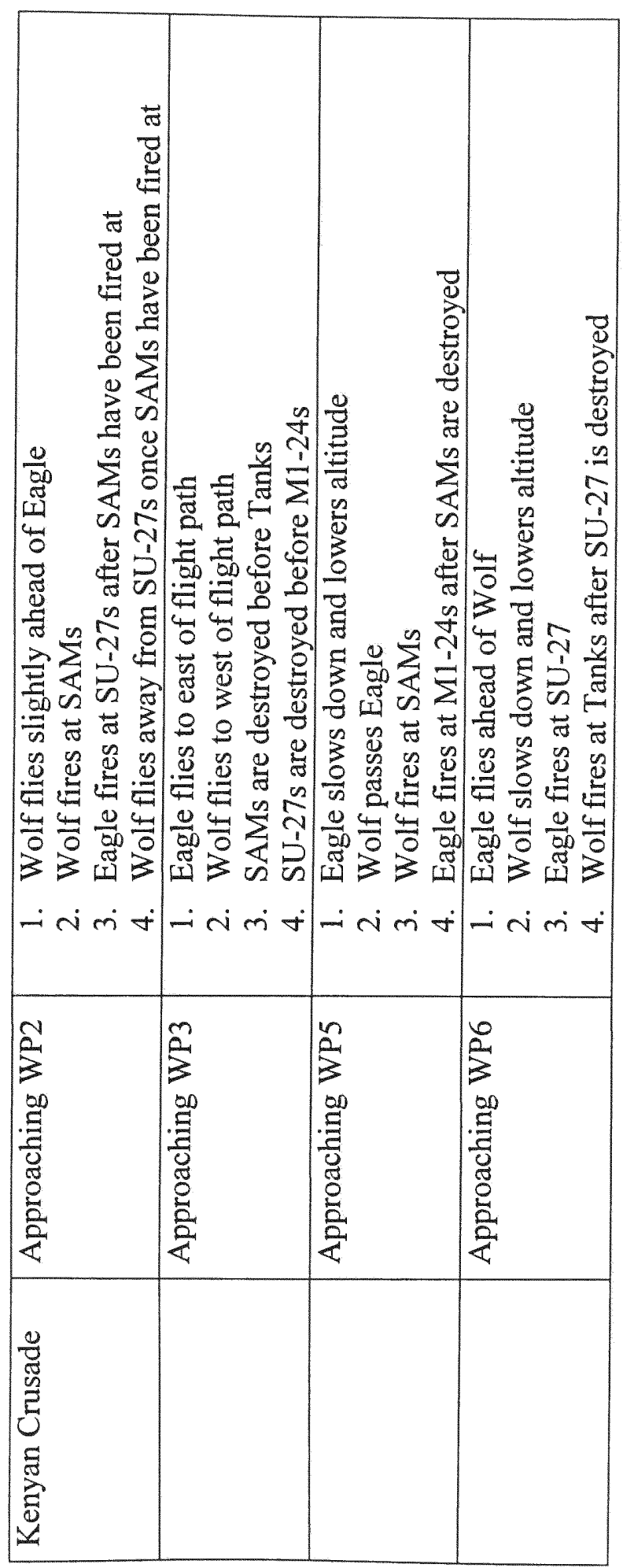




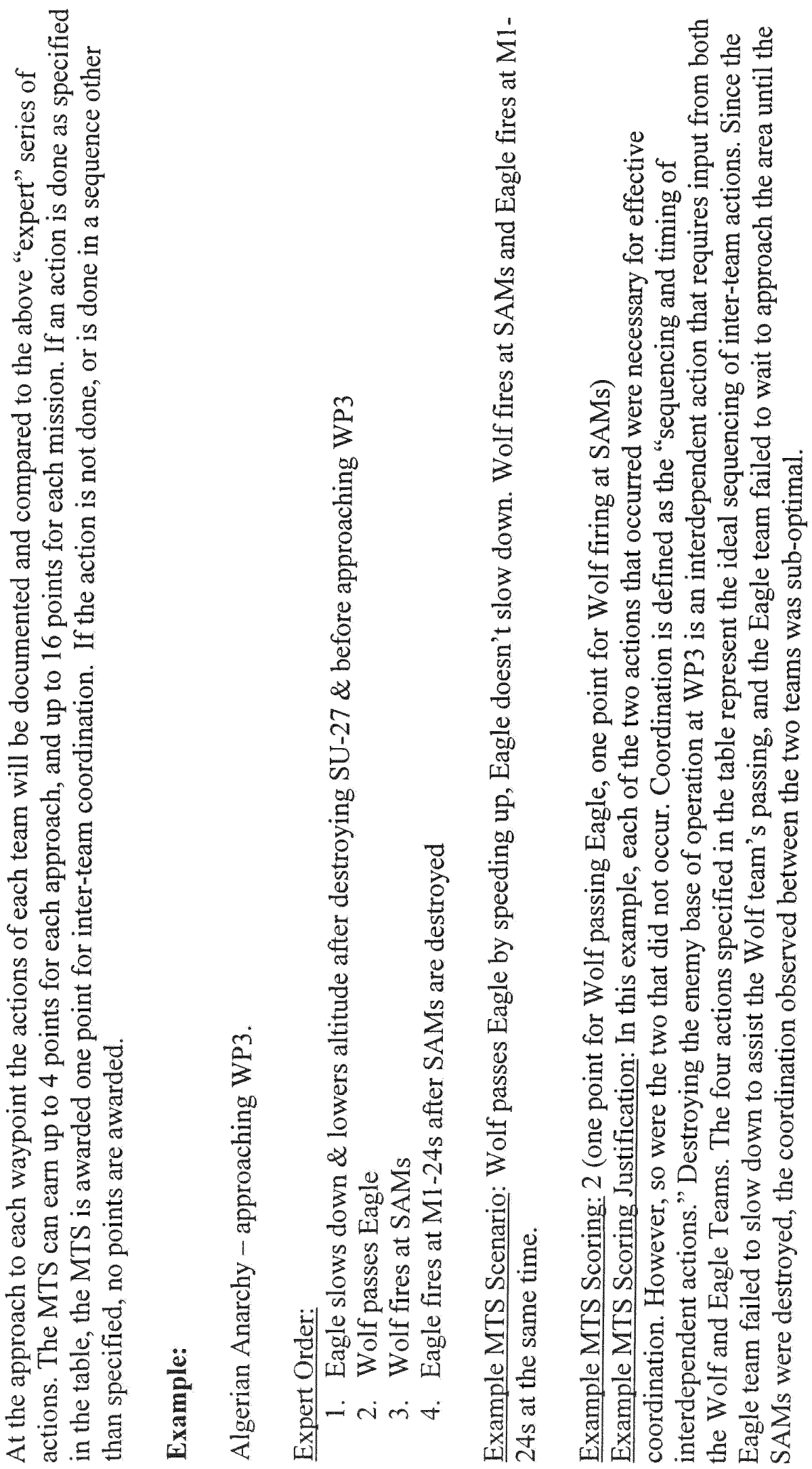




\section{Appendix GG}

\section{Results of Covariate Analyses}

Table GG1

Analysis of Variance for Psychomotor Ability, Spatial Ability, and Leader Intelligence Composites

\begin{tabular}{lll}
\hline DV $=$ Psychomotor Ability & & \\
\hline Source & df & F-value \\
Strategy Manipulation (SM) & 1 & 0.20 \\
Coordination Manipulation (CM) & 1 & 2.04 \\
SM * CM Interaction & 1 & 0.28 \\
Total & 63 & -- \\
\hline DV = Spatial Ability & & \\
\hline Source & df & F-value \\
Strategy Manipulation (SM) & 1 & 1.42 \\
Coordination Manipulation (CM) & 1 & 0.06 \\
SM * CM Interaction & 1 & $6.32^{*}$ \\
Total & 63 & -- \\
\hline DV = Leader Intelligence & & \\
\hline Source & df & F-value \\
Strategy Manipulation (SM) & 1 & 0.74 \\
Coordination Manipulation (CM) & 1 & 1.21 \\
SM * CM Interaction & 1 & 0.08 \\
Total & 63 & -- \\
\hline
\end{tabular}




\begin{tabular}{|c|c|c|}
\hline \begin{tabular}{|} 
Table GG2 \\
Average Covariate Scores and Standard Deviations by Leader Training Condition
\end{tabular} \\
\hline \multicolumn{3}{|c|}{ Psychomotor Ability } \\
\hline \multicolumn{3}{|c|}{ Strategy Training } \\
\hline Coordination Training & Control & Experimental \\
\hline Control & $29.42(8.41)$ & $32.45(8.58)$ \\
\hline Experimental & $27.19(10.69)$ & $27.65(11.46)$ \\
\hline \multicolumn{3}{|c|}{ Spatial Ability } \\
\hline Coordination Training & Control & Experimental \\
\hline Control & $5.33(0.78)$ & $5.04(1.00)$ \\
\hline Experimental & $4.72(1.09)$ & $5.54(0.61)$ \\
\hline \multicolumn{3}{|c|}{ Strategy Training } \\
\hline Coordination Training & Control & Experimental \\
\hline Control & $23.91(4.24)$ & $24.38(2.44)$ \\
\hline Experimental & $24.57(3.06)$ & $25.50(2.82)$ \\
\hline
\end{tabular}




\section{LESLIE A. DECHURCH}

September 27, 1974

1996

2000

1999-2002

2002-2003
Born, Hollywood, FL

B.S. in Environmental Science (General Honors) University of Miami

Coral Gables, FL

M.S. in Industrial \& Organizational Psychology Florida International University

Miami, FL

Project Manager

US Air Force (AFSOR) Grant

Integrated Multi-Team Decision Making

Visiting Assistant Professor of I/O Psychology

Florida International University

Miami, FL

\section{PUBLICATIONS \& PRESENTATIONS}

DeChurch, L. A. \& Marks, M. A. (2001). Maximizing the benefits of task conflict: The role of conflict management. International Journal of Conflict Management, 12, 1, 5-22.

Schweitzer, M. E. \& DeChurch, L. A. (2001). Linking frames in negotiations: Gains, losses, and conflict frame adoption. International Journal of Conflict Management, 12, 2 , 100-113.

Academy of Management, Denver, CO, August 2002

Diversity in member ability as a predictor of teamwork processes and outcomes

Society for Industrial/Organizational Psychology, San Diego, CA, April 2001 Monitoring Training: An examination of the effects of training monitoring skills on team performance

Academy of Management, Toronto, ON, Canada, August 2000

The effects of group conflict handling on group conflict - group outcome relationships

Society for Industrial/Organizational Psychology, New Orleans, LA, April 2000

Linking frames in negotiations: Gains, losses, and conflict frame adoption 
Academy of Management, Toronto, ON, Canada, August 2000/ Chicago, IL, August 1999 A workshop on using within-and between-entities analysis (WABA) for examining level of analysis hypotheses (Research Methods Division, Professional Development Workshop)

Southern Management Association, New Orleans, LA, November, 1998 A workshop on using within-and between-entities analysis (WABA) for examining level of analysis hypotheses (Research Methods Division, Professional Development Workshop)

American Psychological Society, Miami, FL, June 2000

Self, peer, and collective efficacy in work teams

Southern Management Association, New Orleans, LA, November, 1998

Research methodology in organizational studies: A ten year follow-up

Southern Management Association, New Orleans, LA, November, 1998 An empirical investigation of the path-goal leadership theory prediction that extrinsic rewards negatively moderate transformational leadership at the individual level of analysis

Southern Management Association, Atlanta, GA, November, 1997

An investigation of augmentation relationships among leader-member exchange, transformational leadership, and transactional leadership

Southern Management Association, Atlanta, GA, November, 1997

The validity and reliability of the transformational leadership inventory (TLI):

Experimental and field investigations

Academy of Management, Boston, MA, August 1997

Current practices in confirmatory factor analysis and structural equations modeling 